\title{
WestVirginiaUniversity
}

THE RESEARCH REPOSITORY @ WVU

Graduate Theses, Dissertations, and Problem Reports

2000

\section{Burnout, stress and social support among doctoral students in psychology}

\author{
Kelli Lee Weaver \\ West Virginia University
}

Follow this and additional works at: https://researchrepository.wvu.edu/etd

\section{Recommended Citation}

Weaver, Kelli Lee, "Burnout, stress and social support among doctoral students in psychology" (2000). Graduate Theses, Dissertations, and Problem Reports. 1216.

https://researchrepository.wvu.edu/etd/1216

This Dissertation is protected by copyright and/or related rights. It has been brought to you by the The Research Repository @ WVU with permission from the rights-holder(s). You are free to use this Dissertation in any way that is permitted by the copyright and related rights legislation that applies to your use. For other uses you must obtain permission from the rights-holder(s) directly, unless additional rights are indicated by a Creative Commons license in the record and/ or on the work itself. This Dissertation has been accepted for inclusion in WVU Graduate Theses, Dissertations, and Problem Reports collection by an authorized administrator of The Research Repository @ WVU.

For more information, please contact researchrepository@mail.wvu.edu. 
Burnout, Stress and Social Support Among Doctoral Students in Psychology

Kelli L. Weaver, M.A., M.S.

Dissertation submitted to the College of Human Resources and Education

at West Virginia University in partial fulfillment of the requirements

for the degree of

Doctor of Philosophy

in

Counseling Psychology

Cynthia R. Kalodner, Ph.D., Chair

Edward F. Etzel, Ed.D.

Robert P. Marinelli, Ed.D.

David J. Srebalus, Ed.D.

Richard T. Walls, Ph.D.

Department of Counseling, Rehabilitation Counseling, and Counseling Psychology

Morgantown, West Virginia

2000

Keywords: Burnout, Stress, Social Support, Doctoral Student

Copyright 2000 Kelli L. Weaver 


\begin{abstract}
Burnout, Stress and Social Support Among Doctoral Students in Psychology
\end{abstract}

\title{
Kelli L. Weaver
}

The relationships between burnout, stress, and social support have been evaluated across a number of populations within the helping professions. However, no published studies have addressed the relationships between the aforementioned variables among doctoral students in psychology. As a result, the current study attempted to expand knowledge of the relationships between burnout, stress, and social support specifically among Clinical, Counseling, and School Psychology doctoral students. Results suggested that Clinical, Counseling, and School Psychology doctoral students are generally similar in their reports of burnout, stress, and social support. However, several differences were observed between the groups, and these differences are reported. The direct influence of stress on burnout was supported. Minimal support was observed for the direct influence of social support on burnout. Limited support was observed for the moderating or buffering effect of social support on the stress-burnout relationship. Implications of research findings for practice are evaluated. Additionally, recommendations for future research are provided. 


\section{Acknowledgments}

I am fortunate to have many supportive individuals in my life who consistently encourage, challenge, console, inspire, and comfort me, and generally add color to my life. As a result, I wish to thank a number of individuals for the support, guidance, and friendship they have offered to me specifically during the completion of this dissertation. First, I wish to thank my classmates, Brian, Jan, Justin, Larry, Lynn, and Heather. I am grateful for their support, humor, and encouragement, in spite of their own personal and professional challenges. Second, I wish to thank my lifelong friends, Denise and Erin, and more recently established friends Sarah, Becky, Julie, and Vicki for their patience, assistance, and consistent encouragement throughout the dissertation process. Thank you to my faculty advisor and dissertation chair, Dr. Cyndee Kalodner, for her time and effort associated with reading numerous drafts of this document, and for her gentle push to complete this task in a timely manner. I thank my other dissertation committee members, Dr. Edward Etzel, Dr. Robert Marinelli, Dr. David Srebalus, and Dr. Dick Walls, for their constructive feedback associated with the completion of this task. Additionally, I thank Dr. Walls for his assistance with the Results section of this document. I wish to thank my significant other, Andrew, for his constant support and friendship, especially at a time when he too was completing a similar challenging task. It truly is easier with two. And finally, I wish to thank my family members, Mom, Dad, Mike, Jess, and Ashley for their consistent support and encouragement to pursue my dreams, and for their belief that no dream is out of my reach. 


\section{TABLE OF CONTENTS}

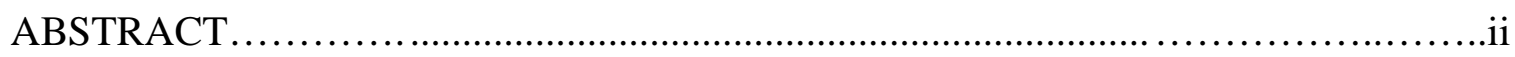

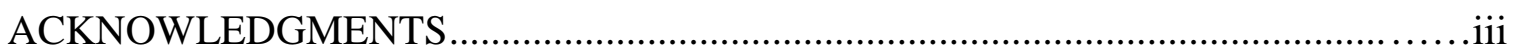

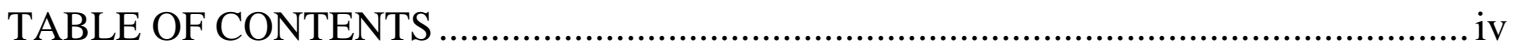

CHAPTER ONE

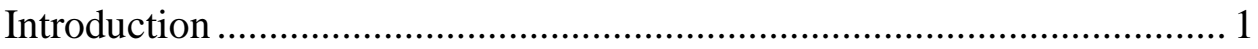

Statement of the Problem ......................................................................... 11

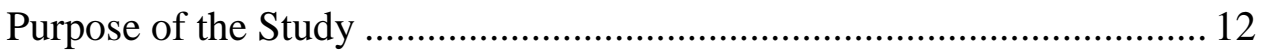

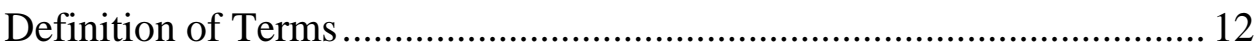

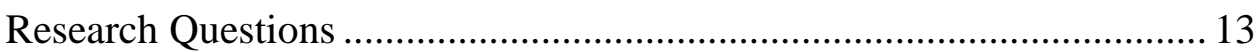

CHAPTER TWO

Review of the Literature........................................................................... 15

CHAPTER THREE

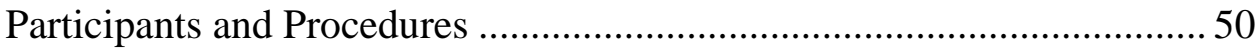

Instruments

Demographic Questionnaire of Doctoral Students in Psychology

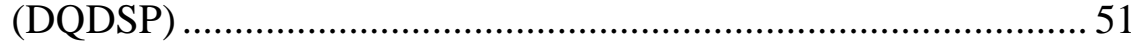

Maslach Burnout Inventory - Human Services Survey (MBI) ..... 52

Modified Psychology Student Stress Questionnaire (MPSSQ) .... 54

Modified Sources of Support Questionnaire (MSOSQ) ................ 56

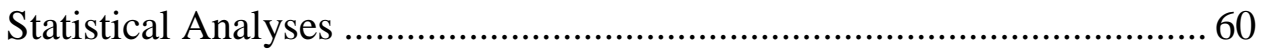

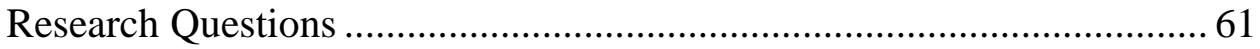

CHAPTER FOUR

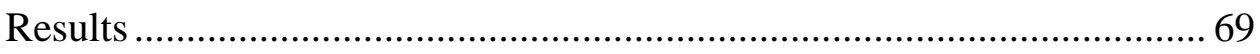

Demographic Data........................................................................ 71

Student Differences Related to Burnout........................................ 76

Student Differences Related to Stress ............................................. 79

Student Differences Related to Social Support ............................... 81 


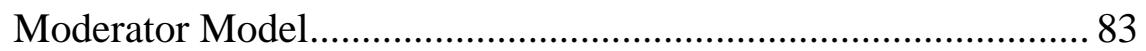

Direct Influence of Stress on Burnout..................................................... 84

Direct Influence of Social Support on Burnout............................. 86

Social Support as a Moderator of Stress and Burnout .................. 88

Supplemental Analyses ............................................................. 102

\section{CHAPTER FIVE}

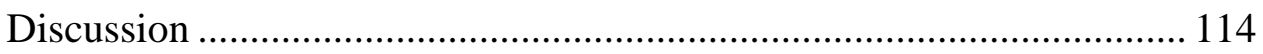

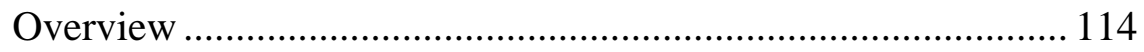

Student Differences Related to Burnout...................................... 115

Student Differences Related to Stress ......................................... 118

Student Differences Related to Social Support ............................. 119

Direct Influence of Stress on Burnout........................................... 120

Direct Influence of Social Support on Burnout............................. 121

Social Support as a Moderator of Stress and Burnout ................. 123

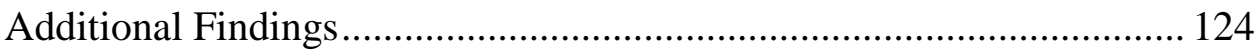

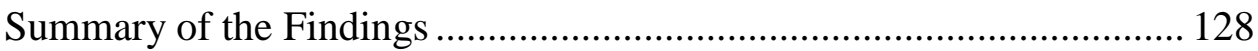

Implications for Practice …………..................................................... 129

Limitations of the Study ...................................................................... 132

Recommendations for Future Research ................................................ 135

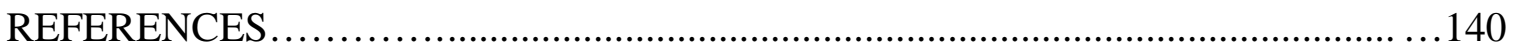

APPENDICES

A. Cover Letter to Participants............................................................. 152

B. Reminder Letter to Participants........................................................ 153

C. Demographic Questionnaire of Doctoral Students in Psychology (DQDSP) 
D. Maslach Burnout Inventory Scoring Procedures

(Emotional Exhaustion Subscale)

E. Maslach Burnout Inventory Scoring Procedures

(Depersonalization Subscale).

F. Maslach Burnout Inventory Scoring Procedures

(Personal Accomplishment Subscale).

G. Maslach Burnout Inventory Frequency Score Categorizations.......... 159

H. Maslach Burnout Inventory Cover Sheet for Participants ................. 160

I. The Modified Psychology Student Stress Questionnaire (MPSSQ) . 161

J. The Modified Sources of Support Questionnaire (MSOSQ) ............. 162

K. Summary Table of the Direct Influence of Stress on Burnout and the Direct Influence of Social Support on Burnout

L. Summary Table of the Moderating Influence of Social Support on the Stress-Burnout Relationship........................................................ 165

CURRICULUM VITAE 166

Table of Figures

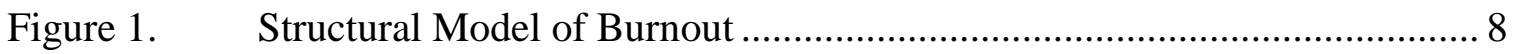

Figure 2. Moderator Model....................................................................... 9, 84 


\section{Chapter I}

\section{Introduction}

Burnout can develop when prolonged exposure to personal and environmental stressors occurs in conjunction with perceptions of inadequate resources to alleviate the strain associated with the perceived stressors (Maslach, Jackson, \& Leiter, 1996). Burnout is frequently associated with individuals who work in the helping professions and do long term, "people oriented" work under conditions of chronic stress. The development of burnout is of concern because its occurrence is associated with negative outcomes at a number of different levels. First, at the individual level, burnout may be accompanied by a variety of negative physical and emotional consequences for the individual experiencing burnout. Second, at the organizational level, burnout may result in increased absenteeism and job turnover, as well as decreased organizational commitment. Finally, and perhaps most importantly, at the service level burnout may negatively influence the quality of care provided by human service professionals to care recipients (Maslach et al., 1996).

Burnout among professionals in psychology has been an area which has received particular attention in the literature (Leiter \& Harvie, 1996). Many psychologists are challenged to manage a large case load, often involving therapy with clients exhibiting severe psychopathology. Management of such work related stressors, as well as the emotional demands inherent in work involving direct contact with clients, may occur in conjunction with insufficient supervision, as well as pressure from employers or outside agencies to provide cost effective, time limited treatment to clients. According to Maslach et al. (1996), if stress from sources such as those previously mentioned is sustained over time, and resources to alleviate the stressors are perceived to be insufficient or do not exist, burnout may occur.

Doctoral student therapists face a number of the same stressors faced by professionals in the field of psychology. However, in addition to specific work related stressors and the 
emotional challenges associated with therapeutic work with clients, student therapists are also challenged by several demands unique to the graduate school experience. These demands often include rigorous class assignments, examinations and evaluations, and time constraints (Toews, Lockyer, Dobson \& Brownell, 1993). Graduate students in psychology are further extended by demands associated with writing, proposing, completing, and defending their dissertation, as well as demands related to applying, interviewing, and attaining doctoral internship positions. Graduate students are also challenged by stressors associated with studying for comprehensive exams, assistantship obligations, and financial strain. The extent of financial strain experienced by doctoral students is emphasized through analysis of data on cumulative debt related to graduate education in psychology established by the American Psychological Association Research Office (American Psychological Association, 1996). The data suggest that 67 percent of all 1996 doctoral recipients in the field of psychology reported debt as a result of their graduate education. Of the 67 percent who reported debt, 28 percent reported debt between $\$ 11,000$ and $\$ 20,000,24$ percent reported debt between $\$ 21,000$ and $\$ 40,000$, and 13 percent reported that they were greater than $\$ 40,000$ in debt as a result of their graduate education.

Clearly doctoral students in psychology are challenged to manage a number of stressful situations and academic demands during their graduate training, in addition to their familial, personal, and social commitments and responsibilities. As a result, stressors unique to graduate students, stress associated with work in the helping professions, and personal and social commitments combine to make graduate students in psychology a group of individuals who appear to be particularly susceptible to burnout.

\section{Burnout}

A number of definitions of burnout have been proposed in the literature. According to De-Palpe and Croce (1986) burnout is associated with a gradual loss of energy and productivity. Burnout has also been described as a state of mental, emotional and physical exhaustion 
(Freudenberger \& Richelson, 1981; Maslach, 1982; Pines, Aronson, \& Kafry, 1981). Perhaps the most complete definition of burnout was suggested by Freudenberger (1985) who stated, "Burnout is wearing down and wearing out of energy. It is an exhaustion of excessive demands which may be self imposed or externally imposed...which deplete one's energy, coping mechanisms, and internal resources. It is a feeling state which is accompanied by an overload of stress, and which eventually impacts on one's motivation, attitudes, and behavior" (pp. 9, 10). More simply stated, burnout involves pushing one's self too hard for too long without attaining “the expected reward" (Freudenberger \& Richelson, 1980, p. 13).

A variety of symptoms are associated with burnout. Some of the physical symptoms include fatigue, sleep disturbances, and weight loss or gain, as well as negative self-concept, cynicism, perfectionism, defensiveness, and problems with personal relationships (Freudenberger, 1980; Freudenberger, 1985; Freudenberger \& Richelson, 1981; Maslach, 1982; Melendez \& DeGuzman, 1983). Still other symptoms of burnout include increased irritability, feelings of unappreciation, psychosomatic complaints and depression (Freudenberger \& Richelson, 1980). Such symptoms of burnout can lead people to withdraw from others, become rigid and inflexible, and focus only on themselves. It should also be noted that burnout symptoms reinforce themselves. The more one becomes discouraged and disillusioned, the harder it is to motivate one's self to take steps to alleviate the symptoms (Cherniss, 1980).

The construct of burnout is frequently conceptualized multi dimensionally, suggesting composition including three independent, but related, factors (Maslach et al., 1996). One factor, Emotional Exhaustion (EE), involves emotional depletion and fatigue associated with one's work. The second factor, Depersonalization (DP), involves feelings of negativity directed toward those individuals to whom one provides service. Personal Accomplishment (PA), the third factor associated with burnout, assesses feelings of success associated with one's work. Some researchers have placed greater emphasis on the EE factor associated with their 
conceptualization of the burnout construct (Koeske \& Koeske, 1989; Um \& Harrison, 1998), however, it appears that the majority of literature on burnout conceptualizes the construct using all three dimensions.

Teacher burnout has been a popular area in the burnout literature (Cheuk, Wong, \& Rosen, 1994; Fimian \& Blanton, 1987; Gold, 1985), although the health care professions have also received particular attention in the burnout literature (Cherniss, 1980; Freudenberger, 1980; Lubin, Robinson, \& Sailors, 1992; Maslach, 1982). Student burnout, unlike burnout among members of the health care and teaching professions, has been studied less frequently, however. The limited literature on student burnout has focused primarily on young persons (D'Aurora \& Fimian, 1988; Watkins, 1983), undergraduates (Jemmott \& Magliore, 1988; McCarthy, Pretty, \& Catano, 1990; Meier \& Schmeck, 1985; Nowack, Gibbons, \& Hanson, 1985; Powers \& Gose, 1986; Watkins, 1983), medical students (Bair \& Greenspan, 1986; Pradhan \& Misra, 1995; Wolf, Balson, Faucett, \& Randall, 1989), student teachers (Fimian \& Blanton, 1987; Gold, 1985; Gold, Bachelor, \& Michael, 1989), and social work students (Koeske \& Koeske, 1989; Koeske \& Koeske, 1991; Tobin \& Carson, 1994).

Doctoral students in the field of psychology have been the focus of descriptive information related to stress and the resulting development of burnout symptoms. However, the limited information focused more on the specific stressors which may contribute to burnout, such as emotional over involvement with clients and student-supervisor conflict, than on the burnout construct (Morrissette, 1996). Doctoral students in the field of psychology have been subjects in only one published empirical study of burnout (Kahill, 1986).

It is unclear exactly why doctoral students in psychology have not been studied more frequently with regard to burnout. One hypothesis is that more advanced practitioners in psychology may be stereotypically viewed as more likely to burn out due to their perceived increased exposure to work in the helping professions, while students in the field of psychology 
may be viewed as too new to the field to experience burnout. While some students enter graduate school without practical experience, many students enter doctoral programs in psychology after years of work in some area of the helping professions. Additionally, in contrast to the aforementioned perceptions, more experienced practitioners have been observed to experience fewer symptoms of burnout than less experienced practitioners (Huebner, 1994). Further, burnout literature addressing burnout experienced by young athletes emphasizes that one does not need to have decades of exposure to chronic stressors in order to be negatively influenced by burnout symptoms, as even athletes involved in youth sports can develop burnout symptoms (Cohn, 1990; Gould, Tuffy, Udry, \& Loehr, 1996). Doctoral students in psychology are challenged to combine academic, financial, social, and time oriented demands with the emotional demands associated with work in the helping professions. As a result, doctoral students in psychology appear to be prime candidates for experiencing burnout, despite the lack of published literature addressing burnout among this population.

\section{Models of Burnout}

Models have been developed in an effort to describe the constructs of burnout (Maslach et al., 1996), stress, and social support (Cohen \& Wills, 1985). A number of models have also been developed in an attempt to describe the relationships between burnout, stress, and negative outcomes. One model by Perlman and Hartman (1982) suggests that burnout is a response or a reaction to prolonged stress, and that responses to chronic stress may include cognitive, affective, and behavioral components. The model further suggests that coping strategies associated with perceived stressful situations are influenced by personal and organizational variables. According to the researchers, personal variables include ability level, familial support and demands, personal needs, task commitment, physical health, and level of professional identity. Organizational variables are described as including characteristics associated with work load, supervision, institutional climate, organizational mobility, collegial support, performance 
expectations, and role specificity. It is suggested that both personal and organizational variables influence an individual's perceptions of stress and their responses to stressful situations. It is further suggested that personal and organizational variables ultimately influence whether or not individual stress responses result in effective or ineffective coping.

A number of additional models have been discussed in the literature which attempt to describe the relationship between burnout, stress, and negative outcomes. Richardsen and Burke (1995) describe three popular models developed by Cherniss, Golumbiewski, and Leiter. These models share the view that burnout is a multidimensional construct which develops as a process over time, though only Golembiewski separates the process into eight distinct and progressive phases. Like the model by Perlman and Hartman (1982), each of these models also recognizes the role of individual and organizational factors which may contribute to the development of burnout. Cherniss, however, appears to emphasize work related factors to a greater extent than Golembiewski and Leiter. In addition, research associated with these models supports Maslach's three component (Emotional Exhaustion, Depersonalization, and Personal Accomplishment) conceptualization of burnout. However, in contrast to Golembiewski and Cherniss, Leiter emphasizes the role of the Emotional Exhaustion factor in the conceptualization of burnout, and places it in a "central" position (Richardsen \& Burke, 1995).

An additional model of burnout, the Stress-Strain-Outcome (SSO) model, has been proposed in the literature (Koeske \& Koeske, 1993). This model identifies burnout as "strain" and emphasizes the importance of analysis of both the stress-strain and strain-outcome components of the model. This model, like the Cherniss model, emphasizes the importance of the Emotional Exhaustion component of burnout (Um \& Harrison, 1998). However, unlike the Cherniss model, the SSO model completely excludes Depersonalization as a component of burnout. Rather, in the SSO model, burnout is designated as a mediating variable, and Depersonalization is viewed as an outcome of burnout. Personal Accomplishment, along with 
social support, is viewed as a moderating variable within the model (Koeske \& Koeske, 1993). Empirical evaluation of this model, using a sample of 91 social workers, confirmed the mediating role of Emotional Exhaustion with regard to outcome variables job satisfaction and intention to quit. In addition, social support and Personal Accomplishment were found to moderate the relationship between Emotional Exhaustion and intention to quit, however, these components did not moderate the relationship between Emotional Exhaustion and job satisfaction, or the stress-strain relationship (Koeske \& Koeske, 1993).

Maslach et al. (1996) have also developed a structural model of burnout (see Figure 1). Like all of the previous models discussed, the model of burnout developed by Maslach et al. (1996) emphasizes the influence of personal stressors or demands, as well as a lack of personal and environmental resources, in the development of burnout symptoms. Maslach et al. (1996) list work overload and personal conflict as specific "demands" which contribute to burnout. Diminished coping ability, social support, autonomy, and decision involvement are specified as resources which, when insufficient, contribute to burnout. The development of burnout, characterized by Emotional Exhaustion, Depersonalization, and a decreased sense of Personal Accomplishment has led some individuals to experience a variety of negative outcomes including diminished organizational commitment, increased job turnover and absenteeism, and/or physical illness. According to the authors, burnout can be predicted by work demands and diminished resources. Similar to the models proposed by Leiter and Koeske and Koeske, the model of burnout developed by Maslach et al. (1996) emphasizes the importance of the Emotional Exhaustion component of burnout. However, unlike the SSO model (Koeske \& Koeske, 1993), it does not exclude the contribution of Personal Accomplishment and Depersonalization components of the burnout construct. 


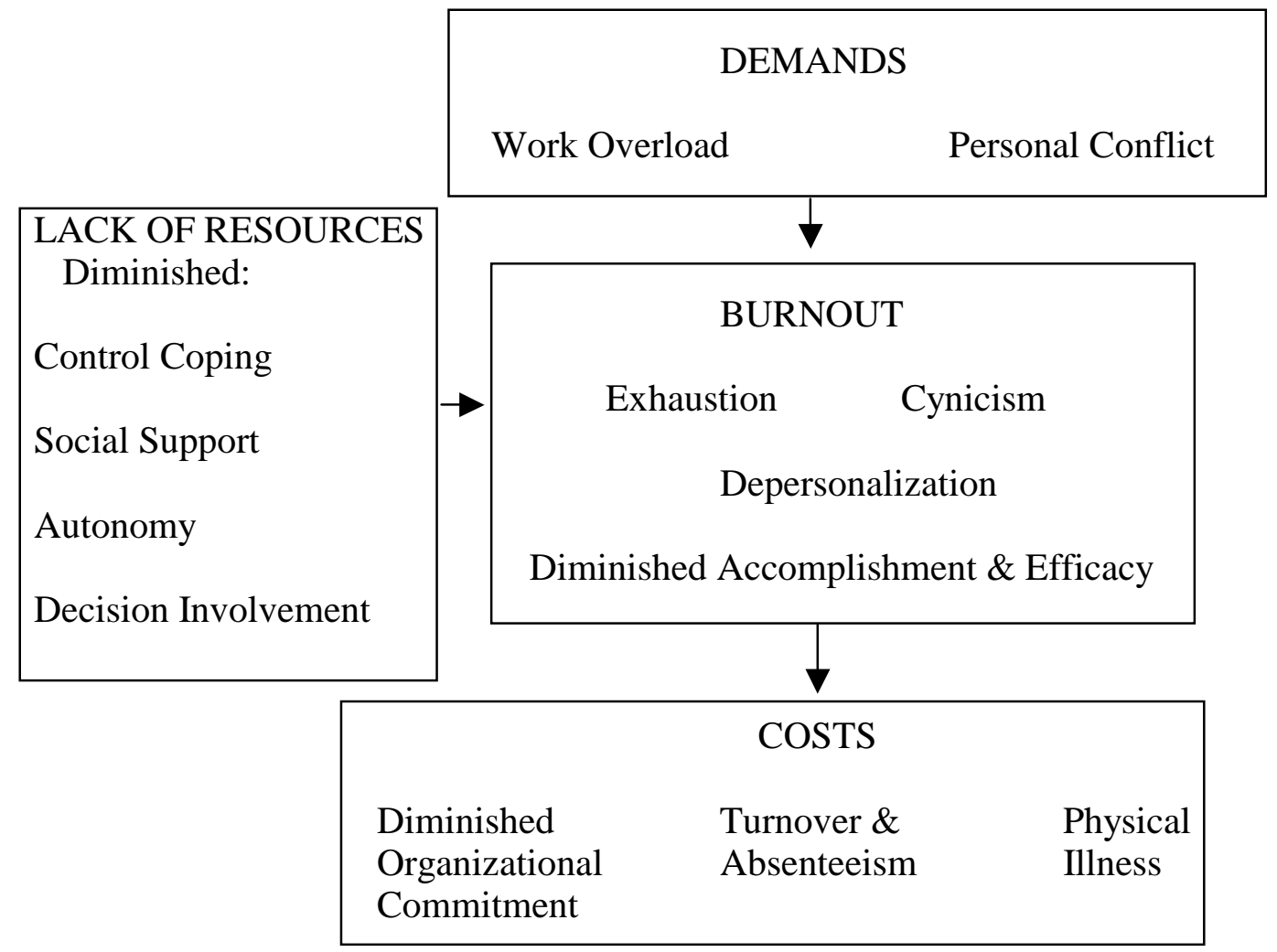

Figure 1. Structural model of burnout described by Maslach et al. (1996).

It is evident that the relationships between the three components of burnout described by Maslach have been disputed in the literature associated with the development and utilization of burnout models (Lee \& Ashforth, 1993). Exploration of the relationship between the components of burnout, and their significance relative to each other, provide important information regarding the burnout syndrome. However, the focus of this study is on the evaluation of relationships between burnout, stress, and social support among a specific population of psychology graduate students, not empirical evaluation of specific burnout models. As a result, evaluation of the effectiveness or comprehensiveness of specific burnout models appears to be beyond the scope of the current study. In addition, although each of the models discussed could provide an adequate structure with which to explore the construct of burnout, the 
model developed by Maslach et al. (1996), which does not exclude any potential components of burnout prior to evaluation, appears to most adequately fit the exploratory nature of the influence of stress and social support on the development of burnout in the present study. As a result, the Structural Model of Burnout proposed by Maslach et al. (1996) will be utilized as a means to conceptualize the burnout syndrome in this study.

It should be emphasized that the portion of the Maslach et al. (1996) burnout model which focuses on "costs" resulting from burnout, including diminished organizational commitment, turnout, absenteeism, and physical illness, will not be addressed in detail in this study. However, each of the remaining subsections of the model will be evaluated individually and in relationship with each other.

First, the "demands" portion of the model will combine work and personal demands and be referred to in this study as "stress." Second, the "lack of resources" component of the model to be evaluated in this study will be "social support." Control coping, autonomy, and decision involvement, additional components of the lack of resources subsection of the model, will not be specifically evaluated in this study. Third, emotional exhaustion, depersonalization, and lack of personal accomplishment will be the components of "burnout" to be addressed in this study. Finally, the relationship between burnout, stress, and social support will be evaluated using the Moderator Model (see Figure 2) proposed by Baron and Kenny (1986).

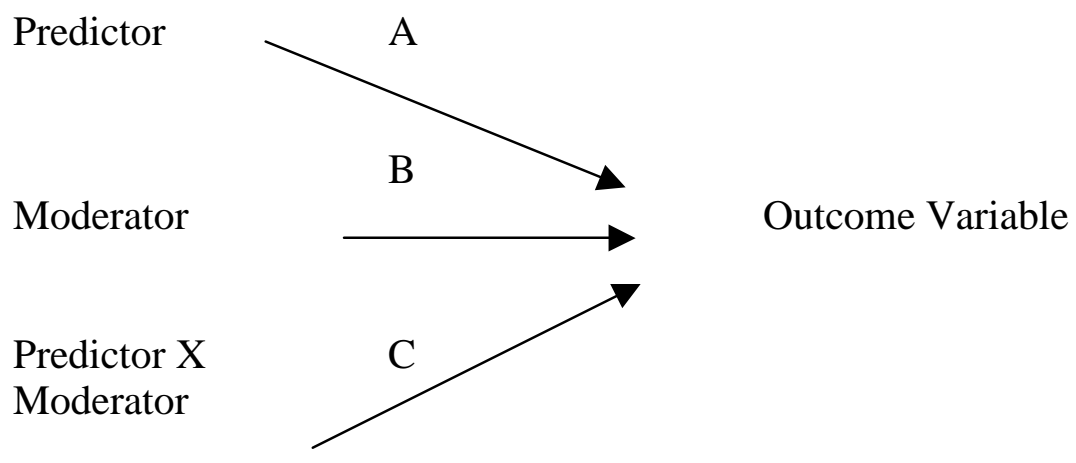

Figure 2. Moderator model (Baron \& Kenny, 1986). 
The Moderator Model described by Baron and Kenny (1986) suggests that a criterion or outcome variable may be influenced in three different manners, or according to three separate "paths." Path A involves the direct influence of a predictor variable on the criterion variable. Path B involves the direct influence of a moderator variable on the criterion variable. Path C focuses on the interaction effects of the predictor and moderator variables on the criterion variable. Paths $\mathrm{A}$ and $\mathrm{B}$ enable main or direct effects associated with changes in the criterion variable to be assessed. Path C enables moderating or "buffering" effects on the criterion variable to be evaluated.

Utilizing the Moderator Model (Baron \& Kenny, 1986) in the present study, stress served as the predictor variable, social support was the moderating variable, and burnout was the outcome variable. Utilization of this Moderator Model enabled evaluation of the direct effect of stress on burnout (Path A), the direct effect of social support on burnout (Path B), and the interaction effects of stress and social support on burnout (Path $\mathrm{C}$ ) to be evaluated.

\section{Burnout, Stress, and Social Support}

The relationship between burnout and stress has been addressed with relative frequency in the burnout literature (D’Aurora \& Fimian, 1988; Fimian \& Blanton, 1987; Perlman \& Hartman, 1982; Tobin \& Carson, 1994). It is suggested that if stress levels are sustained over an extended period of time that burnout symptoms may develop (D’Aurora \& Fimian, 1988).

An additional portion of the research on burnout has attempted to determine the impact of social support on the development of burnout symptoms. This research suggests that an individual's perceptions of social support can influence burnout symptoms (Cheuk et al., 1994; Etzion, 1984; Huebner, 1994; Kahill, 1986; McCarthy et al., 1990). The influence of specific sources (Etzion, 1984; Kruger, Botman, \& Goodenow, 1991; Northrup, 1996; Ross, Altmaier, \& Russell, 1989; Russell, Altmaier, \& Van Velzen, 1987), functions (Northrup, 1996; Ross et al., 1989; Russell et al., 1987), and types (House, 1981) of social support on the development of 
burnout have been assessed in the literature across a variety of populations.

Several studies have addressed the relationships between burnout, stress, and social support within the field of human services. Subjects in these studies have included counseling center staff members (Ross et al., 1989), human service workers (Etzion, 1984; Shinn, Rosario, Morch, \& Chestnut, 1984), nurses or nursing staff members (Northrup, 1996), teachers (Russell et al., 1987), social workers (Himle, Jayaratne, \& Thyness, 1989b; Himle, Jayaratne, \& Thyness, 1991), and masters level social work students (Koeske \& Koeske, 1989; Koeske \& Koeske, 1991). Doctoral students in psychology were subjects in no published studies which assessed the relationships between burnout, stress, and social support.

\section{$\underline{\text { Statement of the Problem }}$}

"Burnout implies that an individual experiences a collection of stressors that cause so much strain that normal coping skills / attitudes do not suffice. Thus overextended, the individual is left vulnerable to various upsets" (Golembrewski \& Munzenrider, 1988, p. 68). Health care professionals, including doctoral students in psychology, have tremendous pressures placed upon them every day. Demands are placed on them by supervisors, professors, coworkers, clients, friends, family members, and peers. This stress filled lifestyle makes them a group of people particularly susceptible to burnout.

Burnout is an even greater concern for students in the field of psychology due to the negative impact on the individual experiencing the symptoms of burnout, as well as on the potential influence that therapist distress or impairment, due to burnout, may have on the clientcounselor relationship, and ultimately on the client's therapeutic experience. Since social support has been identified in the literature as one factor which can influence the development of burnout symptoms (Cheuk et al., 1994; Etzion, 1984; Huebner, 1994; Kahill, 1986; McCarthy et al., 1990), it appears that assessment of the role of social support on the development and magnitude of burnout symptoms experienced by doctoral students in psychology is an 
appropriate issue to explore.

Purpose of the Study

Burnout among those in the helping professions has been documented in the literature with relative frequency. However, graduate student burnout in the helping professions has been studied infrequently. Given the academic, financial, social, and time oriented demands of doctoral students, combined with the emotional demands associated with work in the helping professions, doctoral students in the helping professions appear to be prime candidates for experiencing burnout. As a result, the purpose of this study was to expand knowledge of the relationships between burnout, stress, and social support among doctoral students in the field of psychology.

\section{$\underline{\text { Definition of Terms }}$}

Burnout: A reaction to prolonged emotional stress which includes the following "three components: emotional and / or physical exhaustion, lowered work productivity, and overdepersonalization" (Perlman \& Hartman, 1982, p. 283). In this study burnout was measured using the Maslach Burnout Inventory (MBI) (Maslach et al., 1996). Emotional Exhaustion: A component of burnout which is associated with "feelings of being emotionally overextended and exhausted by one's work" (Maslach et al., 1996, p. 4). In this study Emotional Exhaustion was measured using the MBI (Maslach et al., 1996).

Depersonalization: A component of burnout which "measures an unfeeling and impersonal response toward recipients of one's service, care, treatment or instruction" (Maslach et al., 1996, p. 4). In this study Depersonalization was measured using the MBI (Maslach et al., 1996).

Personal Accomplishment: A subscale of burnout associated with perceptions and "feelings of competence and successful achievement in one's work with people" (Maslach et al., 1996, p. 4). In this study Personal Accomplishment was measured using the MBI (Maslach et 
al., 1996).

Social Support: The "existence or availability of people on whom we can rely, people who let us know that they care about, value, and love us" (Sarason, Levine, Basham, \& Sarason, 1983, p. 127). In this study, Social Support was most specifically related to the identification of individuals, or sources of support, on whom one can "rely" to assist one with addressing specific challenges. Social Support was assessed using the Modified Sources of Support Questionnaire (MSOSQ). See the appendix section of this document to view the MSOSQ.

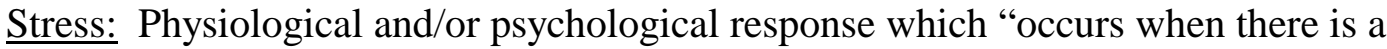
substantial imbalance (perceived or real) between environmental demands and the response capability of the individual" (Farber, 1983, p. 14). Stress was assessed in this study using the Modified Psychology Student Stress Questionnaire (MPSSQ). See the appendix section of this document to view the MPSSQ.

\section{$\underline{\text { Research Questions }}$}

This study addressed sixteen independent research questions associated with the following three variables: 1) burnout, 2) stress, and 3) social support. See pages 71 to 78 to view each specific research question. Questions 1a-1c, 2, and 3a-3f addressed the differences between counseling, clinical, and school psychology doctoral students. Questions 1a-1c addressed differences between groups with regard to reported burnout levels. Question two addressed differences between groups with regard to reported stress levels. Questions 3a-3f addressed differences in reported social support levels among counseling, clinical, and school psychology doctoral students.

Questions 4a-4c were guided by the Moderator Model proposed by Baron and Kenny (1986). These questions addressed the direct influence of the independent or predictor variable, stress, on the dependent variable, burnout.

Questions 5a through 10c were additionally guided by the Moderator Model proposed by 
Baron and Kenny (1986) and addressed the direct influence of the moderating variable, social support, on the dependent variable, burnout. Questions 5a-5c assessed the influence of classmate social support on burnout. Questions 6a-6c assessed the influence of clinical supervisor support on burnout. Questions 7a-7c assessed the influence of faculty advisor social support on burnout. Questions 8a-8c assessed the influence of friends (not yet specified) social support on burnout. Questions 9a-9c assessed the influence of relatives (not yet specified) social support on burnout. And, questions 10a-10c assessed the influence of spouse/significant other social support on burnout

Finally, questions 11a through 16c were additionally guided by the Moderator Model proposed by Baron and Kenny (1986), and addressed the moderating influence of social support on the relationship between the predictor variable, stress, and the outcome variable, burnout. Questions 11a-11c assessed the specific influence of peer or classmate social support on the relationship between stress and burnout. Questions 12a-12c assessed the specific influence of clinical supervisor social support on the relationship between stress and burnout. Questions 13a$13 \mathrm{c}$ assessed the specific influence of faculty advisor social support on the relationship between stress and burnout. Questions 14a-14c assessed the specific influence of friends (not yet specified) social support on the relationship between stress and burnout. Questions 15a-15c assessed the specific influence of relatives (not yet specified) social support on the relationship between stress and burnout. Questions 16a-16c assessed the specific influence of spouse/significant other social support on the relationship between stress and burnout. 


\section{Chapter II}

Literature Review

In their review of the burnout literature on mental health professionals, Leiter and Harvie (1996) concluded that "There are differences evident in their levels of burnout, and the issues researchers examined in regard to them. It is not clear from examining the research the extent to which variations in burnout are a function of being a member of a certain profession or of the organizational context in which a professional works...Only through analysis of a broadly encompassing assessment of the service providers, their work content, and their work activities could begin to identify the primary relationships accounting for the difference" (p. 98). The aforementioned statements suggest the rationale for assessment of the relationships between burnout, stress, and social support experienced by doctoral students in psychology. No research on the relationships between these variables has been published using this population, however. As a result, the remainder of this chapter will focus on providing a summary of the research associated with burnout, stress, and social support, previously documented in the literature.

\section{$\underline{\text { Burnout }}$}

Perlman and Hartman (1982) attempted to provide a comprehensive definition of burnout based on their evaluation of the early burnout literature. According to the authors, burnout is "a response to chronic emotional stress with three components: a) emotional and/or physical exhaustion, b) lowered productivity, and c) overdepersonalization" (p. 293). This identification of separate burnout components ultimately supports the conceptualization of burnout from a multidimensional perspective, a view held by a number of contemporary researchers of burnout (Maslach \& Jackson, 1981).

The construct of burnout has appeared in the literature for approximately 25 years to date. Perlman and Hartman (1982) found no references related to burnout prior to 1974 in their review 
of the literature. However, review of the professional literature between 1974 and 1980 resulted in the identification of 47 sources addressing the topic of burnout. According to the review by Perlman and Hartman (1982), the majority of early publications on burnout were descriptive in nature; only Berkley Planning Associates (1977) and Maslach and Jackson (1981) investigated the topic of burnout empirically. Interest in the topic of burnout has grown significantly since the review of literature conducted by Perlman and Hartman (1982). According to Schaufeli, Van Dierendonch, and Van Gorp (1996), the number of publications related to the topic of burnout totals over 3800 .

Another review of the burnout literature was conducted by Lubin et al. (1992) spanning the time period from 1980 to 1991 . This review classified each of the articles found into a variety of categories including Theory and Models, Measurement, Intervention, and Target Population. The Target Population category provides important information related to the present study. Nurses were cited most frequently in the Target Population category, followed by teachers. A number of articles related to social workers, psychologists, psychiatrists, counselors, and human services workers were also listed. However, none of the published studies listed by Lubin et al. (1992) addressed burnout among doctoral students in psychology.

Eighteen publications on burnout experienced by mental health workers were identified by Leiter and Harvie (1996) in their review of the literature from 1985 to 1995 . These researchers identified "mental health workers" as individuals who were "psychiatrists, psychologists, counselors, mental health social workers and nurses, and occupational therapists providing mental health care" (p. 90). Results suggested that the majority of research on mental health professional burnout, conducted from the mid 1980's to the mid 1990's, focused on the identification of the antecedents of burnout. Most often the antecedents of burnout have been identified as individual characteristics (e.g., coping strategies, affective experiences), client characteristics (e.g., direct client contact hours, patient aggressive behavior), and work 
characteristics (e.g., type of work setting, opportunities for supervision). In addition, the literature has also focused significant attention on the identification of the relationship between the antecedents of burnout and the emotional exhaustion, depersonalization, and personal accomplishment components of burnout. Leiter and Harvie (1996) reported that little attention in the mental health worker burnout literature has focused on the consequences of burnout or on burnout interventions. More recently, studies have attempted to integrate evaluation of predictor variables related to burnout with the three components commonly associated with the burnout construct (i.e., emotional exhaustion, depersonalization, and personal accomplishment). This research has led to increased attention regarding the development of burnout models in the literature (Leiter \& Harvie, 1996). It is noteworthy that none of the target populations evaluated in studies conducted during the time period of the review by Leiter and Harvie (1996), or the research by Lubin et al. (1992), utilized doctoral students in psychology as subjects.

One example of the type of research published during the period reviewed by Leiter and Harvie (1996) was conducted by Ackerley, Burnell, Holder, and Kurdek (1988). In this study, 562 licensed doctoral level psychologists were asked to complete a background questionnaire assessing demographic information and work characteristics, the Maslach Burnout Inventory (MBI), and the Psychologist's Burnout Inventory (PBI). The latter measure included 15 items which assessed respondent experiences related to the following four factors: negative clientele, support, over involvement with clients, and perceived control at work. Mean levels of each of the three components of burnout assessed by the MBI (1) Emotional Exhaustion, (2) Depersonalization, and (3) Personal Accomplishment were higher for the sample surveyed than mean scores obtained for the normative sample of mental health professionals reported by Maslach and Jackson (1986). Further evaluation of the burnout levels obtained were classified by Ackerley et al. (1988) using the MBI subscale classification system developed by Maslach and Jackson (1986). Based on this classification system, greater than $72 \%$ of the sample of 
licensed psychologists fell into the moderate or high burnout classification range on the Emotional Exhaustion (EE) subscale. Fifty-nine percent of the respondents were classified in the moderate or high burnout categories for the Depersonalization (DP) subscale, while less than four percent of the respondents were classified in the moderate or high classification on the Personal Accomplishment (PA) subscale. Results additionally suggested a number of significant correlations, including negative correlations between age, number of years in direct service, and perceived low levels of support and EE. EE was positively related to negative client behaviors, perceptions of low control, and over involvement with clients, as well as a number of challenging therapy issues (i.e., sexual abuse/rape, battery). EE was most significantly predicted by over involvement with clients, followed by perceptions of lack of control, age, and addressing medical, sexual abuse, and sexual dysfunction issues. Significant negative correlations between DP and age, number of years of direct service, conducting couples therapy, and working on selfactualization and sexual dysfunction issues in therapy were reported. DP was significantly and positively related to gender, engaging in clinical supervision, negative client behaviors, low control, over involvement, and therapy involving the following therapeutic issues: medical, substance abuse, financial, psychotic, and sexual abuse/rape. DP was most significantly predicted by perceptions of lack of control and over involvement with clients, followed by age, negative clientele, issues related to self-growth, affect, psychosis, sexual abuse, and the law. Significant negative correlations between PA and therapeutic issues (i.e., group psychotherapy, diagnosis/assessment, teaching, clinical supervision, administration), performing psychodiagnostic duties, working with psychotic clients, and perceptions of low control and support were reported. Significant positive correlations were reported between PA and number of years of direct service, performing individual and couples therapy, addressing interpersonal/relationship and self-actualizing/self-growth issues, and negative client behaviors. PA was most strongly predicted by perceptions of low control. Additional predictors of PA 
included: perceptions of low support, work involving making diagnoses, income, number of hours spent in direct service, and issues related to consultation, administration, and group therapy.

A related study by Wood, Klein, Cross, Lammers and Elliot (1985) supported the findings of Ackerley et al. (1988) which suggested that burnout among therapists exists and is of sufficient magnitude to warrant attention in the literature. Wood et al. (1985) reported that threefourths of the psychologist respondents indicated that they felt that depression or burnout is a serious problem among professional practitioners. Nearly two-thirds of the participants admitted that they were aware of peers whose work was influenced by depression or burnout symptoms. In addition, nearly one-third of the respondents stated that symptoms of depression or burnout had affected their own work, although only slightly more than half of those who reported difficulties had obtained psychological assistance for themselves.

\section{Critical Issues Associated with Burnout}

A number of critical issues are associated with burnout among therapists. One issue involves ethical considerations associated with continued therapeutic practice despite experiencing burnout symptoms. In a study conducted by Skorupa and Agresti (1993), 94 psychologists were surveyed regarding their ethical beliefs concerning continued therapeutic work with clients despite experiencing burnout or impairment. Respondents were asked to complete a demographic questionnaire, a survey assessing their attitudes associated with burnout and impairment, and the MBI. Results suggested that lower scores on the MBI Emotional Exhaustion (EE) subscale were significantly related to stronger ethical beliefs related to burnout. The Depersonalization (DP) subscale was positively related to client contact hours and negative client behaviors (i.e., suicidal gestures), while the Personal Accomplishment (PA) subscale of the MBI was positively associated with client contact hours and knowledge of burnout prevention techniques. Results further suggested that respondents who held strong ethical beliefs associated 
with continued therapeutic practice despite experiencing burnout or impairment tended to report fewer direct contact hours with clients. Additionally, individuals with strong ethical beliefs regarding impairment were determined to be more likely to have knowledge of burnout prevention techniques than those who held less strong ethical beliefs regarding practicing therapy while impaired. Finally, results suggested that the sample utilized in this study reported lower levels of burnout on each subscale of the MBI than the normative mental health professional sample described by Maslach and Jackson (1986). This finding is in contrast to that of Ackerley et al. (1988) who reported their nationwide sample of practitioners to be above the normative scores on each subscale of the MBI. Skorupa and Agresti (1993) suggest that differences in work settings (i.e., private versus public settings) associated with the samples utilized in the aforementioned studies likely contributed to the MBI mean subscale differences detected between these studies.

The article by Skorupa and Agresti (1993) is not the only published research related to the ethical considerations associated with distress experienced by psychotherapists (Thoreson, Miller, \& Krauskopf, 1989). Additional research has focused on impairment (Fly, Van Bark, Weinman, Kitchener, \& Lang, 1997; Frame \& Stevens-Smith, 1995; Stadler, Willing, Eberhage, \& Ward, 1988; Wood et al., 1985), and burnout (Frame \& Stevens-Smith, 1995; Wood et al., 1985) among psychotherapists, emphasizing the importance that individuals in the field of psychology place on these topics. Frame and Stevens-Smith (1995) list the following as manifestations of impairment: chemical dependency, mental illness, personal conflict, job stress, exploitation of clients, burnout, and even the emotional demands associated with graduate school. Fly et al. (1997) also suggest that impairment is an ethical issue which can develop during graduate education.

The relationship between burnout and depression is another critical issue related to burnout (Freudenberger, 1985). It is important to distinguish between burnout and depression 
because burnout and depression share some of the same symptoms, and as a result, can be confused and the terms mistakenly interchanged. Burnout develops from chronic stress and fatigue. Depression, on the other hand, is most frequently caused by a specific and identified event or stressor. In addition, burnout can be environmentally specific (e.g., one may be burned out at work, but not in other areas of one's life), while depression is generally broadly experienced. An additional distinction between burnout and depression involves motivation, such that depressed individuals tend to "give up" while people who are burned out continue to attempt to achieve their goals (Freudenberger, 1985).

It is also important to note that not everyone who complains of symptoms such as fatigue, cynicism, and negative self-concept experiences burnout. Time is an important factor to consider. If the symptoms are quickly remedied, there may be no significant problem. However, if the symptoms persist over a substantial period of time, one could be headed for burnout. According to Freudenberger (1985) the duration and intensity of burnout symptoms "depends on your individual situation, your personality, your inclinations, and your ability to cope with stress" (p. 19). In addition, burnout is generally considered to be a long term, chronic condition. For the most part, one "builds up" to burnout over time (Freudenberger \& Richelson, 1980).

\section{Burnout Assessment}

Several instruments have been developed to measure burnout. Measures of burnout cited in the literature include the Psychologist's Burnout Inventory (Ackerley et al., 1988), the Meier Burnout Assessment (MBA) (Meier \& Schmeck, 1985) and the Maslach Burnout Inventory (MBI) (Maslach et al., 1996). The MBI is a 22 item self-report questionnaire which assesses the frequency of burnout symptoms and is the most frequently utilized measure of mental health professional burnout (Leiter \& Harvie, 1996). Leiter and Harvie (1996) reported that their review of the recent burnout literature among mental health professionals suggested that all studies reviewed, except one, used the MBI to measure burnout. They added that, "Although the 
vast majority of researchers use the MBI, they score it and analyze it inconsistently. We recommend using the full MBI with frequency ratings only, reporting descriptive statistics on all three subscales, reporting correlations of all predictors with all three subscales, and reporting the third scale as personal accomplishment (not reduced personal accomplishment) as recommended in the third edition of the MBI Manual" (p. 98).

Though the MBI has been widely utilized in the assessment of burnout among mental health professionals, it was a study by Meier and Schmeck (1985) which provided empirical evidence that burnout is also experienced by the college student population. This study assessed student burnout using a sample of 120 undergraduate students. Burnout was measured using the MBI and the MBA. Significant correlations between scores on the MBI and MBA supported the construct validity of burnout among the population of college students. Significant negative correlations were obtained between both burnout measures and memory skills, vocational selfconcept, and self-esteem. No information relative to the specific subscales of the burnout measures and their relationship to other variables assessed in the study was provided. Support for the findings of Meier and Schmeck (1985), that burnout, measured using the MBA and the MBI is experienced by college students, was provided by McCarthy et al. (1990).

A significant additional portion of the literature on burnout assessment has focused on the identification of demographic data related to burnout levels. A focus on the relationship between burnout and gender (Ackerley et al., 1988; Corrigan, Holmes, \& Luchins, 1995; Jupp \& Shaul, 1991; Kahill, 1986; Maslach, 1982), race (Corrigan et al., 1995; Maslach, 1982), level of educational attainment (Corrigan et al., 1995; Diezel \& Coursey, 1998; Kahill, 1986; Maslach, 1982), number of direct contact hours (Maslach \& Pines, 1977), size of caseload (Maslach \& Pines, 1977; Raquepaw \& Miller, 1989), and age (Ackerley et al., 1988; Dietzel \& Coursey, 1998; Jupp \& Shaul, 1991; Maslach, 1982; Van Wijk, 1997) has been identified with relative frequency in the literature. However, results of the inquiries associated with these relationships 
have often been contradictory. For example, Maslach (1982) reports that men and women are similar in their experience of burnout although women are more likely than men to exhibit greater Emotional Exhaustion, and men are more prone to experience Depersonalization. Corrigan et al. (1995), on the other hand, reported no significant differences related to gender on the Emotional Exhaustion and Depersonalization subscales of the MBI, and suggested that females reported higher levels of Personal Accomplishment than did males. Additional studies report no gender differences in levels of burnout (Ackerley et al., 1988; Jupp \& Shaul, 1991; Kahill, 1986).

It appears, therefore, that generalizations about "who is most likely to burnout" are difficult to develop as the literature on this subject appears to be somewhat contradictory. However, exploration of specific characteristics associated with narrowly defined groups, such as doctoral students in psychology, may permit more informed conclusions about the relationship between demographic information and burnout to be made, at least for that specific group. Replication of research related to these specific populations would then permit more broad generalizations to be made regarding the relationships between burnout and demographic characteristics.

\section{Burnout Within the Health Care Professions}

Health care professions have received particular attention in the burnout literature (Beehr \& Newman, 1978; Freudenberger, 1980; Maslach, 1982; Pines et al., 1981). Cherniss (1980) discussed symptoms of burnout which are specifically associated with persons in the helping professions. A lack of desire to go to work, feelings of indifference toward clients, clock watching, and postponing sessions with clients were mentioned. In addition, an inability to concentrate in therapy sessions, decreased ability to empathize with clients, decreased idealism, inflexibility, and increased client stereotyping, drug or alcohol use, and absenteeism may also indicate that a helping professional is burning out. Um and Harrison (1998) suggest that the 
most frequent consequences of such symptoms of burnout include job dissatisfaction and intention to quit one's job.

Psychotherapists have been the subject of a growing body of literature on burnout (Ackerley et al., 1988; Farber \& Heifetz, 1982; Kahill, 1986; Raquepaw \& Miller, 1989; Snibbe, Radcliffe, Weisberger, Richards, \& Kelly, 1989; Suran \& Sheridan, 1985). A portion of this literature has focused on the causes of psychotherapist burnout. For some psychologists, a lack of objective measures which can help to identify therapeutic success, a methodical pace of therapy, feelings of detachment from coworkers due to individual responsibilities, and the constant demand of the therapist's attention in therapy may lead to burnout (Farber \& Heifetz, 1982). Other therapists have become burned out due to a sense of powerlessness or lack of control. According to Maslach (1982), people are at a greater risk for burnout when they feel trapped, are unassertive, or feel held down by the people or institutions they serve. Still other therapists have become burned out as a result of an overload of severe cases in their caseload (Parham, 1992), large client caseload, high percentage of direct contact hours with clients, role conflict or role ambiguity (Um \& Harrison, 1998), insufficient supervision, or lack of support from institutional administration (Cherniss, 1980). A lack of balance in one's life (Maslach, 1982), anxiety (Hockey, 1983), and boredom (Csikszentmihalyi, 1975), have also been mentioned in the literature as potential causes or antecedents of burnout. Perhaps the most frequently sited precipitant to burnout discussed in the literature, however, is stress (LeUnes \& Nation, 1989).

Doctoral students in the field of psychology have been subjects in only one descriptive article (Morrissette, 1996), and one empirical study (Kahill, 1986) on burnout despite the fact that the academic, financial, social, and time oriented demands of these students, combined with the emotional demands of work in the helping professions, make advanced students in the field of psychology prime candidates for experiencing burnout. Morrissette (1996) provides a 
description of a number of issues which masters and doctoral level counseling psychology students may encounter in their academic and clinical training. Several of these issues include emotional overinvolvement, sexual attraction, countertransference, skill related anxiety, conflicts associated with the supervision process, and negative counselor reactions to client trauma. Morrissette (1996) suggests that stress and burnout can result from inadequate resolution of the aforementioned issues. The study by Kahill (1986) includes assessment of the influence of family support, friend support, and professional expectations on burnout symptoms, and is discussed in the social support section of this review.

$\underline{\text { Stress }}$

Stress has been defined as a physiological and/or psychological response which "occurs when there is a substantial imbalance (perceived or real) between environmental demands and the response capability of the individual" (Farber, 1983, p. 14). Models which conceptualize burnout typically include stress as an antecedent to the development of burnout symptoms (Koeske \& Koeske, 1993; Maslach et al., 1996; Perlman \& Hartman, 1982; Richardsen \& Burke, 1995). Within the helping professions, potential stressors include lack of supervisory support, increased responsibility due to insufficient personnel resources, long hours, task overload (Van Wijk, 1997), work accountability, justification of client need for services, and cost containment (Bedini, Williams, \& Thompson, 1995). Negative outcomes may occur at both an individual and an organizational level as a result of the aforementioned stressors. Negative individual stress outcomes may include physical illness, psychological difficulties, and substance abuse. Negative organizational outcomes may include decreased productivity, and increased absenteeism and turnover.

\section{Measurement of Stress}

Matheny, Aycock, Curlette and Junker (1993) provide information about the measurement of stress, suggesting that measures of stress originally focused on measuring 
cumulative life event stress. These measures, such as The Social Readjustment Rating Subtest (Holmes \& Rahe, 1967) and the Life Experiences Survey (Sarason, Johnson, \& Siegel, 1978) excluded subjective appraisal of stressful life events, however, and "attended to one-half of the stress equation - namely, the measurement of perceived demands" (Matheny et al., 1993, p. 815). As a result, measures such as The Derogatis Stress Profile (Derogatis, 1987) later focused on incorporating subjective appraisals of stress by respondents. More recent measurement of stress such as the Coping Resources Inventory for Stress, has focused on including assessment of coping resources, in addition to assessment of the quantity of perceived stressors, and subjective responses to stress (Matheny et al., 1993).

Ray and Miller (1994) suggest that the literature addressing life stress has frequently utilized measures of life event stress to the exclusion of the assessment of daily hassles. These authors report that literature on life stress should include assessment of daily life stressors. Shinn et al. (1984) additionally suggest that current research associated with stress should address specific stressors associated with specific populations. Based on these recommendations, it appears that the Modified Psychology Student Stress Questionnaire (MPSSQ) was an appropriate measure to use in this study. The MPSSQ assesses specific stressors experienced by a specific population, graduate students in psychology, and, therefore, satisfies the recommendations for future stress related research proposed most specifically by Shinn et al. (1984).

Student Stress

A number of articles have discussed specific stressors associated with completing a graduate degree. These stressors include confusion regarding the student role within the educational system (Fimian \& Blanton, 1987; Um \& Brown-Standridge, 1993), transitions from classroom to applied settings (Gold, 1985; Mitchell \& Kampke, 1993), financial changes, changes in social networks, fear of failure, lack of knowledge about the educational program, and adjustments to family life (Bowman, Bowman, \& DeLucia, 1990). 
Studies which assess the stress experienced in the process of professional education have also been documented in the literature (Goplerud, 1980; Polson \& Nida, 1998; Toews et al., 1993; Wolf, 1994). In a discussion of "lifestyle and psychosocial sacrifices made during medical education", Wolf (1994) suggested that medical students often report decreased physical activity, sleep, self-esteem, and time spent engaging in leisure or recreational activities, while reports of stress, anxiety, cynicism, and depression increased after beginning medical school education (p. $13)$.

In a related study conducted by Toews et al. (1993), stress levels of medical residents, medical students, and graduate science students enrolled in a Canadian college were measured using the Social Readjustment Rating Scale (SRRS), the Symptom Check List 90-R (SCL-90-R), and an additional measure of stress associated with the academic environment. Results suggested that medical residents, medical students, and graduate science students experience levels of stress during their training that are elevated in comparison to non-psychiatric norms. Information provided by Goplerud (1980) further emphasizes the stress experienced by some students during their graduate education. Goplerud (1980) reported results of a study by Holmes and Masuda (1974) which suggested that greater than 50 percent of "the first and second-year graduate students tested on the Social Readjustment Rating Scale reported life changes that placed them in the life crisis category" (p. 283). Goplerud (1980) further reported findings of a study by Halleck (1976) in which "record reviews at two university health services showed that, after freshman, graduate students were the most frequent utilizers of psychiatric services in the university community" (p. 283). Information provided by Goplerud (1980), though a secondary source, was utilized because the primary sources (Halleck, 1976; Holmes \& Masuda, 1974) were unavailable to the current researcher.

Graduate student stress experienced specifically in psychology related educational programs has also been evaluated (Cahir \& Morris, 1991; Goplerud, 1980; Hudson \& O’Regan, 
1994; Polson \& Nida, 1998). Polson and Nida (1998) evaluated stress reported by 329 masters and doctoral level student members of the American Association for Marriage and Family Therapy. More than one-fourth of the respondents had considered dropping out of their program as a result of "program demands." More than one in ten respondents had actually dropped out. Responses to questions related to antidepressant use suggested that of the individuals who acknowledged current antidepressant use, $57 \%$ of respondents began using antidepressant medication within the previous six months.

In a study of 133 graduate psychology students conducted by Cahir and Morris (1991), student stress was measured using the Psychology Student Stress Questionnaire (PSSQ), the SCL-90-R, and the 15 item Negative Life Change Events portion of the Health and Daily Living Form (HDL). Stress levels measured by the SCL-90-R and the HDL suggested that graduate student subjects scored "approximately one standard deviation above the non-patient norms" (p. 416). More specifically with regard to demographic variables, results revealed that females reported higher stress levels than did males. Additionally, higher stress scores were observed for graduate students in their third year of study than those obtained for students in any other year of graduate psychology education.

Similar to the study conducted by Cahir and Morris (1991), the study by Hudson and O’Regan (1994) also assessed the relationship between psychology graduate student stress and demographic variables. The Psychology Student Stress Questionnaire (PSSQ) and a demographic data form were utilized in this study of students from the Minnesota School of Professional Psychology. Unlike results reported by Cahir and Morris (1991) which suggested that females and students in their third year of graduate education reported significantly higher levels of stress, results reported by Hudson and O’Regan (1994) suggested no significant differences in student stress levels across the following demographic variables: age, gender, year in school, income level, relationship status, number of children, and number of hours spent 
working each week. However, several significant interaction effects were observed and reported.

It appears, based on the research studies discussed regarding graduate student stress, and in particular graduate psychology student stress, that significant stress is experienced by these students (Cahir \& Morris, 1991; Hudson \& O’Regan, 1994; Polson \& Nida, 1998). Results of studies which have attempted to determine the relationship between demographic variables and graduate psychology student stress have been mixed, however (Cahir \& Morris, 1991; Hudson \& O’Regan, 1994). It appears, therefore, that additional research related to the unique characteristics and demands of graduate students in psychology is necessary. This view is supported by Polson and Nida (1998) who suggest that despite the knowledge that graduate students in psychology experience elevated stress levels, insufficient research has been conducted to assess the influence of combining clinical, research, and classwork demands on the development of stress related symptoms among such students. Polson and Nida (1998) added that "unfortunately, the research base for understanding this process has changed very little since Stevenson, Norcross, King, and Tobin stated,'Despite the need for empirical evaluation of training to both improve its quality and justify support, little systematic evaluation of the impact of training on students or their clients has been conducted'(1984, p. 212)" (p. 96).

\section{Student Stress and Burnout}

The relationship between student stress and the development of burnout symptoms has additionally been established in the literature (Fimian \& Blanton, 1987; Tobin \& Carson, 1994). In one study of 413 teacher trainees and first-year teachers (Fimian \& Blanton, 1987), significant positive correlations were reported between burnout assessed using the MBI and stress strength, stress frequency, role conflict and role ambiguity. According to the researchers, "it was apparent that role conflict and ambiguity were related more strongly to stress than they were to burnout, but that stress and burnout were even more strongly correlated" (p. 163). 
In a related study (Tobin \& Carson, 1994), stress and burnout were assessed for social work students and education students seeking a postgraduate certificate. Stress was measured using the General Health Questionnaire (GHQ-28) and burnout was measured using the MBI. According to the authors, both groups of students reported high levels of psychological distress, as measured by the GHQ-28. In addition, social work students "scored in the moderate range on all three Maslach subscales", scores which were higher than postgraduate students in education on the Depersonalization and Personal Accomplishment subscales (p. 247). The authors also compared the stress and burnout responses of the social work students to responses provided by qualified social workers obtained in a study conducted by Gibson, McGrath, and Reid (1989). Tobin and Carson (1994) concluded that "the stress of the dual roles of practitioner and student undertaken by student social workers, manifests itself in a different way from the stress experienced by qualified social workers...(and that) the student social worker appears to be under considerable stress even before she/he takes up the more onerous responsibilities of the qualified social worker" (p. 253).

No studies of the influence of stress on burnout were found for graduate students in psychology, despite documentation that a significant amount of stress is experienced by this group of students. As a result, it appears that exploration of the relationship between stress and burnout among the population of graduate students in psychology is an important area to explore.

\section{$\underline{\text { Social Support }}$}

Social support is currently regarded by researchers as a multidimensional construct (Cutrona \& Russell, 1987) of which several definitions have been proposed in the literature. According to Lin, Ensel, Simeone, and Kuo (1979), social support is, "support accessible to an individual through social ties to other individuals, groups, and the larger community" (p. 109). Sarason et al. (1983) define social support as the "existence or availability of people on whom we can rely, people who let us know that they care about, value, and love us" (p. 127). 
Several types of social support have been identified by researchers and described in the literature (Cutrona, 1986; House, 1981; Schaefer, Coyne, \& Lazarus, 1981; Smith, Fernengel, Holcroft, Gerald, \& Marien, 1994). According to Cutrona (1986), social support can be classified in terms of helping and nonhelp-oriented behaviors. Schaefer et al. (1981) identified emotional support, tangible support, and informational support as distinct types of social support, while House (1981) described four types of social support including emotional, appraisal, informational, and instrumental support. Smith et al. (1994) identified three additional types of social support including quantitative social support, qualitative social support, and functional social support.

Social support can also be described in terms of its functions (Cutrona \& Russell, 1987). The components of a model of social support developed by Weiss (1974) include the following six functions of social support: attachment, social integration, reassurance of worth, reliable alliance, guidance, and opportunity for nurturance.

In addition to describing social support in terms of type and function, social support can also be evaluated based on the source providing the support to the recipient (Constable \& Russell, 1986). Sources of support frequently found in the literature have included family members, friends, spouse/significant others, supervisors, and coworkers.

\section{Measurement of Social Support}

A number of instruments have been developed which measure social support. Some measures of social support, such as the measure of Perceived Social Support From Family and Friends, assess the quality of social support reported by individuals (Procidano \& Heller, 1983; Sarason, Shearin, Pierce, \& Sarason, 1987). Other measures, such as the Inventory of Socially Supportive Behaviors, typically assess the quantity of social support assistance perceived by an individual (Sarason et al., 1987). Still other measures, such as the Social Support Questionnaire, assess both the quantity and quality of perceived social support (Sarason et al., 1987; Tardy, 
1985; Vaux, Phillips, Holly, Thomson, Williams, \& Stewart, 1986). Additionally, other measures of social support, such as the Interpersonal Support Evaluation List, address the availability of various types of social support perceived by an individual (Sarason et al., 1987). Of particular importance for the current study is the Sources of Support (SOS) measure developed by Northrup (1996). This self-report instrument focuses on sources of perceived support and is a modification of a measure originally developed by House (1981). The SOS assesses the quantity and quality of social support attained from the following four sources: 1) supervisors; 2) coworkers; 3) spouse/significant others; and 4) friends/family. A modified version of the SOS, the Modified Sources of Support Questionnaire (MSOSQ), was utilized in the current study.

\section{Social Support and Stress}

The relationship between social support and stress has been addressed in the literature (Cohen \& Hoberman, 1983; Cohen \& Wills, 1985; Himle, Jayaratne, \& Thyness, 1989a; Jemmott \& Magliore, 1988; Lin et al., 1979; Reifman \& Dunkel-Schetter, 1990; Weinberger, Tierney, Booker, \& Hiner, 1990; Wethington \& Kessler, 1986). Research on the relationship between social support and stress has often focused on the influence of stress and social support on psychological and physical health. Results of many of these studies of social support have suggested that there is a positive relationship between perceived social support and well-being (Cohen \& Wills, 1985).

\section{Direct and Buffering Effects of Social Support on Stress}

Cohen and Wills (1985) suggest that significant disagreement exists among researchers regarding whether social support is more accurately described as a buffering or direct effect process. Those who propose that social support is a main or direct effect process suggest that all individuals can benefit from social support, regardless of the magnitude of an individual's stress level. Social support is, therefore, negatively related to stress and ultimately serves to enhance 
general well-being by supplying individuals with a source of "positive affect, a sense of predictability and stability in one's life situation, and a recognition of self-worth" (Cohen \& Wills, 1985, p. 311). Those who explain the influence of social support in terms of the buffering hypothesis, on the other hand, suggest that social support is not beneficial to individuals who were not experiencing stress, but rather is beneficial only to persons who already perceive themselves to be under the influence of stress (Cohen \& Wills, 1985).

Evaluation of the influence of social support on the stress response is further complicated by the results of a number of studies which have found support for both the main effect hypothesis and the buffering hypothesis (Constable \& Russell, 1986; Etzion, 1984; Russell et al., 1987). Such inconsistencies in the research regarding the influence of direct and buffering effects of social support on stress may reflect the lack of a theoretical base associated with the conceptual, methodological, and statistical study of social support (Cohen \& Wills, 1985). According to Northrup (1996), "The degree to which each is accurate depends, in part, upon the dimensions of stress and support being addressed and the degree to which various stressors and supports are matched" (p. 4). Exploration of the direct and buffering influence of social support was a significant focus of the current study. The influence of social support specifically on the stress-burnout relationship was evaluated.

Social Support and Graduate Student Stress

The influence of social support on graduate student stress has also been addressed in the literature (Goplerud, 1980; Hodgson \& Simoni, 1995; Mallinckrodt \& Leong, 1992). These studies generally suggest that graduate students who perceive themselves to have an adequate social support system report lower stress levels, and are more likely to report physical and emotional well-being than are graduate students lacking adequate social support.

A study conducted by Goplerud (1980) emphasizes the magnitude of stress experienced by some graduate students during their graduate education, as well as the influence that social 
support can have on such stress. In this study of 22 graduate students in psychology, social support and stress experienced during the first six months of their graduate program were assessed. Subjects included students from clinical, developmental, social, biopsychology, and cognitive psychology graduate programs. Results suggested that graduate student respondents reported an average of nearly four stressful life events during the first six months of their graduate program, and that nearly half of the reported life events were reported as highly stressful. It was further reported that 57 percent of all stressful events reported by subjects, and 59 percent of all events classified as intensely stressful, were related to events associated with the graduate school experience (i.e., moving, finals, paper deadlines). Physical and emotional concerns were positively related to the number of intensely stressful events reported by students. "The most frequently reported problems were primarily emotional: periods of intense anxiety $(81.8 \%)$; two or more periods of intense anxiety $(63.9 \%)$; depression lasting 3 or more consecutive days (50\%); and severe sleep problems unrelated to studying (31.8\%). On four items concerning physical wellbeing, about $30 \%$ responded positively to each: missing classes due to illness (36.4\%); confined to bed for 1 day or more $(27.3 \%)$; periods of intense somatic symptoms (27.3\%); and flare-ups of preexisting illnesses (18.2\%)" (Goplerud, 1980, p. 286). The impact of the aforementioned statistics is intensified when considering that the symptoms were reported by a sample whose average age was merely 23.7 years. The relationship between social support and graduate student reports of stress was also addressed in this study. The quantity of social support contacts with peers and faculty members was found to moderate student reports of stressful life events, health problems, and emotional problems. Subjects who reported adequate social relations reported less stress and fewer physical and emotional concerns than individuals who lacked adequate social support.

In a related study by Mallinckrodt and Leong (1992), the relationship between academic program and family environment social support on reports of stress, depression, and anxiety was 
assessed for a sample of 166 graduate students from various fields. Subjects were asked to complete two measures of functional social support, the Graduate Program Support and the Family Environment Support, as well as two measures of stress, the Stressful Life Events, and the Psychological Stress Symptoms. Results supported the findings of Goplerud (1980), suggesting that, in general, students experience heightened levels of stress during graduate school. However, Mallinckrodt and Leong (1992) further suggested that student experiences of stress, reactions to stress, and perceptions of social support varied significantly according to gender. Female students reported higher stress levels and more stress related symptoms, such as depression and anxiety, than did males. Additionally, male and female subjects differed relative to their perceptions of the amount of social support they were currently receiving. Female respondents "reported significantly less support from their academic departments and family environments than did men" (p. 716). The sources of support perceived as most beneficial in reducing the negative influence of stress also differed according to gender. "Family support had only buffering effects, but no direct effects on stress symptoms for women. Graduate program and family support had direct effects, but no buffering effects on stress symptoms for men" (p. 716). These results suggest that female graduate students perceive that they are supported within their familial, but not their academic environment, and that familial support is only beneficial at times of high stress. Males, on the other hand, appear to perceive that they are supported in school and at home, and males appear to benefit from the support regardless of their perceived stress levels. The authors of this study suggest that attempts to balance multiple life roles, including the role of graduate student, may lead to greater role strain and more reports of stress related symptoms for females than males. Mallinckrodt and Leong (1992) emphasize that future research should focus on identifying the sources and types of social support which would address the needs of graduate students most effectively, adding that such a focus should consider the unique needs of male and female graduate students. 
An additional study of the relationship between social support and graduate student stress was conducted by Hodgson and Simoni (1995). This study assessed the influence of social support on the psychological distress reported by 566 doctoral students enrolled in humanities, social sciences, life sciences, and physical science programs. Participants were asked to answer questions regarding their financial and employment status, and to complete the Graduate Life Events Scale, the Graduate Student Stress Survey, and the Graduate Social Support Scale, a measure of functional social support. Results suggested that student perceived academic success and social support were negatively related to psychological distress (i.e., depression, anxiety, and suicidality), while financial problems were positively related to physiological distress. With regard to demographic variables, the results suggested a significant positive relationship between age and psychological distress, such that older students reported greater suicidality than younger students. Similar to the findings of Mallinckrodt and Leong (1992), the researchers suggest that female students report more psychological stress during graduate school than do males. No relationship between field of study and psychological distress, including reports of depression, anxiety, and suicidality, was observed to be significant. Differences between the fields of study were observed, on the other hand, with regard to graduate social support, financial support, financial problems, and perceived academic functioning. Life Sciences students reported the highest levels of social support followed by Humanities and Physical Sciences students. Financial difficulties were most frequently reported by Social Sciences and Humanities students. It appears, therefore, that some graduate students, including graduate students in psychology, experience physical and emotional distress during graduate school (Goplerud, 1980; Hodgson \& Simoni, 1995; Mallingcrodt \& Leong, 1992). It also appears that these students experience physical and emotional benefits, such as decreased stress levels and negative physical and emotional symptoms, when they perceive that they are receiving adequate social support (Goplerud, 1980; Hodgson \& Simoni, 1995; Mallinckrodt \& Leong, 1992). It is suggested, 
however, that the sources and types of support perceived as beneficial may differ among students due to variations in perceived stressors reported by students, and individual characteristics such as gender (Hodgson \& Simoni, 1995; Mallinckrodt \& Leong, 1992) and age (Hodgson \& Simoni, 1995). As a result, it appears that more specific evaluation of specific stressors, demographic characteristics, and social support is necessary with regard to the graduate student population.

\section{Social Support and Burnout}

A number of studies have assessed the influence of social support on the development of burnout symptoms. Of particular relevance to the current study are studies of school psychologists (Huebner, 1994), clinical psychology and nursing staff (Corrigan et al., 1995), undergraduate students (Nowack et al., 1985), and doctoral students in psychology (Kahill, 1986). These studies generally suggest a negative relationship between social support and burnout. However, determination of which characteristics (i.e., quantity of social support, satisfaction with social support, source of social support) most significantly influence burnout has been difficult to ascertain due to inconsistent measurement and conceptualization of burnout and social support, as well as variations in populations being assessed across studies. As a result, the following four studies serve as examples of research assessing populations closely related to the population being assessed in the current study, which have addressed the social supportburnout relationship. These studies will additionally highlight the inconsistencies associated with the assessment and conceptualization of burnout and social support observed within the social support-burnout literature.

A study of 114 school psychologists was conducted by Huebner (1994) to determine the influence of specific sources of social support (i.e., supervisor, co-worker, spouse, and friend support) and demographic variables (i.e., age, gender, and highest educational level) on the development of burnout. The MBI was used to measure burnout. The Perceived Social Support 
Scale (PSSS), a measure similar to the Sources of Support Scale (SSS) developed by House (1981), was used to measure social support. Results suggested that of the sources of support evaluated, the Emotional Exhaustion (EE) subscale of the MBI was most strongly correlated with friend support, suggesting that it is the support obtained from friends which respondents find most helpful when feeling emotionally depleted from their work. The Depersonalization (DP) and Personal Accomplishment (PA) subscales of the MBI were most highly correlated with supervisory support, suggesting that respondents benefit most from supervisory support when they experience a sense of detachment from their care recipients and feelings of decreased effectiveness associated with their work. Age was the demographic variable most strongly correlated with the DP and EE subscales, such that younger respondents were more likely to report feelings of emotional depletion and detachment from their care recipients than older respondents. No additional specific demographic information addressing gender and educational variables was presented by the authors. Relative to all demographic variables and sources of support, however, the authors reported that the total social support score was most strongly related to each of the three MBI subscales. These results imply that it is the quantity of perceived social support which is most influential in addressing emotional exhaustion, feelings of detachment from clients, and perceptions of ineffectiveness at work (Huebner, 1994).

In a related study conducted by Corrigan et al. (1995), clinical psychology staff and nursing staff members $(n=47)$ from an inpatient psychiatric hospital were asked to complete a variety of inventories (i.e., MBI, STAI, SSQ, and a demographic questionnaire) to determine the relationship between burnout, quantity of and satisfaction with collegial support, and a number of additional variables such as anxiety and illness. The authors anticipated that the EE and DP subscales of the MBI would be highly correlated. As a result, for the purposes of this study, respondent scores on the $\mathrm{EE}$ and the $\mathrm{DP}$ subscales of the $\mathrm{MBI}$ were combined to simplify data analysis (Corrigan et al., 1995). Results suggested that nurses were similar to psychology staff 
members on measures of burnout, especially with regard to EE and DP. Evaluation of the relationship between demographic variables and MBI subscales suggested a number of trends. Although no significant gender differences were observed on EE+DP measures of burnout, females reported a greater sense of accomplishment associated with work, as measured by the PA scale of the MBI, than did males. PA was also positively related to educational level for the sample. While no differences with regard to PA were observed among minority groups, minority groups reported significantly higher EE+DP than did individuals from non-minority groups. EE+DP showed a moderate negative correlation with age and years working in the mental health field. These results suggest that younger, less experienced individuals, and individuals from minority groups are most likely to feel emotionally drained from their work and emotionally detached from their patients. Educated individuals and females are most likely to feel that they are effectively doing their work. Additional data analysis suggested that EE+DP was significantly correlated with STAI Trait Anxiety scores, reports of illness frequency, and satisfaction with one's support network, such that increased emotional exhaustion and emotional depletion corresponded to higher trait anxiety scores, more frequent illness, and less satisfaction with the social support network. In contrast to the results of Huebner (1984), size of support network was significantly related to no subscale scores of the MBI. Results observed by Corrigan et al. (1995) suggest, therefore, that it is satisfaction with social interactions, rather than the quantity of social interactions, which has a beneficial impact on physical health, psychological health, and burnout.

A related study conducted by Nowack et al. (1985) assessed the influence of social support and health related coping on burnout, psychological distress, and job performance among a sample of undergraduate resident assistants. The MBI was used to measure burnout while the Social Support Questionnaire was used to measure the quantity of, and satisfaction with, social support. Similar to the results suggested by Corrigan et al. (1995), quantity of social support was 
not significantly related to either the EE or DP subscales of the MBI. However, unlike the results of the Corrigan et al. (1995) study, quantity of social support was significantly related to the PA subscale of the MBI (Nowack et al., 1985). Satisfaction with the social support network, on the other hand, was significantly related only to the DP and PA subscales of the MBI for the sample of resident assistants. Additional results of this study suggested that each of the MBI subscales was significantly related to psychological distress, such that psychological distress increased as feelings of emotional depletion and detachment associated with work increased, and as feelings that one's work is worthwhile decreased. In general, results of this study suggest that perceptions of detachment from clients are most effectively influenced by a social support network that is satisfying, regardless of size. Perceptions of a lack of achievement at work were positively influenced by a large social network, and also by a satisfying social support system. Feelings associated with emotional depletion do not appear to be positively influenced by the quantity of, or satisfaction with, one's social network (Nowack et al., 1985).

Finally, in the only published study of burnout and social support associated with doctoral students in psychology, Kahill (1986) assessed the influence of family support, friend support, and professional expectations on burnout symptoms. Additional subjects in this study included "new" practitioners and "experienced" practitioners. Burnout was measured using the Tedium Burnout Measure, a measure of physical, emotional and mental exhaustion.

Descriptions of emotional and physical exhaustion described by the author appear to correspond with the Emotional Exhaustion subscale of the MBI. Mental exhaustion described by Kahill (1986) appears to combine the characteristics of the Depersonalization and Personal Accomplishment subscales of the MBI. In the study by Kahill (1986), social support was measured using the Social Relations Scale, a quantitative measure of perceived support from friends and family. Results of the study suggested that the overall burnout level of the sample fell in the low-moderate range. Results further suggested that doctoral students experienced 
greater disillusionment regarding the profession of psychology than did new and experienced practitioners, however, these groups did not differ significantly in terms of burnout, total social support, friend or family social support, or professional expectations. For each group, burnout was negatively related to social support from friends and family, disillusionment, and optimistic expectations related to work. Based on the results of this study, it appears, that doctoral students in psychology are similar to more experienced professionals with regard to reports of burnout and social support. However, doctoral students appear to have less positive thoughts about the profession of psychology than do more experienced professionals.

$\underline{\text { Stress, Social Support, and Burnout Among Human Service Workers }}$

A significant amount of research associated with evaluation of the relationships between stress, social support, and burnout has been published in the literature. A large portion of this research has focused on evaluation of the aforementioned variables within human service settings. Subjects in these studies have frequently included nurses or nursing staff members (Constable \& Russell, 1986; Ray \& Miller, 1994; Northrup, 1996), social workers (Himle et al., 1989b; Himle et al., 1991), and other human service workers (Etzion, 1984; Shinn et al., 1984) including counselors (Jupp \& Shaul, 1991; Ross et al., 1989). Five studies addressing the stresssocial support-burnout relationship within the human services setting will be discussed in greater detail, and serve as examples of the type of research which has been conducted in this area (Etzion, 1984; Northrup, 1996; Ray \& Miller, 1994; Ross et al., 1989; Shinn et al., 1984). Each of these studies has provided guidance related to the conceptualization of the current study, and the contribution of each of the studies to the current investigation will additionally be highlighted.

In the study conducted by Shinn et al. (1984), job stress, burnout, and coping strategies among a sample of 141 human service workers including psychologists, social workers, psychiatrists, pastoral counselors, and nurses were evaluated. A number of stressors were 
identified by respondents as particularly common in their work setting. The most common stressors, described by $47 \%$ of respondents, included those related to job design (i.e., excessive workload, role conflict). Stress associated within the agency structure itself was reported by $44 \%$ of respondents. Stress related to perceptions of therapeutic competency and expectations (34\%), relationships with coworkers (19\%), and emotional demands of therapeutic work with clients $(23 \%)$ were also endorsed by respondents. With regard to report of stress among men and women, gender differences were reported by the researchers such that female respondents reported greater stress associated with characteristics of their job design and professional helping role, and more frequently reported physical concerns than did male respondents. Notably, female respondents also reported greater levels of social support than did male respondents. Analyses of the relationships between stress and strain suggested that psychological strain (burnout) could be predicted from stress related to job alienation, job satisfaction, and psychological symptoms. Stress related to somatic symptoms was the only stress related component which did not predict psychological strain. Based on the results of this study, the authors concluded that "patterns of stress and strain may differ markedly among human service workers and workers in different settings, just as they do among different occupations in general" (p. 870).

Similar to the focus of the study by Shinn et al. (1984), an emphasis on the evaluation of specific work related stressors, and their contribution to the development of burnout symptoms, was maintained in the current investigation. For the purposes of the current study it appeared to be particularly necessary to evaluate the specific characteristics of the 'work' setting experienced by doctoral students in psychology. Specific stressors associated with the graduate school experience were assessed using the Modified Psychology Student Stress Questionnaire.

Evaluation of the moderating role of social support in the stress-burnout relationship was emphasized in the study by Etzion (1984). In this study, the relationship between stress and 
burnout among Israeli managers and human service professionals, as well as the influence of both life and work social support on reports of burnout, were assessed. Results suggested that across genders experienced stress, regardless of environmental source, was positively associated with burnout, while perceptions of social support, again regardless of environmental source, were negatively related to reported burnout symptoms. These results support the direct influence of stress on burnout, and the direct effect of social support on burnout, respectively. However, evaluation of the manner in which social support influenced the stress-burnout relationship suggested that the moderating or buffering effect of social support is different when assessing life stress and work stress, and is additionally influenced by gender. For example, social support did not moderate the influence of life stress on the development of burnout symptoms among men or women in the sample. However, the work stress-burnout relationship was moderated by supportive interactions cultivated within the work environment (i.e., supervisor, coworkers) among men, and by life sources of support (i.e., family, friends) among women. The authors noted that generalizations from their results should be made with caution due to their use of a ethnically homogeneous sample. Similar to the study conducted by Etzion (1984), the current investigation emphasized evaluation of the moderating role of social support on the stressburnout relationship.

Guidance associated with the measurement of stress, social support, and burnout was obtained for the current study through evaluation of the research of Northrup (1996). In this study of nursing home staff members, the relationships between stress, social support and burnout were assessed. Burnout was measured using the MBI. Stress was measured using two separate measures. One measure, the Daily Stress Inventory (DSI), measures stress experienced within the past 24 hours (Brantley \& Jones, 1989). The second stress measure utilized in this study, the Nursing Home Stress Inventory (NHSI), measures stress perceived specifically by nursing home staff members. Social support was measured using two separate instruments. The 
Social Provisions Scale (SPS) was utilized to assess 6 specific functions of social support (i.e., guidance, reassurance of worth, social integration, attachment, nurturance, and reliable alliance). The second measure of social support utilized in this study, the Sources of Support (SOS), was developed by Northrup (1996). The SOS is a modification of the SSS developed by House (1981), and assesses support from supervisor, coworker, spouse/significant other, and family/friends. Results of the study suggested a positive relationship between stress and burnout. More specifically, the EE subscale of the MBI was significantly related to stress intensity scores obtained from both measures of stress, such that increased feelings of emotional fatigue were associated with higher scores on the DSI and NHSI. The DP subscale of the MBI was significantly related only to the DSI intensity score. The MBI PA subscale was significantly related to neither the DSI nor the NHSI total impact scores. In addition, results of this study suggest a negative relationship between social support and burnout. Significant correlations between each source of support and each subscale of the MBI were reported, although supervisor support was most strongly correlated with the MBI subscales. Northrup (1996) suggested that modification of the SOS, to include an equal number of questions per SOS subscale, may have accounted for the significant impact of all SOS subscales on each of the MBI subscales. Details of the modification of the SOS can be found in Chapter 3 of this document. In addition, Northrup (1996) reported that each subscale of the SPS was significantly correlated with each subscale of the MBI, further supporting the impact of social support on burnout. While evaluation of the effect of social support on the stress-burnout relationship provided most significant support for the direct influence of social support on the stress-burnout relationship, supervisor support did moderate the influence of NHSI stress on the PA subscale of the MBI, evidence which supports the buffering influence of social support on the stress-burnout relationship. Evaluation of the relationship between demographic variables and burnout was also conducted by Northrup (1996). Results of this evaluation suggested that age was the most 
significant predictor of the EE and DP subscales of the MBI, such that younger respondents were more likely to express feelings of emotional fatigue and emotional detachment from clients, than were older respondents.

The influence of the Northrup (1996) study on the current investigation was most significant with regard to measurement issues. With the exception of the SPS and the DSI utilized by Northrup (1996), each of the measures utilized in the current study corresponded to measures utilized by Northrup (1996). The MBI was utilized in both studies. The measure of psychology student stress utilized in the current study corresponded to the NHSI utilized by Northrup (1996). And finally, the SOS utilized by Northrup (1996) was modified by the current researcher to more effectively address the specific characteristics of doctoral students in psychology.

In the study conducted by Ross et al. (1989), the influence of job stress and social support on burnout was assessed among 169 doctoral level counseling center staff members. The MBI was utilized to assess burnout levels. Job related stress was measured using an instrument specifically developed to address stressors encountered by counseling center staff members. Social support was measured using the Social Provision Scale (SPS) and an unnamed measure of social support which assessed support from supervisors, coworkers, spouse, and friends/relatives. Results suggested a direct and significant relationship between number of stressful job events and burnout, specifically with regard to the EE and PA subscales of the MBI. Results further suggested significant direct effects of supervisor support on the DP and PA subscales of the MBI. No other sources of support significantly and directly influenced burnout, and no sources of social support served to buffer the influence of stress on burnout for respondents. Results also suggested that Emotional Exhaustion (EE) was predicted by years of counselor experience, supervision responsibilities, and marital status, such that inexperienced counselors, counselors who supervised others, and counselors who were married reported more feelings of emotional 
fatigue than other counselors. Depersonalization (DP) was predicted by client contact hours and minority status, such that non-minority status and working frequently in direct contact with clients was associated with increased emotional detachment from clients. No counselor or setting characteristics predicted PA. Several social provisions assessed by the SPS were significantly related to burnout, such that social integration was a significant predictor of EE and DP, and reassurance of worth and guidance were significant predictors of PA. Although no studies of the stress-social support-burnout relationship have utilized doctoral students in psychology as subjects, the sample utilized by Ross et al. (1989) is somewhat similar to doctoral students in psychology, and can, therefore, provide some guidance regarding potential predictors of burnout, and the influence of social support on the stress-burnout relationship, which may be relevant to the current investigation.

Finally, evaluation of the study by Ray and Miller (1994) guides the development of research questions to be utilized in the current investigation. In this study, 119 charge nurses and nursing assistants were subjects in the assessment of the relationship between home/work stress, social support, and burnout (Ray \& Miller, 1994). Measures utilized included a demographic questionnaire, a five item home/work stress questionnaire developed by the researchers, a measure of perceptions of support obtained from supervisors, coworkers, family members and administrators, and the MBI. This study addressed two specific research questions. The first question addressed by Ray and Miller (1994) was: "What demographic factors affect perceptions of home/work stress?" (p. 362). Results of ANOVA and correlational procedures suggested that no demographic variables associated with work characteristics (i.e., work shift, part time/full time status) were significantly related to perceptions of work/home stress. Two home life demographic variables (i.e., number of children, marital status) were significantly related to reports of home/work stress. Specifically, individuals who had children reported more home/work stress than individuals without children, and single, cohabitating individuals 
perceived more home/work stress than married, single, and divorced individuals.

The second issue addressed by Ray and Miller (1994) involved evaluation of the "differential impact of various sources of support and the specific way in which support can help individuals deal with stress and burnout" (p. 362). As a result, the second research question, which specifically addressed the direct and buffering effects of social support, was "Are different sources of support differentially effective in reducing home/work stress, reducing burnout, or buffering the stress/burnout relationship for home/work stress?” (p. 362). The direct relationship between stress and burnout, and the direct relationships between each source of social support and each subscale of the MBI were listed by the authors. Interaction effects observed among the aforementioned variables were also reported. For the Emotional Exhaustion (EE) subscale, a significant direct effect of stress on burnout was observed, suggesting that increased perceptions of work/home stress were associated with increased feelings of emotional fatigue. A significant direct effect was observed with regard to the relationship between both supervisor and family support and EE. Notably, however, family support was related to EE in a positive manner, suggesting that emotional fatigue increased as support from family members increased. One interaction effect was observed between home/work stress, coworker support, and the EE subscale. Similar to the aforementioned finding related to family support, the observed interaction effect was unexpected as it suggested that coworker support was most positively related to emotional fatigue at high levels of stress. The authors suggested that, "Coupled with our finding that family support had a direct effect on emotional exhaustion, this interaction term suggests that social support may not always decrease burnout among human service workers “ (p. 367), at least with regard to the EE subscale of the MBI. For the DP subscale of the MBI, direct effects were observed for both home/work stress on DP and supervisor support on DP. These findings suggest that reports of higher stress levels were related to increased feelings of detachment from care recipients. Additionally, increased perceptions of support, specifically 
obtained from supervisors, were related to decreased feelings of detachment from clients. No interaction effects were observed among home/work stress, sources of support, and the DP subscale. With regard to the Personal Accomplishment subscale of the MBI, a direct relationship between home/work stress and burnout was not observed. One direct effect between support and the PA subscale of the MBI was reported, such that increased support from administrators was related to a greater sense of accomplishment relative to work tasks. No interaction effects between home/work stress and social support were observed with regard to the PA subscale.

Research questions described by Ray and Miller (1994), which evaluated the direct and buffering effects of specific sources of social support on MBI subscales, were influential in the development of research questions associated with the current study. In particular, research questions which evaluated the direct and buffering effects of social support obtained from clinical supervisors, faculty advisors, classmates, spouse/significant others, friends, and relatives on the stress-burnout relationship were emphasized in the current study.

\section{Conclusions}

Evaluation of the stress-social support-burnout relationship has been described frequently in the human services literature (Etzion, 1984; Northrup, 1996; Ray \& Miller, 1994; Ross et al., 1989; Shinn et al., 1984). Results of these studies generally suggest a positive relationship between stress and burnout, and a negative relationship between social support and burnout. Additional conclusions associated with the predictors of burnout, types and sources of support most beneficial to burned out individuals, and the method through which social support influences the stress-burnout relationship (i.e., through direct or buffering effects) are difficult to determine due to inconsistent measurement and conceptualization of the constructs, variations in settings where the research has been conducted, and variations in findings across studies.

In addition to the aforementioned difficulties associated with stress-social supportburnout research, no research has been published which addresses the stress-social support- 
burnout relationship specifically among doctoral students in psychology. As a result, there was no specific previous research on which to build the foundation of the current study.

As a result, five studies of the stress-social support-burnout relationship guided the current research. These studies addressed critical aspects of stress, social support, and burnout, which were highlighted in this review of literature. The current study's emphasis on evaluation of specific work stressors associated with the development of burnout was supported by Shinn et al. (1984). Emphasis in the current study on the evaluation of the moderating role of social support in the stress-burnout relationship was supported by Etzion (1984). Utilization of measures which assess stressors specific to the population being assessed, as well as measures of specific sources of support likely to ameliorate the negative influence of the stressors, was supported by Northrup (1996). Evaluation of doctoral students in psychology, a specific population within the human services field which may be likely to experience burnout, was supported by Ross et al. (1989). And finally, emphasis on research questions which address demographic characteristics associated with the prediction of burnout, as well as assessment of the direct and buffering effects of social support on the stress-burnout relationship, were supported by Ray and Miller (1994). Based on the aforementioned literature focused support of the current study, it appears that evaluation of the relationships between burnout, stress, and social support among doctoral students in psychology was an appropriate topic to explore. 


\section{Chapter III}

Methodology

\section{$\underline{\text { Participants and Procedures }}$}

Participants were Student Affiliate Members of the American Psychological Association (APA). Participants were randomly chosen by APA staff members from the list of all Student Affiliate Members. Equal representation of Student Affiliate Members from the fields of Clinical Psychology, Counseling Psychology, and School Psychology were requested. Mailing labels were provided by APA staff members for those individuals chosen through the random selection process. Human participation in this study was approved using West Virginia University Internal Review Board procedures.

Participants in this study were mailed a packet of questionnaires. Included in the packet of materials was a cover letter explaining the purpose of the study (see Appendix A). In addition, all subjects were sent the Demographic Questionnaire for Doctoral Students in Psychology (DQDSP) and the following three questionnaires: 1) Maslach Burnout Inventory Human Services Survey (MBI), 2) The Modified Psychology Student Stress Questionnaire (MPSSQ), and the 3) Modified Sources of Support Questionnaire (MSOSQ). The DQDSP was always placed on top of the three questionnaires included in this study. The order of the remaining questionnaires was randomly organized to minimize the influence of presentation order on participant responses. Participants were provided with a self-addressed, stamped envelope with which to return the completed inventories to the researcher. It was anticipated that it would take participants approximately 20 minutes to complete the packet of questionnaires.

Four hundred participants were contacted in the initial mailing. It was anticipated that $50 \%$ of the packets would be returned by the participants (Weathers, Jurlong, \& Solorzono, 1993), although a similar study of student members of the America Association for Marriage and Family Therapy obtained only a 37\% return rate when 900 students were surveyed via mail 
(Polson \& Nida, 1998). Follow-up letters were sent to participants who failed to return their materials two weeks after the initial mailing (see Appendix B).

Identifying information was not elicited from respondents at any time during this study. However, survey materials were numbered in order to permit the researcher to mail "reminder letters" to subjects who failed to return their questionnaires to the researcher within two weeks of the initial mailing of the questionnaires. All materials were identified by numbers placed in the bottom right hand corner of each survey and envelope. Subjects were informed of the use of numerical identification procedures in the cover letter which accompanied each set of surveys.

Subjects were informed in their cover letter that monetary prizes would be awarded to two randomly chosen individuals who completed their packet of materials and returned them to the researcher by a specified date. Two numerical identification numbers were chosen from the list of all numerical identification numbers returned to the researcher which included a complete set of usable questionnaires. The two individuals matched to those identification numbers were sent checks by this researcher in the amount of $\$ 35.00$, the amount necessary for American Psychological Association Student Affiliate Members to renew their annual membership in APA. Instruments

Demographic Questionnaire of Doctoral Students in Psychology (DQDSP). The DQDSP is a self-report questionnaire developed by the current investigator (see Appendix C). The DQDSP assesses demographic information and addresses the following categories: age, gender, race, marital status, and number of children currently residing in the student's household. The DQDSP also asks respondents to answer a number of questions about their experience in their current graduate program. These questions include: type of graduate program, year in current graduate program, number of years anticipated to complete program requirements, expected degree following program completion, years spent providing clinical services to individuals prior to enrollment in current doctoral program, number of credit hours currently being taken, and the 
number of hours per week spent in class, traveling to class, performing practicum related activities, in direct contact with clients, doing dissertation research, doing research unrelated to the dissertation, performing assistantship duties, completing class related tasks, in formal supervision, and meeting with professors or faculty members. In addition, the DQDSP asks respondents if they receive tuition waivers and school related stipends, if they take oral and/or written comprehensive exams, if they work in addition to their school related commitments, and how many hours per week they work outside of school. The final question on the DQDSP asks participants to describe their overall satisfaction with their current doctoral program using a 7 point Likert Scale. Responses on the scale range from a score of 1 ("very satisfied") to 7 ("very unsatisfied").

Maslach Burnout Inventory - Human Services Survey (MBI) (Maslach et al., 1996). The third edition of this 22 item questionnaire assesses the frequency of burnout symptoms associated with the following three subscales: 1) Emotional Exhaustion, 2) Depersonalization, and 3) Personal Accomplishment. Subjects are asked to indicate the frequency in which they experience the feeling or attitude described in each item of the MBI using a 7-point Likert Scale. The frequency scale responses range from 0 ("never") to 6 (“every day") (Maslach et al., 1996). Subjects are no longer asked to indicate the intensity they associate with the feeling or attitude described in each item of the MBI, as they were asked to do in an earlier edition of the measure. According to Maslach et al. (1996), only the frequency dimension of the MBI is currently utilized because: “(a) The frequency format is least similar to the typical format used in other self-report measures of attitudes and feelings; therefore, spurious correlations with other measures, due to similarities of response formats, should be minimized. (b) The seven points on the frequency dimension are all explicitly anchored for the respondent, creating a more standardized response scale; therefore, the researcher can be fairly certain about the meanings assumed by respondents for each scale value" (p. 11). 
The Emotional Exhaustion subscale (EE) of the MBI includes nine items and is associated with feelings of emotional fatigue and depletion as a result of one's work. The Depersonalization subscale (DP) consists of five items and is related to feelings of detachment and negativity toward individuals who receive one's care. The third subscale of the MBI, Personal Accomplishment (PA), includes eight items which address the caregiver's feelings of "competence and successful achievement" associated with their work (Maslach et al., 1996, p. 10). Scoring procedures associated with the EE, DP, and PA subscales of the MBI can be viewed in Appendices D, E, and F, respectively. Low, moderate, and high classification ranges for each subscale of the MBI, using a sample of 730 mental health professionals, can be viewed in Appendix G.

Cronbach's alpha coefficients for the subscales were reported to be .90 for EE, .79 for DP, and .71 for PA, suggesting that the MBI generally possesses satisfactory internal consistency (Maslach et al., 1996). However, it should be noted that the report of these alpha coefficients did not specify whether they were associated with the MBI frequency dimension only, the MBI intensity dimension only, or a combination of the frequency and intensity dimensions of the MBI subscales. The MBI's internal consistency was more specifically supported by research using a sample of 72 upper division undergraduates and graduate students. Cronbach's alpha coefficient for the frequency dimensions of the MBI were determined to be .86 for EE, .63 for DP, and .72 for PA (Powers \& Gose, 1986). Alpha coefficients for MBI subscales observed in the current study are reported in Chapter Four. Test-retest reliability was reported by Maslach et al. (1996) for five samples. One sample of social welfare graduate students and health agency administrators $(n=53)$ reported test-retest reliability coefficients of .82 for EE, .60 for DP and .80 for PA using a two to four week testing interval. Test-retest reliability for the remaining samples reported by Maslach et al. (1996) ranged from .59 to .75 for EE, .50 to .72 for DP, and .57 to .65 for PA. Test-retest intervals ranged from three months to one year for the 
aforementioned studies.

Due to the fact that doctoral students in psychology typically combine a variety of responsibilities in their role as doctoral students (i.e., student, clinician, researcher), one modification was made to the MBI for the purpose of this study. This modification involved placing a piece of paper with the following statement on top of the MBI, in an effort to clarify the perspective students should take when answering the MBI questions: "For the purpose of this study, consider your combined student responsibilities (i.e., going to classes, studying for exams, clinical duties, research commitments, assistantship responsibilities, etc.) as your "work" or "job", and answer the following questions accordingly. Additionally, answer specific questions which refer to "recipients" of care in terms of your clinical interactions with clients." A copy of the aforementioned statement can be found in Appendix $\mathrm{H}$.

The Modified Psychology Student Stress Questionnaire (MPSSQ). The 30 item MPSSQ was developed by the current researcher, and is a modified version of the Psychology Student Stress Questionnaire (PSSQ) developed by Cahir and Morris (1991). Similar to the 30 item PSSQ, the MPSSQ assesses both the prevalence and magnitude of stressors experienced specifically during the past year in graduate training in psychology, emphasizing academic, emotional, and financial stressors (see Appendix I). Like the PSSQ, each of the items on the MPSSQ lists a specific stressor. However, no longer are respondents asked to respond to each item by choosing "yes" or "no" to indicate whether or not they had experienced the specific stressor, as they were asked to do so on the PSSQ. Rather, on the MPSSQ students are asked only to respond to items to which they have experienced the stressor described. Then, similar to the procedures utilized with the PSSQ, respondents are asked to rate the magnitude of the stressor experienced using a Likert scale.

Several modifications related to the Likert Scale utilized with the PSSQ were made in the development of the MPSSQ. One change involves the range of scores associated with the Likert 
Scale. The PSSQ included a rating of 0 which corresponded to "none" on the stress rating, while respondents assessed using the MPSSQ are asked simply not to rate any item of the MPSSQ not perceived as stressful for the individual. In addition, the MPSSQ extended the range of the Likert Scale. The original PSSQ's scale scores ranged from 0 to 5 while the MPSSQ's scale scores range from 1 to 7 . The final change to the Likert Scale involved revisions of the words utilized to describe potential responses. PSSQ Likert ratings of 1 or 2 suggested "low" stress while a Likert rating of 5 suggested "high" stress. Modifications of the MPSSQ resulted in responses ranging from 1 which suggested that the event "occurred but was not stressful" to 7 which suggests that the item "caused me to panic." The aforementioned Likert Scale changes were made in an effort to make response options more clear to respondents, and to enable respondents to report their experienced stress more accurately.

A number of structural changes were also made to the PSSQ in the development of the MPSSQ. First, the 30 questions of the PSSQ were condensed from a four page measure to a one page measure. Second, one question ("How stressful was a 'hold' on your registration for you?") which was included in the PSSQ, was eliminated on the MPSSQ. The question was eliminated because an almost identical question regarding registration ("How stressful was the registration process for you?") already existed in the measure. Third, one item ("Had direct therapy contact with clients, students, etc.”) was added in the development of the MPSSQ because no items on the PSSQ had addressed the clinical experiences of psychology graduate students.

The final structural changes made to the PSSQ, in the development of the MPSSQ, involved modifying each question in some fashion. The most frequent modification involved changing the wording of the items from a question to a statement. For example, PSSQ item "Did you choose (or change) your academic advisor over the past year? If yes, how stressful was the process?" was changed on the MPSSQ to "Chose or changed an academic advisor." Other 
changes to specific questions involved simplification of PSSQ questions. For example, PSSQ item, "Did you receive a GSL, NDSL, or personal loan(s), over the past year? If yes, how stressful did you find the process of obtaining support?" was changed on the MPSSQ to, "Applied for a student loan." These structural changes to individual items of the PSSQ were made in an effort to simplify the response process for respondents by requiring responses to be made only to items experienced as stressful.

Scoring procedures associated with the PSSQ were also modified in the development of the MPSSQ for the purposes of this study. Scoring for the original PSSQ involved the calculation of a "PSSQ Stress Score" for individual subjects by adding each response provided on the Likert Scale, and dividing that number by 30, the total number of items on the PSSQ (Cahir \& Morris, 1991). For the purposes of this study a total number of events endorsed by subjects provided a 'MPSSQ Events' (MPSSQ.E) score. The sum of all intensity ratings of endorsed items composed the 'MPSSQ Intensity' (MPSSQ.I) score. An "Average Intensity of Stress" (MPSSQ.IE) score was calculated by dividing the MPSSQ.I score by the MPSSQ.E score for each respondent. Alpha coefficients are reported for MPSSQ.I, MPSSQ.E, and MPSSQ.IE in Chapter Four.

Cahir and Morris (1991) reported concurrent validity for the PSSQ, comparing mean scores obtained from 133 graduate psychology students on the PSSQ to their mean scores on the Symptom Checklist-90-R $(\underline{r}=.28, \mathrm{p}<.05)$, and to their mean scores on the Negative Life Events component of the Health and Daily Living Form, Adult Form B $(\underline{r}=.32, p<.05)$. The PSSQ also was utilized in a study of graduate student stress conducted by Hudson and O'Regan (1994), however, no additional information on the reliability and validity of the measure was provided.

The Modified Sources of Support Questionnaire (MSOSQ). The MSOSQ is a 72 item self-report inventory developed by the researcher which assesses perceived social support obtained from the following six sources: 1) clinical supervisor, 2) faculty advisor, 3) classmates, 
4) spouse/significant other, 5) friends not yet specified, and 6) relatives not yet specified (see Appendix J). Respondents are asked to rate their responses to each item using a 5 point Likert Scale. For the first 60 items of the MSOSQ, responses to the Likert Scale range from 1 ("not at all") to 5 ("completely"). Responses to the final 12 items of the MQSOS range from 1 ("not at all true") to 5 ("always true").

The MSOSQ is a modified version of the Sources of Support (SOS) measure developed by Northrup (1996). The development of the MSOSQ can also be traced through another measure which assesses specific sources of social support perceived by respondents, the Sources of Support Scale (SSS) developed by House (1981). It was the SSS which provided the basis for the development of the SOS. Clearly the content of both the SSS and the SOS have contributed significantly to the MSOSQ. As a result, information associated with the contribution of each of these measures to the MSOSQ will be described.

The Development of the SOS from the SSS

The SSS has been utilized to assess the relationship between burnout, stress, and social support among nurses (Constable \& Russell, 1986), teachers (Russell et al., 1987), and counseling center staff members (Ross et al., 1989). The four subscales of the SSS, followed by the number of items included in each subscale include: 1) supervisor support (five items), 2) coworker support (three items), 3) spouse support (two items), and 4) friend/family support (two items). Although the original source could not be located by this researcher, according to Northrup (1996), Cronbach's alpha coefficients were reported by House (1981) to range from .75 to .92 for the four subscales of the SSS. These results suggest that the SSS is a reliable and internally consistent measure of perceived social support. Northrup (1996) also reported that no additional information regarding the SSS's reliability has been published and that support for the validity of the SSS has been most significant for the supervisor support subscale (Northrup, 1996). Several studies have suggested that the supervisor support subscale of the SSS can 
predict reactions to job related stress, including burnout, in samples of public school teachers and nurses, and have led some researchers to emphasize the impact of supervisory support within the work setting (Ross et al., 1989; Russell, et al., 1987). However, results of studies which utilized the SSS and which emphasize the role of supervisory support in the prediction of job related stress reactions have been questioned by Northrup (1996). She suggests that an unequal distribution of subscale items may have positively influenced the impact of the supervisory support subscale, especially in relation to the other subscales of the SSS.

As a result, Northrup (1996) added eight new items to the SSS in an effort to develop a measure which included a parallel number of items for each of the supervisor, coworker, spouse/significant other, and friend/family subscales. In addition to the eight items added by Northrup (1996) to equalize the number of items per subscale, an additional 28 items, seven items per subscale, were added to develop a more comprehensive measure of social support. As a result, the additional items, combined with the original items of the SSS compose the 48 item SOS developed by Northrup (1996). According to Northrup (1996) the modified SOS was "designed to assess social support targeted at decreasing job stress, improving job performance, or increasing coping with job stress or burnout" (Northrup, 1996, p. 26).

Evidence of the SOS's internal consistency and validity was reported by Northrup (1996) for a sample of 250 nursing home staff members. Alpha coefficients ranged from .94 to .97 for the four subscales of the SOS, suggesting that the SOS is a reliable measure of social support. Convergent validity of the SOS was supported by comparisons to subscales of the Social Provisions Scale (SPS) (Cutrona \& Russell, 1987). All four SOS total subscale scores were positively and significantly related to all six total subscale scores of the SPS.

The Development of the MSOSQ from the SOS

Although it appears that the SOS is a reliable and valid measure of perceived social support obtained from a variety of sources, several modifications to the SOS were necessary in 
order to address the specific characteristics of doctoral students in psychology most effectively. The modifications to the SOS, which ultimately resulted in the development of the MSOSQ, are described below.

The specific sources of support evaluated using the MSOSQ were modified relative to the SOS to make them more relevant to doctoral students in psychology. SOS "Supervisor" support was replaced with MSOSQ "Clinical Supervisor" support and SOS "Coworker" support was replaced with MSOSQ "Classmate" support. SOS "Friends/Relatives (who were not already included in $\mathrm{a}, \mathrm{b}$, or $\mathrm{c}$ )" support was modified on the MSOSQ to assess the support perceived from friends and relatives separately. As a result, separation into the categories of "Friends (not yet specified)" support and "Relatives (not yet specified)" support resulted in the addition of 12 items to the MSOSQ relative to the SOS. Additionally, one source of support not utilized on the SOS, "Faculty Advisor" support, was added in the development of the MSOSQ. Inclusion of the Faculty Advisor source of support also resulted in the addition of 12 items to the MSOSQ relative to the SOS.

The general content of each question of the SOS remained unchanged in the development of the MSOSQ, with two exceptions. These exceptions included changing the word "resident" to "client" in questions 6 and 10, and changing all references of "work" or "job" to "school" or "school related activities." These changes were made to make the terminology more relevant to the population assessed in the current study.

An additional modification to the SOS involves the manner in which individuals are asked to respond to specific questions on the MSOSQ. A Likert Scale format is utilized with the MSOSQ while SOS respondents are asked to circle their responses to specific questions. Additionally, the presentation of the MSOSQ was simplified in comparison to the SOS so that respondents could rate each of the six items associated with each question in a more clear and efficient manner. 
In conclusion, the MSOSQ used in this study assesses the following six sources of support: 1) clinical supervisor, 2) faculty advisor, 3) classmate, 4) spouse/significant other, 5) friends (not yet specified), and 6) relatives (not yet specified). Each of these sources of support is evaluated in each of the 12 questions of the MSOSQ. The 12 items associated with each source of support comprise the subscale for that particular source of support.

Scoring procedures for the MSOSQ mirror those utilized by Northrup (1996).

Procedures involve the determination of total subscale scores for the clinical supervisor, faculty advisor, classmate, spouse/significant other, friends (not yet specified), and relatives (not yet specified) subscales of the MSOSQ. The sum of ratings to items 1a, 2a, 3a, 4a, 5a, 6a, 7a, 8a, 9a, 10a, 11a, and 12a determine the Total Clinical Supervisor Support score. The sum of ratings to items 1b, 2b, 3b, 4b, 5b, 6b, 7b, 8b, 9b, 10b, 11b, and 12b determine the Total Faculty Advisor Support score. The sum of ratings to items 1c, 2c, 3c, 4c, 5c, 6c, 7c, 8c, 9c, 10c, 11c, and 12c determine the Classmate Support score. The sum of ratings to items $1 \mathrm{~d}, 2 \mathrm{~d}, 3 \mathrm{~d}, 4 \mathrm{~d}, 5 \mathrm{~d}, 6 \mathrm{~d}, 7 \mathrm{~d}$, 8d, 9d, 10d, 11d, and 12d determine the Total Spouse/Significant Other Support score. The sum of the ratings to items $1 \mathrm{e}, 2 \mathrm{e}, 3 \mathrm{e}, 4 \mathrm{e}, 5 \mathrm{e}, 6 \mathrm{e}, 7 \mathrm{e}, 8 \mathrm{e}, 9 \mathrm{e}, 10 \mathrm{e}, 11 \mathrm{e}$, and $12 \mathrm{e}$ determine the Total Friends (Not Yet Specified) Support score. And finally, the sum of the ratings to items 1f, 2f, 3f, 4f, 5f, 6f, 7f, 8f, 9f, 10f, 11f, and 12f determine the Total Relatives (Not Yet Specified) Support score. Alpha coefficients are reported for each subscale of the MSOSQ in Chapter Four. $\underline{\text { Statistical Analyses }}$

Descriptive data (i.e., age, gender, marital status) related to the sample is provided in Chapter Four. In addition, descriptive data related to doctoral program requirements and commitments (i.e., number of hours/week spent in class, number of hours/week spent in supervision) were determined for the sample and are additionally presented in Chapter Four.

Analysis of Variance (ANOVA) statistical procedures were utilized to assess the differences among counseling, clinical, and school psychology doctoral students with regard to 
burnout, stress and social support. These procedures address questions 1a-1c, 2, and 3a-3f, respectively, and are presented on pages 61 and 62 .

To test the direct influence of the predictor variable, stress, on the dependent variable, burnout, three separate regression analyses were conducted. Separate analyses tested the influence of stress, a continuous variable, on each of the three subscales of burnout (EE, DP, PA). These procedures addressed research questions $4 \mathrm{a}, 4 \mathrm{~b}$, and $4 \mathrm{c}$, respectively, and are presented on pages 62 and 63.

To test the direct influence of the moderating variable, social support, on the dependent variable, burnout, eighteen separate regression analyses are reported. These analyses permitted the direct effects of six types of social support to be evaluated in terms of all three subscales of the MBI (EE, DP, and PA). These procedures addressed research questions 5a through 10c, and are presented on pages 63 to 65 .

To test the moderating influence of social support on the relationship between the predictor variable, stress, and the outcome variable, burnout, a separate regression analysis was conducted for research questions 11a though 16c. Eighteen separate analyses were necessary because the moderator, social support, had six separate levels, and the outcome variable, burnout, had three levels. These questions are presented on pages 65 to 68 .

\section{$\underline{\text { Research Questions }}$}

The following research questions were addressed in this study:

1a) Are there differences in reported burnout levels, as measured by the Emotional Exhaustion (EE) subscale of the MBI, among counseling, clinical, and school psychology doctoral students?

1b) Are there differences in reported burnout levels, as measured by the Depersonalization (DP) subscale of the MBI, among counseling, clinical, and school psychology doctoral students? 1c) Are there differences in reported burnout levels, as measured by the Personal Accomplishment (PA) subscale of the MBI, among counseling, clinical, and school psychology 
doctoral students?

2) Are there differences in reported stress levels of counseling, clinical, and school psychology doctoral students as measured by the total stress events score, total stress intensity score, and average intensity of stress score on the MPSSQ?

3a) Are there differences in reported social support levels of counseling, clinical, and school psychology doctoral students as measured by the Classmate Social Support subscale of the MSOSQ?

3b) Are there differences in reported social support levels of counseling, clinical, and school psychology doctoral students as measured by the Clinical Supervisor Social Support subscale of the MSOSQ?

3c) Are there differences in reported social support levels of counseling, clinical, and school psychology doctoral students as measured by the Faculty Advisor Social Support subscale of the MSOSQ?

3d) Are there differences in reported social support levels of counseling, clinical, and school psychology doctoral students as measured by the Friends (Not Yet Specified) Social Support subscale of the MSOSQ?

3e) Are there differences in reported social support levels of counseling, clinical, and school psychology doctoral students as measured by the Relatives (Not Yet Specified) Social Support subscale of the MSOSQ?

3f) Are there differences in reported social support levels of counseling, clinical, and school psychology doctoral students as measured by the Spouse/Significant Other Social Support subscale of the MSOSQ?

4a) To what extent does stress, measured by the average intensity of stress score on the MPSSQ, directly influence burnout, as measured by the Emotional Exhaustion (EE) subscale of the MBI? 4b) To what extent does stress, measured by the average intensity of stress score on the MPSSQ, 
directly influence burnout, as measured by the Depersonalization (DP) subscale of the MBI? 4c) To what extent does stress, measured by the average intensity of stress score on the MPSSQ, directly influence burnout, as measured by the Personal Accomplishment (PA) subscale of the MBI?

5a) To what extend does classmate social support, measured by the MSOSQ Classmate Support subscale directly influence burnout, as measured by the Emotional Exhaustion (EE) subscale of the MBI?

5b) To what extend does classmate social support, measured by the MSOSQ Classmate Support subscale directly influence burnout, as measured by the Depersonalization (DP) subscale of the $\mathrm{MBI}$ ?

5c) To what extend does classmate social support, measured by the MSOSQ Classmate Support subscale directly influence burnout, as measured by the Personal Accomplishment (PA) subscale of the MBI?

6a) To what extend does clinical supervisor social support, measured by the MSOSQ Clinical Supervisor Support subscale directly influence burnout, as measured by the Emotional Exhaustion (EE) subscale of the MBI?

6b) To what extend does clinical supervisor social support, measured by the MSOSQ Clinical Supervisor Support subscale directly influence burnout, as measured by the Depersonalization (DP) subscale of the MBI?

6c) To what extend does clinical supervisor social support, measured by the MSOSQ Clinical Supervisor Support subscale directly influence burnout, as measured by the Personal Accomplishment (PA) subscale of the MBI?

7a) To what extend does faculty advisor social support, measured by the MSOSQ Faculty Advisor Support subscale directly influence burnout, as measured by the Emotional Exhaustion (EE) subscale of the MBI? 
7b) To what extend does faculty advisor social support, measured by the MSOSQ Faculty Advisor Support subscale directly influence burnout, as measured by the Depersonalization (DP) subscale of the MBI?

7c) To what extend does faculty advisor social support, measured by the MSOSQ Faculty advisor Support subscale directly influence burnout, as measured by the Personal Accomplishment (PA) subscale of the MBI?

8a) To what extend does friends (not yet specified) social support, measured by the MSOSQ Friends (Not Yet Specified) Support subscale directly influence burnout, as measured by the Emotional Exhaustion (EE) subscale of the MBI?

8b) To what extend does friends (not yet specified) social support, measured by the MSOSQ Friends (Not Yet Specified) Support subscale directly influence burnout, as measured by the Depersonalization (DP) subscale of the MBI?

8c) To what extend does friends (not yet specified) social support, measured by the MSOSQ Friends (Not Yet Specified) Support subscale directly influence burnout, as measured by the Personal Accomplishment (PA) subscale of the MBI?

9a) To what extend does relatives (not yet specified) social support, measured by the MSOSQ Relatives (Not Yet Specified) Support subscale directly influence burnout, as measured by the Emotional Exhaustion (EE) subscale of the MBI?

9b) To what extend does relatives (not yet specified) social support, measured by the MSOSQ Relatives (Not Yet Specified) Support subscale directly influence burnout, as measured by the Depersonalization (DP) subscale of the MBI?

9c) To what extend does relatives (not yet specified) social support, measured by the MSOSQ Relatives (Not Yet Specified) Support subscale directly influence burnout, as measured by the Personal Accomplishment (PA) subscale of the MBI?

10a) To what extend does spouse/significant other social support, measured by the MSOSQ 
Spouse/Significant Other Support subscale directly influence burnout, as measured by the Emotional Exhaustion (EE) subscale of the MBI?

10b) To what extend does spouse/significant other social support, measured by the MSOSQ Spouse/Significant Other Support subscale directly influence burnout, as measured by the Depersonalization (DP) subscale of the MBI?

10c) To what extend does spouse/significant other social support, measured by the MSOSQ Spouse/Significant Other Support subscale directly influence burnout, as measured by the Personal Accomplishment (PA) subscale of the MBI?

11a) To what extent does classmate social support, measured by the MSOSQ Classmate Support subscale, moderate the relationship between stress, as measured by the average intensity of stress score on the MPSSQ, and burnout as measured by the Emotional Exhaustion (EE) subscale of the MBI?

11b) To what extent does classmate social support, measured by the MSOSQ Classmate Support subscale, moderate the relationship between stress, as measured by the average intensity of stress score on the MPSSQ, and burnout as measured by the Depersonalization (DP) subscale of the MBI?

11c) To what extent does classmate social support, measured by the MSOSQ Classmate Support subscale, moderate the relationship between stress, as measured by the average intensity of stress score on the MPSSQ, and burnout as measured by the Personal Accomplishment (PA) subscale of the MBI?

12a) To what extent does clinical supervisor social support, measured by the MSOSQ Clinical Supervisor Support subscale, moderate the relationship between stress, as measured by the average intensity of stress score on the MPSSQ, and burnout as measured by the Emotional Exhaustion (EE) subscale of the MBI?

12b) To what extent does clinical supervisor social support, measured by the MSOSQ Clinical 
Supervisor Support subscale, moderate the relationship between stress, as measured by the average intensity of stress score on the MPSSQ, and burnout as measured by the Depersonalization (DP) subscale of the MBI?

12c) To what extent does clinical supervisor social support, measured by the MSOSQ Clinical Supervisor Support subscale, moderate the relationship between stress, as measured by the average intensity of stress score on the MPSSQ, and burnout as measured by the Personal Accomplishment (PA) subscale of the MBI?

13a) To what extent does faculty advisor social support, measured by the MSOSQ Faculty Advisor Support subscale, moderate the relationship between stress, as measured by the average intensity of stress score on the MPSSQ, and burnout as measured by the Emotional Exhaustion (EE) subscale of the MBI?

13b) To what extent does faculty advisor social support, measured by the MSOSQ Faculty Advisor Support subscale, moderate the relationship between stress, as measured by the average intensity of stress score on the MPSSQ, and burnout as measured by the Depersonalization (DP) subscale of the MBI?

13c) To what extent does faculty advisor social support, measured by the MSOSQ Faculty advisor Support subscale, moderate the relationship between stress, as measured by the average intensity of stress score on the MPSSQ, and burnout as measured by the Personal Accomplishment (PA) subscale of the MBI?

14a) To what extent does friends (not yet specified) social support, measured by the MSOSQ Friends (Not Yet Specified) Support subscale, moderate the relationship between stress, as measured by the average intensity of stress score on the MPSSQ, and burnout as measured by the Emotional Exhaustion (EE) subscale of the MBI?

14b) To what extent does friends (not yet specified) social support, measured by the MSOSQ Friends (NotYet Specified) Support subscale, moderate the relationship between stress, as 
measured by the average intensity of stress score on the MPSSQ, and burnout as measured by the Depersonalization (DP) subscale of the MBI?

14c) To what extent does friends (not yet specified) social support, measured by the MSOSQ Friends (Not Yet Specified) Support subscale, moderate the relationship between stress, as measured by the average intensity of stress score on the MPSSQ, and burnout as measured by the Personal Accomplishment (PA) subscale of the MBI?

15a) To what extent does relatives (not yet specified) social support, measured by the MSOSQ Relatives (Not Yet Specified) Support subscale, moderate the relationship between stress, as measured by the average intensity of stress score on the MPSSQ, and burnout as measured by the Emotional Exhaustion (EE) subscale of the MBI?

15b) To what extent does relatives (not yet specified) social support, measured by the MSOSQ Relatives (NotYet Specified) Support subscale, moderate the relationship between stress, as measured by the average intensity of stress score on the MPSSQ, and burnout as measured by the Depersonalization (DP) subscale of the MBI?

15c) To what extent does relatives (not yet specified) social support, measured by the MSOSQ Relatives (Not Yet Specified) Support subscale, moderate the relationship between stress, as measured by the average intensity of stress score on the MPSSQ, and burnout as measured by the Personal Accomplishment (PA) subscale of the MBI?

16a) To what extent does spouse/significant other social support, measured by the MSOSQ Spouse/Significant Other Support subscale, moderate the relationship between stress, as measured by the average intensity of stress score on the MPSSQ, and burnout as measured by the Emotional Exhaustion (EE) subscale of the MBI?

16b) To what extent does spouse/significant other social support, measured by the MSOSQ Spouse/Significant Other Support subscale, moderate the relationship between stress, as measured by the average intensity of stress score on the MPSSQ, and burnout as measured by the 
Depersonalization (DP) subscale of the MBI?

16c) To what extent does spouse/significant other social support, measured by the MSOSQ Spouse/Significant Other Support subscale, moderate the relationship between stress, as measured by the average intensity of stress score on the MPSSQ, and burnout as measured by the Personal Accomplishment (PA) subscale of the MBI? 


\section{Chapter IV}

Results

The focus of the present investigation was to assess the relationships between burnout, stress, and social support among graduate students in psychology. Preliminary analyses included the calculation of Cronbach's alpha coefficients for the Maslach Burnout Inventory (MBI) subscales, for the Modified Psychology Student Stress Questionnaire (MPSSQ), and the Modified Sources of Support (MSOSQ) subscales. Alpha coefficients for the MBI subscales were determined to be .89 for Emotional Exhaustion (EE), .59 for Depersonalization (DP), and .75 for Personal Accomplishment (PA). These results suggest that the MBI exhibited satisfactory internal consistency only for the EE subscale. However, these results are similar to those obtained in a study of 72 undergraduate and graduate students, where Cronbach's alpha coefficient was determined to be .86 for EE, .63 for DP, and .72 for PA (Powers \& Gose, 1986).

Cronbach's alpha levels could not be calculated for each of the three MPSSQ subscales (i.e., MPSSQ.E, MPSSQ.I, MPSSQ.IE) because scores from each item of the MPSSQ are utilized to calculate all three subscale scores. As a result, one overall Cronbach's alpha level was calculated for the MPSSQ. The Alpha coefficient was .85, suggesting that the MPSSQ exhibited satisfactory internal consistency.

Cronbach's alpha coefficients calculated for the MSOSQ subscales were .96 for Clinical Supervisor, .94 for Classmate, .92 for Friend, .95 for Faculty Advisor, .98 for Spouse/Significant Other, and .93 for Relatives. These results support that the MSOSQ is an internally consistent measure. Preliminary analyses additionally included the calculation of means and standard deviations for each of the stress variables, as well as each of the social support and burnout subscales. These data are presented in Table 1. 
Table 1

Means and Standard Deviations for Burnout Subscales, Stress Variables, and Social Support Subscales

\begin{tabular}{|c|c|c|c|c|}
\hline & & $\mathrm{N}$ & $\underline{\mathrm{M}}$ & SD \\
\hline \multicolumn{5}{|l|}{$\begin{array}{l}\text { Maslach Burnout } \\
\text { Inventory (MBI) }\end{array}$} \\
\hline & $\begin{array}{l}\text { Emotional Exhaustion } \\
\text { (EE) }\end{array}$ & 151 & 21.80 & 10.19 \\
\hline & Depersonalization (DP) & 152 & 4.68 & 3.71 \\
\hline & $\begin{array}{l}\text { Personal Accomplishment } \\
\text { (PA) }\end{array}$ & 149 & 38.79 & 5.00 \\
\hline \multirow{5}{*}{$\begin{array}{l}\text { Modified Psychology } \\
\text { Student Stress } \\
\text { Questionnaire (MPSSQ) }\end{array}$} & & & & \\
\hline & & & & \\
\hline & Event Total (MPSSQ.E) & 159 & 16.92 & 5.95 \\
\hline & $\begin{array}{l}\text { Intensity of Events } \\
\text { (MPSSQ.I) }\end{array}$ & 159 & 60.45 & 26.45 \\
\hline & $\begin{array}{l}\text { Average Intensity of } \\
\text { Events (MPSSQ.IE) }\end{array}$ & 159 & 3.53 & .81 \\
\hline \multirow{7}{*}{$\begin{array}{l}\text { Modified Sources of } \\
\text { Support Questionnaire } \\
\text { (MSOSQ) }\end{array}$} & & & & \\
\hline & Classmate & 159 & 38.53 & 12.08 \\
\hline & Clinical Supervisor & 159 & 34.63 & 14.69 \\
\hline & Faculty Advisor & 159 & 33.47 & 12.79 \\
\hline & Friend (Not Yet Specified) & 159 & 38.65 & 11.28 \\
\hline & $\begin{array}{l}\text { Relative (Not Yet } \\
\text { Specified) }\end{array}$ & 159 & 35.01 & 12.81 \\
\hline & Spouse/Significant Other & 159 & 37.39 & 20.63 \\
\hline
\end{tabular}


Results of the statistical analysis of data are presented in four separate sections of this chapter. The first section presents demographic data obtained for the sample. The second section describes the differences observed among counseling, clinical, and school psychology doctoral students with regard to burnout, stress, and social support levels. The third section utilizes the Moderator Model (Barron \& Kenny, 1986) to present data addressing the direct influence of stress on burnout, the direct influence of social support on burnout, and the moderating influence of social support on the relationship between stress and burnout. Finally, the fourth section describes supplementary statistical analyses.

As discussed in Chapter III, participants in this study were Counseling Psychology, Clinical Psychology and School Psychology Student Affiliate Members of the American Psychological Association (APA). These participants were randomly chosen by APA staff from the list of all Student Affiliate Members. Four hundred participants were mailed a packet of questionnaires including a cover letter explaining the purpose of the study, the Demographic Questionnaire for Doctoral Students in Psychology (DQDSP), the Maslach Burnout Inventory Human Services Survey (MBI), the Modified Psychology Student Stress Questionnaire (MPSSQ), and the Modified Sources of Support Questionnaire (MSOSQ). "Reminder letters" were mailed to subjects who failed to return their questionnaires to the researcher within two weeks of the initial mailing of the questionnaires. These individuals were identified using numerical coding procedures which participants were informed about in their consent letter.

\section{Demographic Data}

Of the 400 packets mailed, 21 packets were returned by individuals who stated that they were no longer doctoral students in psychology. An additional 15 packets were returned unopened because the addressee could not be located due to an address change. As a result, after eliminating the 36 packets which never reached current doctoral students in psychology, it appears that the current sample is most accurately represented as a total of 364 participants, not 
400 participants. Of the 364 packets sent to current doctoral students in psychology, 180 packets were returned; representing a return rate of $49 \%$. One hundred fifty-nine packets (44\%) included usable data.

Basic demographic information was requested of each respondent (see Appendix C). This demographic information included: age, gender, race, marital status, and number of children currently residing in the student's household. Respondents were also asked to answer a number of questions about their experience in their current graduate program (i.e., number of years anticipated to complete program requirements, number of hours per week spent in class, whether they receive tuition waivers and school related stipends, and their overall satisfaction with their current doctoral program).

The ages of participants ranged from 23 to 62 years with a mean age of 34.08 years and a standard deviation of 8.59 years. The modal age of the sample was 28 years. Thirty-six participants were male $(23.4 \%)$ and 118 participants were female (76.6\%). Eleven participants were African American (7.0\%), one was American Indian (0.6\%), seven were Asian (4.4\%), 119 were Caucasian (75.3\%), nine were Hispanic (5.7\%), four were Latino (2.5\%), and seven were classified as "Other" (4.4\%). The aforementioned sample data, specifically addressing gender, is relatively similar to demographic data provided by the American Psychological Association (APA), which represents Student Affiliate membership from 1987 to the present. However, the current sample data represents a greater percentage of Caucasian Student Affiliate Members of APA $(75 \%)$ than was reported by APA of its Student Affiliate membership from 1987 to the present $(68 \%)$.

Sixty-seven participants in the current study were single (42.4\%), 74 were married (46.8\%), 2 were separated (1.3\%), and 10 participants were divorced $(6.3 \%)$. One hundred twenty-four respondents had no children (79.0\%), 21 had one child (13.4\%), 11 had two children (13.4\%), and one had three children $(0.6 \%)$. Respondents averaged 2.60 years of clinical 
experience prior to entering their current doctoral program.

Evaluation of program characteristics associated with the current sample suggests that 119 respondents were enrolled in Clinical Psychology graduate programs (77.3\%), 16 were enrolled in Counseling Psychology programs (10.4\%), 15 were enrolled in School Psychology programs $(9.7 \%)$, and four were enrolled in some other unspecified type of graduate program in psychology (2.6\%). The aforementioned program enrollment breakdown is not consistent with data provided by APA regarding Student Affiliate enrollment from 1987 to the present. According to data provided by APA of Student Affiliate members from 1987 to the present, 29\% of members were enrolled in Clinical Psychology programs, 15\% were enrolled in Counseling Psychology programs, and 4\% were enrolled in School Psychology programs. The unequal representation of students across graduate programs observed among the current sample, as well as the incongruence between the graduate program representation of the current sample and data provided by APA regarding Student Affiliate program enrollment from 1987 to the present, are viewed as a limitations of the study. These limitations are addressed in Chapter Five.

Respondents in the current study have been enrolled in their respective graduate programs from one to eight years, with a modal value of four years, and a standard deviation of 1.44 years. One respondent was in the first year of graduate study $(0.6 \%), 25$ were in their second year (15.8\%), 29 in their third year (18.4\%), 37 in their fourth year (23.4\%), 32 in their fifth year $(20.3 \%)$, and 34 in their sixth or greater year $(21.4 \%)$. Respondents anticipated an average of 5.39 years to complete all requirements for their degrees with a standard deviation of 1.33 years. Upon completion of all requirements for graduate degrees in psychology, three respondents anticipated earning an Ed.D. (1.9\%), 100 a Ph.D. (64.5\%), and 52 a Psy.D. (33.5\%). Respondents reported an average of 5.97 credit hours with a standard deviation of 5.55 hours, and a range up to 18 credit hours. Oral comprehensive exams were required for $54.4 \%$ of respondents, written comprehensive exams were required for $84.1 \%$ of respondents. 
Respondents provided information specific to their current graduate school experience (see Table 2). Respondents spend the majority of their time completing practicum and clinical activities, an average of 16.37 hours per week with a standard deviation of 17.20 hours.

Respondents spend the least amount of their time in meetings, traveling to class, teaching, and in formal supervision. Notably, adding each of the mean scores from the categories listed in Table 2 suggests that doctoral students in psychology spend approximately 60 hours per week completing tasks related to their graduate school experience. This number likely overestimates the time students spend completing doctoral program related activities, as it appeared from the information provided by a number of respondents that several categories on the Demographic Questionnaire of Doctoral Students in Psychology (DQDSP) overlapped, and were not distinct. For example, it is likely that "Practicum/Clinical Activities (Including Travel Time)" overlapped with responses to "Direct Contact with Clients." This lack of distinction likely contributed to elevated totals related to how many hours per week students spend completing specific tasks. The lack of clarity on the DQDSP is a limitation of the current study, a limitation addressed more specifically in Chapter Five. Information related to the data presented in Table 2 should be interpreted with caution. 
Table 2

Hours per Week Spent Completing Various Tasks Related to Graduate Study in Psychology

\begin{tabular}{|c|c|c|c|c|}
\hline Variable & $\underline{\mathrm{M}}$ & SD & Minimum & Maximum \\
\hline Clinical Service & 2.60 & 3.76 & .00 & 20.00 \\
\hline Dissertation Research & 6.50 & 8.47 & .00 & 40.00 \\
\hline $\begin{array}{l}\text { Assistantship Duties (not } \\
\text { including teaching) }\end{array}$ & 3.38 & 7.94 & .00 & 50.00 \\
\hline In Class & 3.77 & 4.54 & .00 & 18.00 \\
\hline In Meetings & 1.06 & 1.33 & .00 & 10.00 \\
\hline Traveling to Class & 1.27 & 1.96 & .00 & 12.00 \\
\hline Non-Dissertation Research & 2.94 & 5.29 & .00 & 30.00 \\
\hline Teaching & 1.86 & 4.92 & .00 & 30.00 \\
\hline $\begin{array}{l}\text { Practicum/Clinical Activities } \\
\text { (Including Travel Time) }\end{array}$ & 16.37 & 17.20 & .00 & 68.00 \\
\hline Direct Contact with Clients & 11.74 & 11.02 & .00 & 40.00 \\
\hline $\begin{array}{l}\text { Reading/Writing } \\
\text { Papers/Homework }\end{array}$ & 6.06 & 7.81 & .00 & 50.00 \\
\hline In Formal Supervision & 2.50 & 2.25 & .00 & 12.00 \\
\hline
\end{tabular}


Respondent financial support was assessed. Tuition waivers were reported by $29.7 \%$ of respondents and school related stipends by $32.9 \%$ of respondents. Financial aid other than tuition waivers and stipends are received by $56.1 \%$ of respondents. Jobs, not including school supported assistantships, are held in addition to school related activities by $51.6 \%$ of respondents. Those who hold such jobs report working an average of 21.94 hours per week with a standard deviation of 14.53 hours.

Respondents were asked to rate their overall satisfaction with their current graduate program using a Likert Scale ranging from 1 "very satisfied" to 7 "very unsatisfied." The mean rating was 4.25 . The modal rating was 3.00. Seven respondents provided ratings of one (4.4\%), 33 rated their program satisfaction as two (20.9\%), 36 as three (22.8\%), 18 as four (11.4\%), 32 as five (20.3\%), 21 as six (13.3\%), and 10 as seven (6.3\%).

\section{$\underline{\text { Student Differences Related to Burnout }}$}

Differences in reported burnout levels of clinical, counseling, and school psychology doctoral students, as measured by EE, DP, and PA subscale scores on the MBI, were determined for the sample. These differences address research questions 1a-1c, respectively. One hundred forty-three subjects enrolled in clinical $(n=112)$, counseling $(n=16)$, or school $(n=15)$ psychology programs provided data which could be utilized in this analysis. MANOVA results revealed no significant differences among psychology doctoral students in terms of overall burnout levels $(\mathrm{F}=1.08, \underline{\mathrm{p}}>.05)$. MANOVA results further revealed no significant differences among psychology doctoral students in terms of DP or PA. Results did suggest a significant difference among students enrolled in clinical, counseling, and school psychology programs in terms of EE $(F=3.10, \underline{p}<.05)$. Post hoc analyses using the Scheffe and Student-Newman-Keuls tests did not suggest meaningful differences between these groups, however. Table 3 displays 
EE, DP, and PA mean and standard deviation burnout levels for the sample. This table additionally includes classification of sample MBI mean subscale scores into categories developed by Maslach et al. (1996). These categories were developed for mental health professionals, and include low, moderate, and high burnout categories. 
Table 3

Burnout Level Differences Observed Among Clinical, Counseling, and School Psychology Doctoral Students as Measured by the MBI EE, DP, and PA Subscales

\begin{tabular}{|c|c|c|c|c|c|}
\hline $\begin{array}{l}\text { Program } \\
\text { Type }\end{array}$ & $\mathrm{N}$ & $\begin{array}{l}\text { Burnout } \\
\text { Subscale }\end{array}$ & $\underline{\mathrm{M}}$ & SD & $\begin{array}{l}\text { MBI Score Category } \\
\text { Mental Health } \\
\text { Professionals }\end{array}$ \\
\hline \multicolumn{6}{|l|}{ Clinical } \\
\hline \multirow[t]{3}{*}{ Psychology } & 112 & $\mathrm{EE}$ & 22.02 & 9.94 & High \\
\hline & & DP & 4.86 & 3.76 & Low-Moderate \\
\hline & & PA & 38.63 & 4.97 & Low \\
\hline \multicolumn{6}{|l|}{ Counseling } \\
\hline \multirow[t]{3}{*}{ Psychology } & 16 & $\mathrm{EE}$ & 24.75 & 12.52 & High \\
\hline & & DP & 4.75 & 3.79 & Low-Moderate \\
\hline & & PA & 38.38 & 5.41 & Low \\
\hline \multicolumn{6}{|l|}{ School } \\
\hline \multirow[t]{3}{*}{ Psychology } & 15 & $\mathrm{EE}$ & 16.07 & 8.73 & Moderate \\
\hline & & DP & 3.53 & 3.58 & Low \\
\hline & & PA & 39.80 & 4.99 & Low \\
\hline
\end{tabular}




\section{$\underline{\text { Student Differences Related to Stress }}$}

Differences in reported stress levels of clinical, counseling, and school psychology doctoral students, as measured by the total stress events score (MPSSQ.E), total stress intensity score (MPSSQ.I), and average intensity of stress score (MPSSQ.IE) on the MPSSQ were determined for the sample. These differences address research question two. One hundred fifty subjects indicated that they were enrolled in clinical $(n=119)$, counseling $(n=16)$, or school $(n$ $=15)$ psychology programs and these individuals were utilized in this analysis. MANOVA results revealed no significant differences among psychology doctoral students in terms of overall stress levels $(\mathrm{F}=1.58, \mathrm{p}>.05)$. MANOVA results further revealed no significant differences among psychology doctoral students in terms of MPSSQ.E $(F=.07, \underline{p}>.05)$ and MPSSQ.I $(F=.58, \underline{p}>.05)$. Significant differences between doctoral students in psychology were observed for MPSSQ.IE $(F=3.83, \underline{p}<.05)$. Post hoc analyses using the Scheffe test revealed significant differences between Clinical Psychology students and School Psychology students $(\underline{p}=.036)$ and a trend toward differences between Counseling Psychology students and School Psychology students $(\mathrm{p}=.052)$. These results suggest that Clinical Psychology students reported significantly more stress, as measured by the average intensity of stress score of the MPSSQ (MPSSQ.IE), than did School Psychology students. Additionally, Counseling Psychology students reported higher levels of MPSSQ.IE than School Psychology students, levels which nearly reached significance. No other statistically significant differences between graduate programs were observed. Table 4 displays MPSSQ.IE mean and standard deviation stress levels for the sample. 
Table 4

Average Intensity of Stress (MPSSQ.IE) Level Differences Observed Among Clinical, Counseling, and School Psychology Doctoral Students

\begin{tabular}{llll}
\hline Program Type & $\mathrm{N}$ & $\underline{\mathrm{M}}$ & $\mathrm{SD}$ \\
\hline & & & \\
Clinical Psychology & 119 & 3.58 & .80 \\
Counseling Psychology & 16 & 3.71 & .84 \\
School Psychology & 15 & 3.00 & .79 \\
\hline
\end{tabular}




\section{$\underline{\text { Student Differences Related to Social Support }}$}

Differences in reported social support levels of clinical, counseling, and school psychology doctoral students, as measured by the six subscales of the MSOSQ (Classmate, Clinical Supervisor, Faculty Advisor, Friend Not Yet Specified, Relative Not Yet Specified, and Spouse/Significant Other) were determined for the sample. These differences address research questions 3a-3f, respectively. One hundred fifty respondents indicated that they were enrolled in clinical $(n=119)$, counseling $(n=16)$, or school $(n=15)$ psychology programs and these individuals were utilized in this analysis. MANOVA results revealed no significant differences among psychology doctoral students in terms of overall social support levels $(F=1.28, \underline{p}>.05)$. MANOVA results revealed no significant differences among doctoral students enrolled in clinical, counseling, and school psychology doctoral programs in terms of their reports of classmate support $(\mathrm{F}=.49, \mathrm{p}>.05)$, clinical supervisor support $(\mathrm{F}=1.33, \mathrm{p}>.05)$, faculty advisor support $(\mathrm{F}=.94, \mathrm{p}>.05)$, spouse/significant other support $(\mathrm{F}=.13, \mathrm{p}>.05)$, and relative not yet specified support $(\mathrm{F}=1.98, \underline{\mathrm{p}}>.05)$. Significant differences among doctoral students in psychology were observed only in terms of friend social support $(\mathrm{F}=4.56, \underline{\mathrm{p}}<.05)$.

Post hoc analyses using the Scheffe test revealed significant differences between Clinical Psychology students and Counseling Psychology students $(\mathrm{p}=.013)$. These results suggest that Counseling Psychology students reported significantly more friend social support, as measured by the friend (not yet specified) social support subscale of the MSOSQ, than did Clinical Psychology students. No other statistically significant differences between graduate programs were observed. Table 5 displays MSOSQ friend subscale mean and standard deviation social support levels for the sample. 
Table 5

Friend Social Support Levels Observed Among Clinical, Counseling, and School Psychology Doctoral Students

\begin{tabular}{lccc}
\hline Program Type & $\mathrm{N}$ & $\underline{\mathrm{M}}$ & $\mathrm{SD}$ \\
\hline Clinical Psychology & 119 & 37.38 & 11.42 \\
Counseling Psychology & 16 & 46.25 & 9.98 \\
School Psychology & 15 & 37.48 & 9.27 \\
\hline
\end{tabular}




\section{$\underline{\text { Moderator Model }}$}

As discussed in Chapter One, the Moderator Model (Baron \& Kenny, 1986) suggests that a criterion or outcome variable may be influenced in three different manners, or according to three separate "paths" (See Figure 1). Path A involves the direct influence of a predictor variable on the criterion variable. Path B involves the direct influence of a moderator variable on the criterion variable. Path $\mathrm{C}$ focuses on the interaction effects of the predictor and moderator variables on the criterion variable. Paths $\mathrm{A}$ and $\mathrm{B}$ enable main or direct effects associated with changes in the criterion variable to be assessed. Path $\mathrm{C}$ enables moderating or "buffering" effects on the criterion variable to be evaluated.

Using the Moderator Model (Baron \& Kenny, 1986) in the present study, stress served as the predictor variable, social support was the moderating variable, and burnout was the outcome variable. Use of the Moderator Model enabled evaluation of the direct effect of stress on burnout (Path A), the direct effect of social support on burnout (Path B), and the interaction effects of stress and social support on burnout (Path C) to be evaluated. Results of evaluation using the Moderator Model additionally permitted conclusions to be drawn regarding the role of social support in the stress-burnout relationship. Conclusions regarding whether social support influences the stress-burnout relationship directly, or through moderating or buffering effects were most significant to this particular study.

Summaries of regression analyses utilized to evaluate the relationships between burnout, stress, and social support are presented in Tables 6 through 13. These tables address research questions 4 through 16, and will be referred to throughout the report of the findings. Additionally, a summary specifically addressing the direct influence of stress and social support on burnout is presented in Appendix K. A summary specifically addressing the moderating influence of social support on the stress-burnout relationship is presented in Appendix L. 


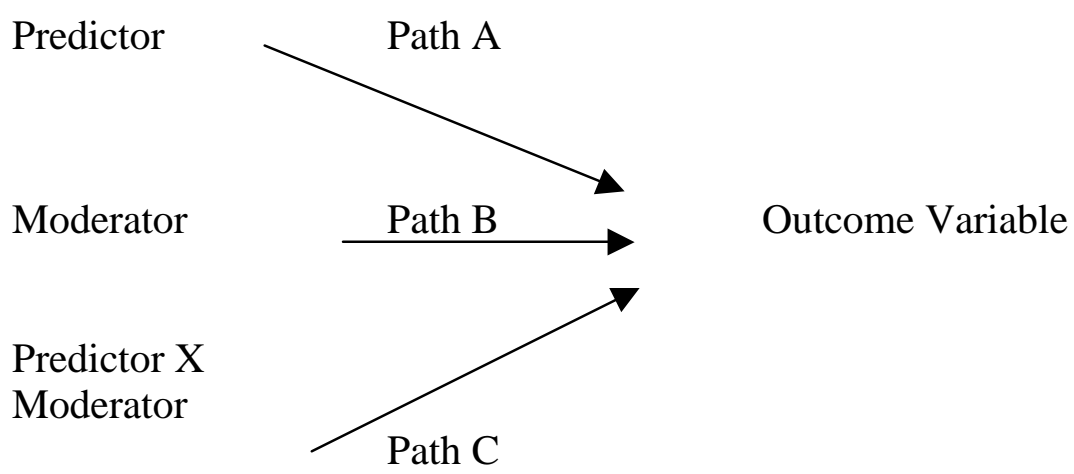

Figure 2. Moderator model (Baron \& Kenny, 1986).

\section{Direct Influence of Stress on Burnout, Moderator Model Path A}

Regression analyses were conducted to determine if the predictor variable, stress (X), has a direct influence on the criterion variable, burnout (Y). Stress was measured using the MPSSQ.IE score, and burnout was measured using the three subscales of the MBI (EE, DP, PA). Three separate analyses were conducted. These analyses address research questions $4 \mathrm{a}-4 \mathrm{c}$, and involve analysis of the direct influence of MPSSQ.IE on EE, DP, and PA, respectively. According to the Moderator Model (Baron \& Kenny, 1986), stress has a direct influence on burnout when these variables are significantly related to each other. Results suggested MMPSSQ.IE was significantly related to EE $(\underline{\mathrm{r}}=.435, \underline{\mathrm{p}}<.01)$, DP $(\underline{\mathrm{r}}=.186, \underline{\mathrm{p}}<.01)$, and PA $(\underline{\mathrm{r}}$ $=-.310, \mathrm{p}<.01$ ). Stress had a direct influence on all subscales of burnout (see Table 6). 
Table 6

Summary of Direct Influence of Stress (MPSSQ.IE) on Burnout (EE, DP, and PA)

\begin{tabular}{llll}
\hline Stress Variable & Burnout Subscale & $\underline{\mathrm{r}}$ & Sig. \\
\hline MPSSQ.IE & & & \\
& & & $* *$ \\
& Emotional Exhaustion & .435 & $* *$ \\
& Depersonalization & .186 & $* *$ \\
& Personal Accomplishment & -.310 & \\
\hline$* * \mathrm{p}<.01$ & & &
\end{tabular}




\section{Direct Influence of Social Support on Burnout, Moderator Model Path B}

Regression analyses were conducted to determine if the moderator variable, social support (Z), has a direct influence on the criterion variable, burnout (Y). Social support was measured using the six subscales of the MSOSQ (Classmate, Clinical Supervisor, Faculty Advisor, Friend Not Yet Specified, Relatives Not Yet Specified, and Spouse/Significant Other). Burnout was measured using the three subscales of the MBI (EE, DP, PA). Eighteen separate analyses were conducted. These analyses address research questions 5a-10c, and involve analysis of the direct influence of each social support subscale (Classmate, Clinical Supervisor, Faculty Advisor, Friend Not Yet Specified, Relatives Not Yet Specified, and Spouse/Significant Other) on each burnout subscale (EE, DP, and PA). For example, research question 5a involves analysis of the direct influence of classmate social support on EE, research question $5 \mathrm{~b}$ involves analysis of the direct influence of classmate social support on DP, and research question 5c involves analysis of the direct influence of classmate social support on PA. Research questions 6a-10c involve similar analyses of the direct influence of social support (clinical supervisor, faculty advisor, friend, relative, and spouse/significant other) on burnout (EE, DP, and PA), respectively. According to the Moderator Model (Baron \& Kenny, 1986), social support has a direct influence on burnout when these variables are significantly related to each other. Only Classmate Social Support had a direct influence on the Personal Accomplishment subscale of burnout $(\underline{r}=.177, \underline{p}<.05)$. No other social support subscale had a direct influence on any subscale of burnout (see Table 7). 
Table 7

$\underline{\text { Summary of Direct Influence of Social Support on Burnout }}$

\begin{tabular}{|c|c|c|c|}
\hline $\begin{array}{l}\text { Social Support } \\
\text { Subscale }\end{array}$ & $\begin{array}{l}\text { Burnout } \\
\text { Subscale }\end{array}$ & $\underline{r}$ & Sig. \\
\hline Classmate & $\begin{array}{l}\text { EE } \\
\text { DP } \\
\text { PA }\end{array}$ & $\begin{array}{l}-.098 \\
-.096 \\
.177\end{array}$ & $\begin{array}{l}\mathrm{ns} \\
\mathrm{ns} \\
*\end{array}$ \\
\hline Clinical Supervisor & $\begin{array}{l}\text { EE } \\
\text { DP } \\
\text { PA }\end{array}$ & $\begin{array}{l}-.101 \\
-.032 \\
.036\end{array}$ & $\begin{array}{l}\text { ns } \\
\text { ns } \\
\text { ns }\end{array}$ \\
\hline Faculty Advisor & $\begin{array}{l}\text { EE } \\
\text { DP } \\
\text { PA }\end{array}$ & $\begin{array}{l}-.039 \\
-.112 \\
.111\end{array}$ & $\begin{array}{l}\text { ns } \\
\text { ns } \\
\text { ns }\end{array}$ \\
\hline $\begin{array}{l}\text { Friend } \\
\text { (Not Yet Specified) }\end{array}$ & $\begin{array}{l}\text { EE } \\
\text { DP } \\
\text { PA }\end{array}$ & $\begin{array}{l}.023 \\
-.141 \\
.090\end{array}$ & $\begin{array}{l}\text { ns } \\
\text { ns } \\
\text { ns }\end{array}$ \\
\hline $\begin{array}{l}\text { Relative } \\
\text { (Not Yet Specified) }\end{array}$ & $\begin{array}{l}\text { EE } \\
\text { DP } \\
\text { PA }\end{array}$ & $\begin{array}{l}.007 \\
-.042 \\
.070\end{array}$ & $\begin{array}{l}\text { ns } \\
\text { ns } \\
\text { ns }\end{array}$ \\
\hline $\begin{array}{l}\text { Spouse/ } \\
\text { Significant Other }\end{array}$ & $\begin{array}{l}\text { EE } \\
\text { DP } \\
\text { PA }\end{array}$ & $\begin{array}{l}-.124 \\
-.074 \\
.155\end{array}$ & $\begin{array}{l}\text { ns } \\
\text { ns } \\
\text { ns }\end{array}$ \\
\hline
\end{tabular}


$\underline{\text { Social Support as Moderator of Stress and Burnout, Moderator Model Path C }}$

Regression analyses were conducted to determine if social support $(\mathrm{Z})$ moderates the relationship between the predictor variable, stress $(\mathrm{X})$, and the criterion variable, burnout $(\mathrm{Y})$. These analyses address research questions 11a-16c.

It has been suggested in the literature that evaluation of the buffering influence of the moderator variable is dependent upon the pre-existence of significant relationships between both the predictor variable and the outcome variable, and the moderator variable and the outcome variable. Baron and Kenny (1986) do not make this specification, however. According to Baron and Kenny (1986), social support (Z) moderates the stress (X) - burnout (Y) relationship if social support $(\mathrm{Z})$, when regressed in combination with stress $(\mathrm{X})$ on burnout $(\mathrm{Y})$, produces a significant effect (Path C).

Moderating Influence of Classmate Social Support on the Stress-Burnout Relationship

Research question "11a" specifically evaluates the extent to which classmate support, measured by the MSOSQ Classmate Support subscale, moderates the relationship between stress, as measured by the average intensity of stress score on the MPSSQ (MPSSQ.IE), and burnout as measured by the EE subscale of the MBI. Regression analysis indicated the combination of stress and classmate social support were significantly related to MBI EE ( $\underline{r}=$ $.197, \underline{p}<.05)$. See Table 8 for $\mathrm{t}$-values and $\mathrm{r}^{2}$ values. These findings support the moderating effect of Classmate Support on the Stress (X) - Burnout (Y) relationship.

Research question " $11 b$ " evaluates the extent to which classmate support, measured by the MSOSQ Classmate Support subscale, moderates the relationship between stress, as measured by the average intensity of stress score on the MPSSQ (MPSSQ.IE), and burnout as measured by the DP subscale of the MBI. Regression analysis indicated the combination of stress and classmate social support was not significantly related to MBI DP $(\underline{r}=.062, \underline{p}>.05)$. See Table 8 for $t$-values and $r^{2}$ values. These findings do not support the moderating effect of Classmate 
Support on the Stress (X) - Burnout (Y) relationship.

Research question " $11 \mathrm{c}$ " evaluates the extent to which classmate support, measured by the MSOSQ Classmate Support subscale, moderates the relationship between stress, as measured by the average intensity of stress score on the MPSSQ (MPSSQ.IE), and burnout as measured by the PA subscale of the MBI. Regression analysis indicated the combination of stress and classmate social support was not significantly related to MBI PA $(\underline{r}=.048, \underline{p}>.05)$. See Table 8 for $t$-values and $r^{2}$ values. These findings do not support the moderating effect of Classmate Support on the Stress (X) - Burnout (Y) relationship. 
Table 8

Moderating Influence of Classmate Social Support on the Stress-Burnout Relationship

\begin{tabular}{lllllllll}
\hline $\mathrm{t}$ & Sig. & $\underline{\mathrm{r}}$ & Sig. & $\mathrm{r}^{2}$ & $\mathrm{~F}$ & Sig.
\end{tabular}

MBI EE / MPSSQ.IE / Classmate Social Support (Research Question 11a)

MBI EE (Y)

$\begin{array}{lccccccc}\text { MPSSQ.IE (X) } & 5.89 & * * & .435 & * * & .189 & 34.73 & * * \\ \text { Classmate (Z) } & -1.20 & \mathrm{~ns} & -.098 & \mathrm{~ns} & .010 & 1.43 & \mathrm{~ns} \\ (\mathrm{X}) \mathrm{x}(\mathrm{Z}) & 2.45 & * & .197 & & .039 & 5.99 & *\end{array}$

MBI DP / MPSSQ.IE / Classmate Social Support (Research Question 11b)

MBI DP (Y)

MPSSQ.IE (X) $\quad 2.32 \quad * \quad \begin{array}{llllll} & .186 & * & .028 & 5.40 & *\end{array}$

$\begin{array}{llllllll}\text { Classmate (Z) } & -1.18 & \text { ns } & -.096 & \text { ns } & .009 & 1.38 & \text { ns }\end{array}$

$\begin{array}{lllllll}(\mathrm{X}) \mathrm{x}(\mathrm{Z}) & .76 & \mathrm{~ns} & .062 & .004 & .58 & \mathrm{~ns}\end{array}$

MBI PA / MPSSQ.IE / Classmate Social Support (Research Question 11c)

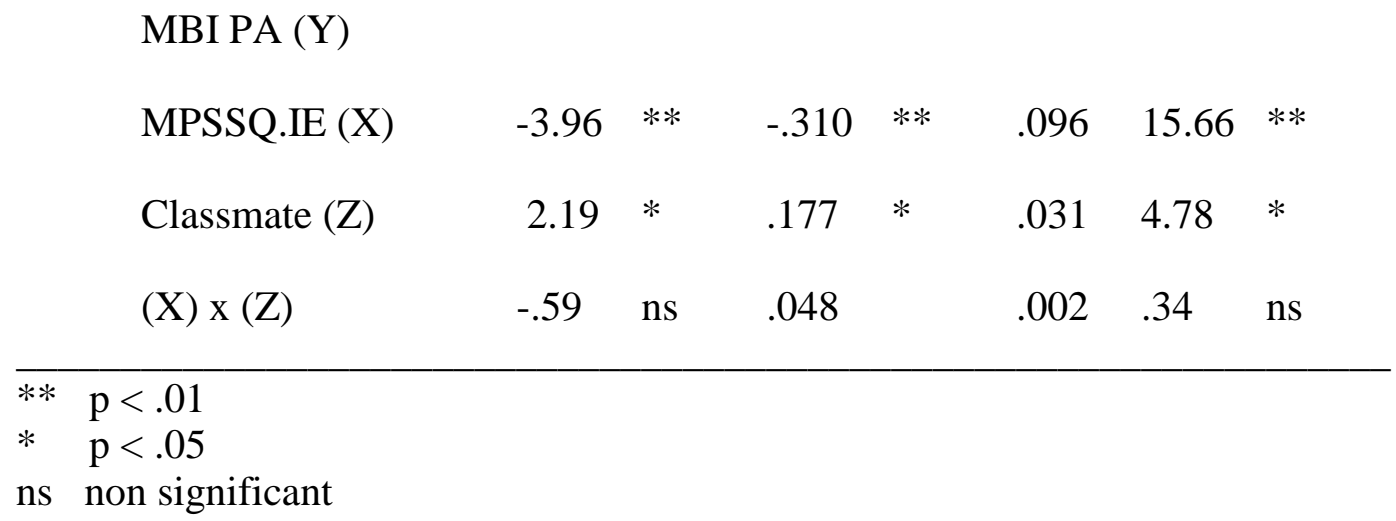


Moderating Influence of Clinical Supervisor Social Support on the Stress-Burnout Relationship

Research question "12a" specifically evaluates the extent to which clinical supervisor support, measured by the MSOSQ Clinical Supervisor Support subscale, moderates the relationship between stress, as measured by the average intensity of stress score on the MPSSQ (MPSSQ.IE), and burnout as measured by the EE subscale of the MBI. Regression analysis indicated the combination of stress and clinical supervisor social support was not significantly related to MBI EE $(\underline{r}=.136, \underline{p}>.05)$. See Table 9 for $t$-values and $r^{2}$ values. These findings do not support the moderating effect of Clinical Supervisor Support on the Stress (X) - Burnout (Y) relationship.

Research question " $12 b$ " evaluates the extent to which clinical supervisor support, measured by the MSOSQ Clinical Supervisor Support subscale, moderates the relationship between stress, as measured by the average intensity of stress score on the MPSSQ (MPSSQ.IE), and burnout as measured by the DP subscale of the MBI. Regression analysis indicated the combination of stress and clinical supervisor social support was not significantly related to MBI $\mathrm{DP}(\underline{\mathrm{r}}=.098, \underline{\mathrm{p}}>.05)$. See Table 9 for $\mathrm{t}$-values and $\mathrm{r}^{2}$ values. These findings do not support the moderating effect of Clinical Supervisor Support on the Stress (X) - Burnout (Y) relationship.

Research question " $12 \mathrm{c}$ " evaluates the extent to which clinical supervisor support, measured by the MSOSQ Clinical Supervisor Support subscale, moderates the relationship between stress, as measured by the average intensity of stress score on the MPSSQ (MPSSQ.IE), and burnout as measured by the PA subscale of the MBI. Regression analysis indicated the combination of stress and clinical supervisor social support was significantly related to MBI PA $(\underline{r}=.165, \underline{p}<.05)$. See Table 9 for $t$-values and $r^{2}$ values. These findings support the moderating effect of Clinical Supervisor Support on the Stress (X) - Burnout (Y) relationship. 
Table 9

Moderating Influence of Clinical Supervisor Social Support on the Stress-Burnout Relationship

\begin{tabular}{llllllll}
\hline & $\mathrm{t}$ & Sig. & $\underline{\mathrm{r}}$ & Sig. & $\mathrm{r}^{2}$ & $\mathrm{~F}$ & Sig.
\end{tabular}

MBI EE / MPSSQ.IE / Clinical Super. Social Support (Research Question 12a) MBI EE (Y)

$\begin{array}{lccccccc}\text { MPSSQ.IE (X) } & 5.89 & * * & .435 & * * & .189 & 34.73 & * * \\ \text { Clin. Super. (Z) } & -1.24 & \mathrm{~ns} & -.101 & \mathrm{~ns} & .010 & 1.54 & \mathrm{~ns} \\ \text { (X) x (Z) } & 1.67 & \mathrm{~ns} & .136 & & .018 & 2.79 & \mathrm{~ns}\end{array}$

MBI DP / MPSSQ.IE / Clinical Super. Social Support (Research Question 12b)

$\begin{array}{lcccccccc}\text { MBI DP (Y) } & & & & & & & \\ \text { MPSSQ.IE (X) } & 2.32 & * & .186 & * & .028 & 5.40 & * \\ \text { Clin. Super. (Z) } & -.39 & \text { ns } & -.032 & \text { ns } & .001 & .152 & \text { ns } \\ \text { (X) x (Z) } & 1.21 & \text { ns } & .098 & & .010 & 1.47 & \text { ns }\end{array}$

MBI PA / MPSSQ.IE / Clinical Super. Social Support (Research Question 12c)

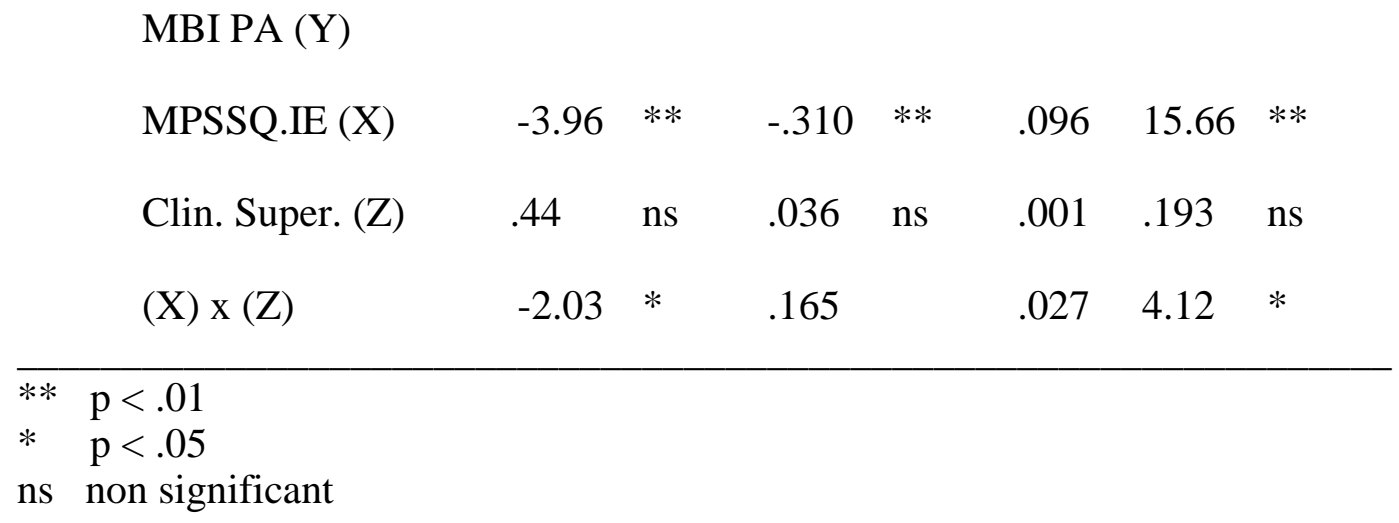


Moderating Influence of Faculty Advisor Social Support on the Stress-Burnout Relationship

Research question "13a" specifically evaluates the extent to which faculty advisor support, measured by the MSOSQ Faculty Advisor Support subscale, moderates the relationship between stress, as measured by the average intensity of stress score on the MPSSQ (MPSSQ.IE), and burnout as measured by the EE subscale of the MBI. Regression analysis indicated the combination of stress and faculty advisor social support was significantly related to MBI EE $(\underline{r}=$ $.207, \mathrm{p}<.05)$. See Table 10 for $\mathrm{t}$-values and $\mathrm{r}^{2}$ values. These findings support the moderating effect of Faculty Advisor Support on the Stress (X) - Burnout (Y) relationship.

Research question " $13 b$ " evaluates the extent to which faculty advisor support, measured by the MSOSQ Faculty Advisor Support subscale, moderates the relationship between stress, as measured by the average intensity of stress score on the MPSSQ (MPSSQ.IE), and burnout as measured by the DP subscale of the MBI. Regression analysis indicated the combination of stress and faculty advisor social support was not significantly related to MBI DP $(\underline{\mathrm{r}}=.022, \underline{\mathrm{p}}>$ $.05)$. See Table 10 for $\mathrm{t}$-values and $\mathrm{r}^{2}$ values. These findings do not support the moderating effect of Faculty Advisor support on the Stress (X) - Burnout (Y) relationship.

Research question " $13 \mathrm{c}$ " evaluates the extent to which faculty advisor support, measured by the MSOSQ Faculty Advisor Support subscale, moderates the relationship between stress, as measured by the average intensity of stress score on the MPSSQ (MPSSQ.IE), and burnout as measured by the PA subscale of the MBI. Regression analysis indicated the combination of stress and faculty advisor social support was not significantly related to MBI PA $(\underline{\mathrm{r}}=.087, \underline{\mathrm{p}}>$ $.05)$. See Table 10 for $\mathrm{t}$-values and $\mathrm{r}^{2}$ values. These findings do not support the moderating effect of Faculty Advisor Support on the Stress (X) - Burnout (Y) relationship. 
Table 10

Moderating Influence of Faculty Advisor Social Support on the Stress-Burnout Relationship

\begin{tabular}{lllllllll}
\hline t & Sig. & $\underline{r}$ & Sig. & r $^{2}$ & F & Sig.
\end{tabular}

MBI EE / MPSSQ.IE / Faculty Advisor Social Support (Research Question 13a)

MBI EE (Y)

MPSSQ.IE (X) $\quad 5.89 \quad * * \quad .435 \quad * * \quad .189 \quad 34.73 \quad * *$

$\begin{array}{llllllll}\text { Faculty Advisor (Z) } & -.48 & \text { ns } & -.039 & \text { ns } & .002 & .23 & \text { ns }\end{array}$

$\begin{array}{lllllll}(\mathrm{X}) \mathrm{x}(\mathrm{Z}) & 2.59 & * & .207 & .043 & 6.70 & *\end{array}$

MBI DP / MPSSQ.IE / Faculty Advisor Social Support (Research Question 13b)

MBI DP (Y)

MPSSQ.IE (X) $\quad 2.32 \quad * \quad \begin{array}{llllll} & .186 & * & .028 & 5.40 & *\end{array}$

$\begin{array}{llllllll}\text { Faculty Advisor (Z) } & -1.38 & \text { ns } & -.112 & \text { ns } & .013 & 1.91 & \text { ns }\end{array}$

$\begin{array}{lllllll}(\mathrm{X}) \mathrm{x}(\mathrm{Z}) & .27 & \mathrm{~ns} & .022 & .000 & .071 & \mathrm{~ns}\end{array}$

MBI PA / MPSSQ.IE / Faculty Advisor Social Support (Research Question 13c) MBI PA (Y)

$\begin{array}{llllllll}\text { MPSSQ.IE (X) } & -3.96 & * * & -.310 & * * & .096 & 15.66 & * *\end{array}$

$\begin{array}{llllllll}\text { Faculty Advisor (Z) } & 1.36 & \text { ns } & .111 & \text { ns } & .012 & 1.85 & \text { ns }\end{array}$

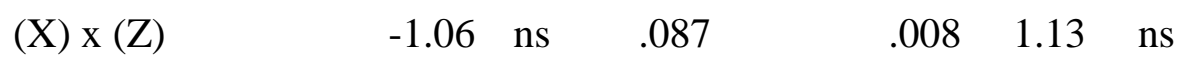

$* * \mathrm{p}<.01$

$* \quad \mathrm{p}<.05$

ns non significant 
Moderating Influence of Friends (Not Yet Specified) Social Support on the Stress-Burnout $\underline{\text { Relationship }}$

Research question "14a" specifically evaluates the extent to which friends (not yet specified) support, measured by the MSOSQ Friends (Not Yet Specified) Support subscale, moderates the relationship between stress, as measured by the average intensity of stress score on the MPSSQ (MPSSQ.IE), and burnout as measured by the EE subscale of the MBI. Regression analysis indicated the combination of stress and friends (not yet specified) social support was significantly related to MBI EE $(\underline{r}=.305, \underline{p}<.01)$. See Table 11 for $t$-values and $r^{2}$ values. These findings support the moderating effect of Friends (Not Yet Specified) Support on the Stress (X) - Burnout (Y) relationship.

Research question "14b" evaluates the extent to which friends (not yet specified) support, measured by the MSOSQ Friends (Not Yet Specified) Support subscale, moderates the relationship between stress, as measured by the average intensity of stress score on the MPSSQ (MPSSQ.IE), and burnout as measured by the DP subscale of the MBI. Regression analysis indicated the combination of stress and friends (not yet specified) social support was not significantly related to MBI DP $(\underline{r}=.020, \underline{p}>.05)$. See Table 11 for $t-v a l u e s$ and $r^{2}$ values. These findings do not support the moderating effect of Friends (Not Yet Specified) Support on the Stress (X) - Burnout (Y) relationship.

Research question " $14 \mathrm{c}$ " evaluates the extent to which friends support, measured by the MSOSQ Friends (Not Yet Specified) Support subscale, moderates the relationship between stress, as measured by the average intensity of stress score on the MPSSQ (MPSSQ.IE), and burnout as measured by the PA subscale of the MBI. Regression analysis indicated the combination of stress and friends (not yet specified) social support was not significantly related to MBI PA $(\underline{r}=.140, \underline{p}>.05)$. See Table 11 for $t$-values and $r^{2}$ values. These findings do not support the moderating effect of Friends Support on the Stress (X) - Burnout (Y) relationship. 
Table 11

Moderating Influence of Friends (Not Yet Specified) Social Support on the Stress-Burnout $\underline{\text { Relationship }}$

$\begin{array}{lllllll}\mathrm{t} & \text { Sig. } & \underline{\mathrm{r}} & \text { Sig. } & \mathrm{r}^{2} & \mathrm{~F} & \text { Sig. }\end{array}$

MBI EE / MPSSQ.IE / Friend Social Support (Research Question 14a)

\begin{tabular}{|c|c|c|c|c|c|c|}
\hline MPSSQ.IE (X) & 5.89 & $* *$ & .435 & $* *$ & .189 & $34.73 * *$ \\
\hline Friend $(\mathrm{Z})$ & .29 & ns & .023 & ns & .001 & .081 \\
\hline$(\mathrm{X}) \mathrm{x}(\mathrm{Z})$ & 3.90 & $* *$ & .305 & & .093 & 15.24 \\
\hline
\end{tabular}

MBI DP / MPSSQ.IE / Friend Social Support (Research Question 14b)

MBI DP (Y)

MPSSQ.IE (X) $\quad 2.32 \quad * \quad .186 \quad * \quad \begin{array}{lllll}0 & * & 028 & 5.40 & *\end{array}$

$\begin{array}{llllllll}\text { Friend }(\mathrm{Z}) & -1.75 & \mathrm{~ns} & -.141 & \mathrm{~ns} & .020 & 3.05 & \mathrm{~ns}\end{array}$

$\begin{array}{lllllll}(\mathrm{X}) \mathrm{x}(\mathrm{Z}) & .24 & \mathrm{~ns} & .020 & .000 & .058 & \mathrm{~ns}\end{array}$

MBI PA / MPSSQ.IE / Friend Social Support (Research Question 14c)

\begin{tabular}{lllllllll} 
& MBI PA (Y) \\
& & & & & & & & \\
& MPSSQ.IE (X) & -3.96 & $* *$ & -.310 & $* *$ & .096 & 15.66 & $* *$ \\
& Friend (Z) & 1.10 & $\mathrm{~ns}$ & .090 & $\mathrm{~ns}$ & .008 & 1.21 & $\mathrm{~ns}$ \\
& \\
& $(\mathrm{X}) \mathrm{x}(\mathrm{Z})$ & -1.72 & $\mathrm{~ns}$ & .140 & & .020 & 2.96 & $\mathrm{~ns}$ \\
& & & & & & & & \\
\hline$*$ & $\mathrm{p}<.01$ & & & & & & & \\
$*$ & $\mathrm{p}<.05$ & & & & & & & \\
$\mathrm{~ns}$ & non significant & & & & & & &
\end{tabular}


Moderating Influence of Relatives (Not Yet Specified) Social Support on the Stress-Burnout $\underline{\text { Relationship }}$

Research question "15a" specifically evaluates the extent to which relatives (not yet specified) support, measured by the MSOSQ Relatives (Not Yet Specified) Support subscale, moderates the relationship between stress, as measured by the average intensity of stress score on the MPSSQ (MPSSQ.IE), and burnout as measured by the EE subscale of the MBI. Regression analysis indicated the combination of stress and relatives (not yet specified) social support was significantly related to MBI EE $(\underline{r}=.239, \underline{p}<.01)$. See Table 12 for $t$-values and $\mathrm{r}^{2}$ values. These findings support the moderating effect of Relatives (Not Yet Specified) Support on the Stress (X) - Burnout (Y) relationship.

Research question " $15 b$ " evaluates the extent to which relatives (not yet specified) support, measured by the MSOSQ Relatives (Not Yet Specified) Support subscale, moderates the relationship between stress, as measured by the average intensity of stress score on the MPSSQ (MPSSQ.IE), and burnout as measured by the DP subscale of the MBI. Regression analysis indicated the combination of stress and relatives (not yet specified) social support was not significantly related to MBI DP $(r=.069, \mathrm{p}>.05)$. See Table 12 for $\mathrm{t}$-values and $\mathrm{r}^{2}$ values. These findings do not support the moderating effect of Relatives (Not Yet Specified) Support on the Stress (X) - Burnout (Y) relationship.

Research question "15c" evaluates the extent to which relatives (not yet specified) support, measured by the MSOSQ Relatives (Not Yet Specified) Support subscale, moderates the relationship between stress, as measured by the average intensity of stress score on the MPSSQ (MPSSQ.IE), and burnout as measured by the PA subscale of the MBI. Regression analysis indicated the combination of stress and relatives (not yet specified) social support was not significantly related to MBI PA $(\underline{r}=.101, \underline{p}>.05)$. See Table 12 for $t-v a l u e s$ and $\mathrm{r}^{2}$ values. These findings do not support the moderating effect of Relatives (Not Yet Specified ) Support on the Stress (X) - Burnout (Y) relationship. 
Table 12

Moderating Influence of Relatives (Not Yet Specified) Social Support on the Stress-Burnout $\underline{\text { Relationship }}$

$\begin{array}{lllllll}\mathrm{t} & \text { Sig. } & \underline{\mathrm{r}} & \text { Sig. } & \mathrm{r}^{2} & \mathrm{~F} & \text { Sig. }\end{array}$

MBI EE / MPSSQ.IE / Relative Social Support (Research Question 15a)

\begin{tabular}{|c|c|c|c|c|c|c|}
\hline MPSSQ.IE (X) & 5.89 & $* *$ & .435 & $* *$ & .189 & 34.73 \\
\hline Relative (Z) & .085 & $\mathrm{~ns}$ & .007 & $\mathrm{~ns}$ & .000 & .007 \\
\hline$(\mathrm{X}) \mathrm{x}(\mathrm{Z})$ & 3.01 & $* *$ & .239 & & .057 & 9.04 \\
\hline
\end{tabular}

MBI DP / MPSSQ.IE / Relative Social Support (Research Question 15b)

MBI DP (Y)

$\begin{array}{lccccccc}\text { MPSSQ.IE (X) } & 2.32 & * & .186 & * & .028 & 5.40 & * \\ \text { Relative (Z) } & -.51 & \mathrm{~ns} & -.042 & \mathrm{~ns} & .002 & .26 & \mathrm{~ns} \\ \text { (X) x (Z) } & .84 & \mathrm{~ns} & .069 & & .005 & .71 & \mathrm{~ns}\end{array}$

MBI PA / MPSSQ.IE / Relative Social Support (Research Question 15c)

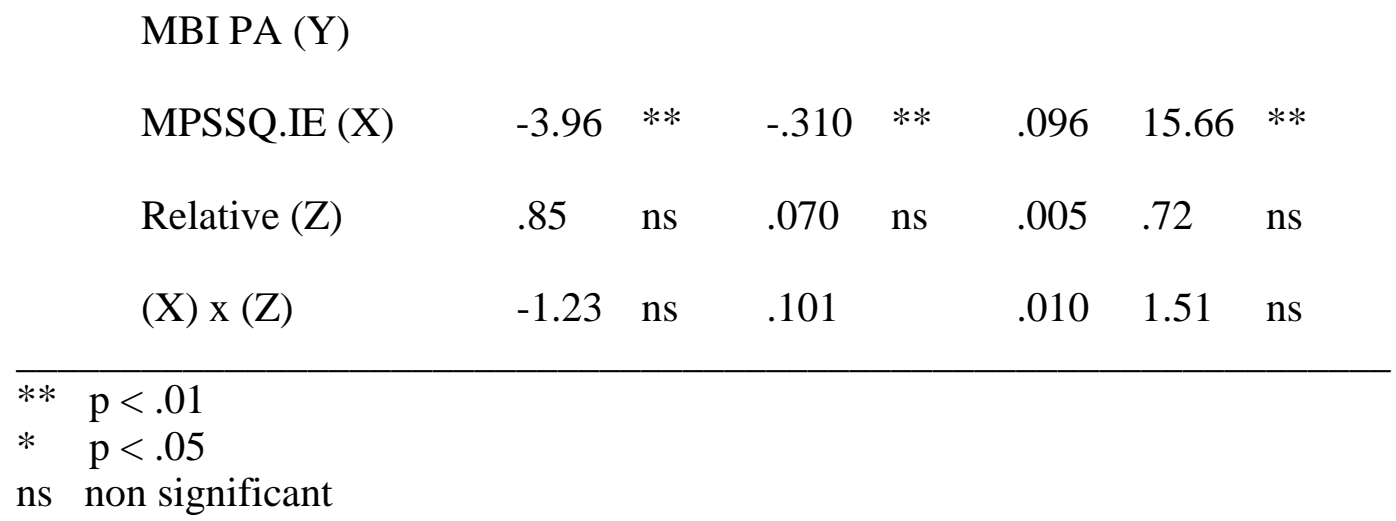


Moderating Influence of Spouse/Significant Other Social Support on the Stress-Burnout Relationship

Research question "16a" specifically evaluates the extent to which spouse/significant other support, measured by the MSOSQ Spouse/Significant Other Support subscale, moderates the relationship between stress, as measured by the average intensity of stress score on the MPSSQ (MPSSQ.IE), and burnout as measured by the EE subscale of the MBI. Regression analysis indicated the combination of stress and spouse/significant other social support was not significantly related to MBI EE $(r=.044, p>.05)$. See Table 13 for $t$-values and $r^{2}$ values. These findings do not support the moderating effect of Spouse/Significant Other Support on the Stress (X) - Burnout (Y) relationship.

Research question " $16 b$ ” evaluates the extent to which spouse/significant other support, measured by the MSOSQ Spouse/Significant Other Support subscale, moderates the relationship between stress, as measured by the average intensity of stress score on the MPSSQ (MPSSQ.IE), and burnout as measured by the DP subscale of the MBI. Regression analysis indicated the combination of stress and spouse/significant other social support was not significantly related to MBI DP $(\underline{r}=.001, \underline{p}>.05)$. See Table 13 for $t$-values and $r^{2}$ values. These findings Spouse/Significant Other Support does not have a moderating effect on the Stress (X) - Burnout (Y) relationship.

Research question "16c" evaluates the extent to which spouse/significant other support, measured by the MSOSQ Spouse/Significant Other Support subscale, moderates the relationship between stress, as measured by the average intensity of stress score on the MPSSQ (MPSSQ.IE), and burnout as measured by the PA subscale of the MBI. Regression analysis indicated the combination of stress and spouse/significant other social support was not significantly related to MBI PA $(\underline{r}=.026, \underline{p}>.05)$. See Table 13 for $t$-values and $r^{2}$ values. These findings do not 
support the moderating effect of Spouse/Significant Other Support on the Stress (X) - Burnout (Y) relationship. 
Table 13

Moderating Influence of Spouse/Significant Other Social Support on the Stress-Burnout $\underline{\text { Relationship }}$

$\begin{array}{lllllll}\mathrm{t} & \text { Sig. } & \underline{\mathrm{r}} & \text { Sig. } & \mathrm{r}^{2} & \mathrm{~F} & \text { Sig. }\end{array}$

MBI EE / MPSSQ.IE / Spouse-Sign. Oth. Social Support (Research Question 16a)

$\begin{array}{lccccccc}\text { MBI EE (Y) } & & & & & & & \\ \text { MPSSQ.IE (X) } & 5.89 & * * & .435 & * * & .189 & 34.73 & * * \\ \text { Spouse/Sig. Oth. (Z) } & -1.53 & \mathrm{~ns} & -.124 & \mathrm{~ns} & .015 & 2.34 & \mathrm{~ns} \\ \text { (X) x (Z) } & .53 & \mathrm{~ns} & .044 & & .002 & .28 & \mathrm{~ns}\end{array}$

MBI DP / MPSSQ.IE / Spouse-Sign. Oth. Social Support (Research Question 16b) MBI DP (Y)

MPSSQ.IE (X) $\quad 2.32 \quad * \quad .186 \quad * \quad \begin{array}{lllll}0 & 028 & 5.40 & *\end{array}$

$\begin{array}{llllllll}\text { Spouse/Sig. Oth. (Z) } & -.91 & \text { ns } & -.074 & \text { ns } & .005 & .826 & \text { ns }\end{array}$

$\begin{array}{lllllll}(\mathrm{X}) \mathrm{x}(\mathrm{Z}) & .01 & \mathrm{~ns} & .001 & .000 & .000 & \mathrm{~ns}\end{array}$

MBI PA / MPSSQ.IE / Spouse-Sign. Oth. Social Support (Research Question 16c) MBI PA (Y)

\begin{tabular}{lccccccc} 
MPSSQ.IE (X) & -3.96 & $* *$ & -.310 & $* *$ & .096 & 15.66 & $* *$ \\
Spouse/Sig. Oth. (Z) & 1.91 & $\mathrm{~ns}$ & .155 & $\mathrm{~ns}$ & .024 & 3.64 & $\mathrm{~ns}$ \\
$(\mathrm{X}) \mathrm{X}(\mathrm{Z})$ & .31 & $\mathrm{~ns}$ & .026 & & .001 & .10 & $\mathrm{~ns}$ \\
\hline$<.01$ & & & & & & & \\
\hline$<.05$ & & & & & & & \\
significant & & & & & & &
\end{tabular}




\section{$\underline{\text { Supplementary Analyses }}$}

Correlational analyses were conducted to determine the relationships between demographic variables and burnout, stress, and social support subscales utilized in this study. Statistically significant relationships observed for age and gender are listed in Table 14. Significant correlations observed for the burnout subscales are listed in Table 15, for the stress subscales in Table 16, and the social support subscales in Tables 17, 18, and 19. Notably, no significant correlations were observed between satisfaction with graduate program and any other variable utilized in this study.

Analysis of Variance (ANOVA) procedures were utilized to determine if Clinical, Counseling, and School Psychology students differed significantly according to any variable utilized in this study. Results suggested statistically significant differences among graduate programs related to the following six variables: 1) degree obtained at the completion of the graduate program $(\mathrm{F}=6.92, \mathrm{p}<.01) ; 2)$ number of hours spent completing assistantship duties $(\mathrm{F}=5.88, \mathrm{p}<.01) ; 3)$ if an individual receives a tuition waiver $(\mathrm{F}=6.92, \mathrm{p}<.01) ; 4)$ level of Emotional Exhaustion (EE) obtained on the Maslach Burnout Inventory $(\mathrm{F}=3.10, \underline{\mathrm{p}}<.05) ; 5)$ Average Intensity of Stress Score (MPSSQ.IE) obtained on the Modified Psychology Student Stress Questionnaire $(F=3.83, \underline{p}<.05)$; and 6) level of Friend Support obtained on the Modified Sources of Support Questionnaire $(F=4.56, p<.05)$. Statistical differences among the aforementioned variables, across type of graduate programs, are reported in Table 20. Signficant F-values were followed up using Scheffe and Student-Newman-Keuls post-hoc tests. Results of post-hoc analyses related to MBI EE, MPSSQ.IE, and Friend Social Support have previously been reported in sections designated as Student Differences Related to Burnout, Stress, and Social Support, respectively. 
Post hoc analyses using the Scheffe test revealed significant differences between groups in terms of degree earned upon the completion of the doctoral program. Significant differences were observed between Clinical Psychology students and Counseling Psychology students ( $\mathrm{p}=$ .036), and Clinical Psychology students and School Psychology students $(\mathrm{p}=.016)$. These results suggest that Clinical Psychology students reported earning a Ph.D. significantly more frequently than did Counseling Psychology or School Psychology students. No other statistically significant differences between graduate programs were observed with regard to degree.

Post hoc analyses using the Scheffe test additionally revealed significant differences between groups in terms of number of hours per week spent completing assistantship duties. Significant differences were observed between Clinical Psychology students and Counseling Psychology students $(\mathrm{p}=.009)$. These results suggest that Clinical Psychology students report significantly fewer numbers of hours per week spent completing assistantship duties than do Counseling Psychology students. No other statistically significant differences between graduate programs were observed with regard to hours spent completing assistantship duties.

Post hoc analyses using the Scheffe test additionally revealed significant differences between groups in terms of whether or not individuals receive tuition waivers. Significant differences were observed between Clinical Psychology students and Counseling Psychology students $(\mathrm{p}=.015)$ and between Clinical Psychology students and School Psychology students ( $\mathrm{p}$ $=.036)$. These results suggest that Clinical Psychology students report receiving tuition waivers significantly less frequently than Counseling Psychology and School Psychology students. No other statistically significant differences between graduate programs were observed with regard to tuition waivers.

Frequency data for type of degree conferred upon completion of the doctoral program 
and whether or not individuals earn tuition waivers are reported in Table 21. Information related to assistantship hours, MBI Emotional Exhaustion levels, MPSSQ Average Intensity of Stress levels, and MSOSQ Friend Social Support levels among clinical, counseling, and school psychology doctoral students are reported using a median-split procedure in Table 22. 
Table 14

Significant Correlations Observed for Age and Gender

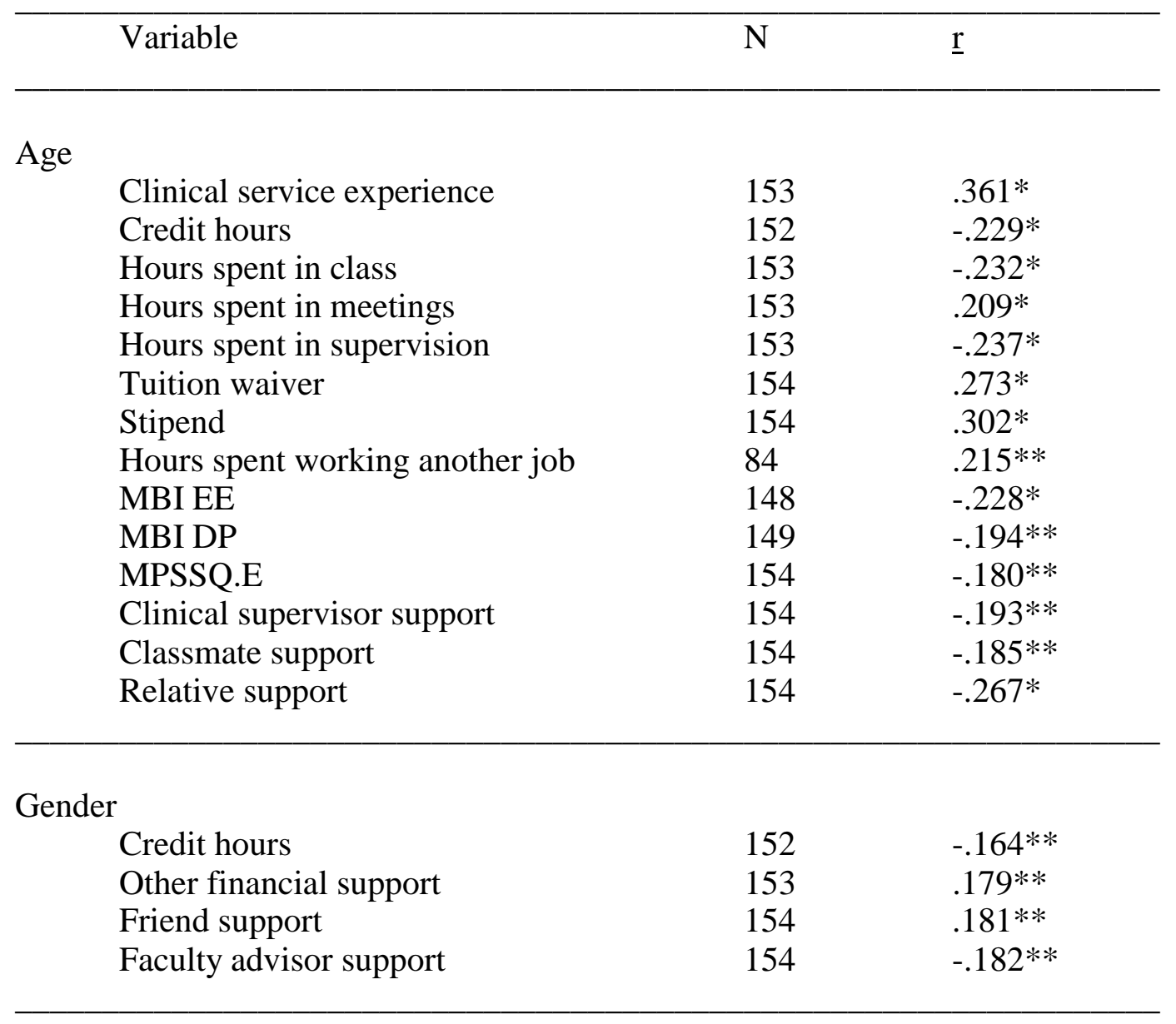

$\begin{array}{ll}* * & \mathrm{p}<.01 \\ * & \mathrm{p}<.05\end{array}$

$* \quad \mathrm{p}<.05$ 
Table 15

$\underline{\text { Significant Correlations Observed for Burnout Subscales }}$

\begin{tabular}{|c|c|c|}
\hline Variable & $\mathrm{N}$ & $\underline{r}$ \\
\hline $\begin{array}{l}\text { MBI Emotional Exhaustion (EE) } \\
\text { Age } \\
\text { Number of children } \\
\text { Credit hours } \\
\text { Hours spent in class } \\
\text { Written comprehensive exams } \\
\text { Stipend } \\
\text { Other financial support } \\
\text { MBI DP } \\
\text { MBI PA } \\
\text { MPSSQ.E } \\
\text { MPSSQ.I } \\
\text { MPSSQ.IE }\end{array}$ & $\begin{array}{l}148 \\
149 \\
149 \\
150 \\
149 \\
150 \\
149 \\
150 \\
148 \\
151 \\
151 \\
151\end{array}$ & $\begin{array}{l}-.228 * \\
-.210 * * \\
.164 * * \\
.179 * * \\
-.194 * * \\
-.236 * \\
-.241^{*} \\
.460 * \\
-.319 * \\
.239 * \\
.393 * \\
.435 *\end{array}$ \\
\hline $\begin{array}{l}\text { MBI Depersonalization (DP) } \\
\text { Age } \\
\text { MBI EE } \\
\text { MBI PA } \\
\text { MPSSQ.IE }\end{array}$ & $\begin{array}{l}149 \\
150 \\
148 \\
152\end{array}$ & $\begin{array}{l}-.194 * * \\
.460 * \\
-.243^{*} \\
.186^{* *}\end{array}$ \\
\hline $\begin{array}{l}\text { MBI Personal Accomplishment (PA) } \\
\text { Number of children } \\
\text { Hours of direct contact with clients } \\
\text { Tuition waiver } \\
\text { Stipend } \\
\text { MBI EE } \\
\text { MBI DP } \\
\text { MPSSQ.I } \\
\text { MPSSQ.IE } \\
\text { Classmate support }\end{array}$ & $\begin{array}{l}147 \\
148 \\
148 \\
148 \\
148 \\
148 \\
149 \\
149 \\
149\end{array}$ & $\begin{array}{l}.220 * \\
.179 * * \\
.204 * * \\
.199 * * \\
-.319 * \\
-.243 * \\
-.244 * \\
-.310 * \\
.177 * *\end{array}$ \\
\hline
\end{tabular}


Table 16

Significant Correlations Observed for Stress Subscales

\begin{tabular}{|c|c|c|c|}
\hline & Variable & $\mathrm{N}$ & $\underline{\mathrm{r}}$ \\
\hline \multicolumn{4}{|c|}{ Event Total (MPSSQ.E) } \\
\hline & Age & 154 & $-.180 * *$ \\
\hline & Credit hours & 157 & $.189 * *$ \\
\hline & Hours spent in class & 158 & $.227 *$ \\
\hline & Hours spent in meetings & 158 & $.193 * *$ \\
\hline & Hours spent traveling to class & 158 & $.218 *$ \\
\hline & Hours spent on schoolwork outside of class & 158 & $.219 *$ \\
\hline & Hours spent in supervision & 158 & $.157 * *$ \\
\hline & Tuition waiver & 158 & $-.158 *$ \\
\hline & Stipend & 158 & $-.159 * *$ \\
\hline & Other financial support & 157 & $-.269 *$ \\
\hline & MBI EE & 151 & $.239 *$ \\
\hline & MPSSQ.I & 159 & $.861 *$ \\
\hline \multicolumn{4}{|c|}{ Intensity of Events (MPSSQ.I) } \\
\hline & Hours spent in class & 158 & $.179 * *$ \\
\hline & Hours spent traveling to class & 158 & $.204 * *$ \\
\hline & Hours spent on schoolwork outside of class & 158 & $.170 * *$ \\
\hline & Other financial support & 157 & $-.239 *$ \\
\hline & Hours spent working at another jobs & 85 & $-.220 * *$ \\
\hline & MBI EE & 151 & $.393 *$ \\
\hline & MBP PA & 149 & $-.244 *$ \\
\hline & MPSSQ.E & 159 & $.861 *$ \\
\hline & MPSSQ.IE & 159 & $.594 *$ \\
\hline & Faculty advisor support & 159 & $-.175 * *$ \\
\hline \multicolumn{4}{|c|}{ Average Intensity of Events (MPSSQ.IE) } \\
\hline & Year in program & 158 & $.160 * *$ \\
\hline & Hours spent on dissertation research & 158 & $.183 * *$ \\
\hline & MBI EE & 151 & $.435^{*}$ \\
\hline & MBI DP & 152 & $.186 * *$ \\
\hline & MBI PA & 149 & $-.310 *$ \\
\hline & MPSSQ.I & 159 & $.594 *$ \\
\hline \multicolumn{4}{|c|}{$* * \quad \mathrm{p}<.01$} \\
\hline
\end{tabular}


Table 17

Significant Correlations Observed for Clinical Supervisor and Faculty Advisor Social Support Subscales

\begin{tabular}{lll}
\hline Variable & $\mathrm{N}$ & $\underline{\mathrm{r}}$ \\
\hline & & \\
Clinical Supervisor Social Support & & \\
& & \\
Age & 154 & $-.193^{* *}$ \\
Year in program & 158 & $.160^{* *}$ \\
Hours spent doing clinical work & 158 & $.180^{* *}$ \\
Hours spent in direct contact with clients & 158 & $.163^{* *}$ \\
Hours spent on schoolwork outside of class & 158 & $-.241^{*}$ \\
Hours spent in supervision & 158 & $.252^{*}$ \\
Classmate support & 159 & $.304^{*}$ \\
Friend support & 159 & $.263^{*}$ \\
Faculty advisor support & 159 & $.323^{*}$ \\
Spouse/Significant other support & 159 & $.223^{*}$ \\
Relative support & 159 & $.220^{*}$ \\
\end{tabular}

Faculty Advisor Social Support

Gender

Year in program

Years to complete program

Hours spent on research other than dissert.

Stipend

MPSSQ.I

Clinical supervisor support

Classmate support

Friend support

Spouse/Significant other support

Relative support

$\begin{array}{ll}154 & -.182^{* *} \\ 158 & -.160^{* *} \\ 154 & -.215^{*} \\ 158 & .176^{* *} \\ 158 & -.226^{*} \\ 159 & -.175^{* *} \\ 159 & .323^{*} \\ 159 & .308^{*} \\ 159 & .286^{*} \\ 159 & .181^{* *} \\ 159 & .286^{*}\end{array}$


Table 18

$\underline{\text { Significant Correlations Observed for Classmate and Friend Social Support Subscales }}$

\begin{tabular}{lll}
\hline Variable & $\mathrm{N}$ & $\underline{\mathrm{r}}$ \\
\hline & & \\
Classmate Social Support & & \\
& & \\
Age & 154 & $-.185^{* *}$ \\
Years to complete program & 154 & $-.200^{* *}$ \\
Assistantship & 158 & $.166^{* *}$ \\
Hours spent in supervision & 158 & $.217^{*}$ \\
Hours spent working at another job & 85 & $-.240^{* *}$ \\
MBI PA & 149 & $.177^{* *}$ \\
Clinical supervisor support & 159 & $.304^{*}$ \\
Friend support & 159 & $.493^{*}$ \\
Faculty advisor support & 159 & $.308^{*}$ \\
Spouse/Significant other support & 159 & $.199^{* *}$ \\
Relative support & 159 & $.334^{*}$ \\
\hline
\end{tabular}

Friend Social Support

Gender

Credit hours

Assistantship

Stipend

Clinical supervisor support

Classmate support

Faculty advisor support

Relative support

$\begin{array}{ll}154 & .181^{* *} \\ 157 & .169^{* *} \\ 158 & .226^{*} \\ 158 & -.168^{* *} \\ 159 & .263^{*} \\ 159 & .493^{*} \\ 159 & .286^{*} \\ 159 & .464^{*}\end{array}$

$\begin{array}{ll}* * & \mathrm{p}<.01 \\ * & \mathrm{p}<.05\end{array}$ 
Table 19

Significant Correlations Observed for Relatives (Not Yet Specified) and Spouse/Significant Other Social Support Subscales

\begin{tabular}{lll}
\hline Variable & $\mathrm{N}$ & $\underline{\mathrm{r}}$ \\
\hline & & \\
Relatives (Not Yet Specified) Social Support & & \\
& & \\
Age & 154 & $-.267^{*}$ \\
Number of children & 157 & $.196^{* *}$ \\
Years to complete program & 154 & $-.174^{* *}$ \\
Credit hours & 157 & $.159^{*}$ \\
Stipend & 158 & $-.159^{*}$ \\
Clinical supervisor support & 159 & $.220^{*}$ \\
Classmate support & 159 & $.334^{*}$ \\
Friend support & 159 & $.464^{*}$ \\
Faculty advisor support & 159 & $.286^{*}$ \\
\end{tabular}

Spouse/Significant Other Social Support

Tuition waiver

Clinical supervisor support

Faculty advisor support

$\begin{array}{ll}158 & .194^{* *} \\ 159 & .223^{*} \\ 159 & .181^{* *}\end{array}$

$\begin{array}{ll}* * & \mathrm{p}<.01 \\ * & \mathrm{p}<.05\end{array}$ 
Table 20

All Statistically Significant Differences Observed Among Clinical, Counseling, and School Psychology Doctoral Programs

\begin{tabular}{|c|c|c|c|c|c|}
\hline Variable & $\begin{array}{l}\text { Sum of } \\
\text { Squares }\end{array}$ & df & $\begin{array}{l}\text { Mean } \\
\text { Square }\end{array}$ & $\mathrm{F}$ & Sig. \\
\hline \multicolumn{6}{|l|}{ Degree } \\
\hline Between Groups & 3.16 & 2 & 1.58 & \multirow{3}{*}{6.92} & \multirow{3}{*}{.001} \\
\hline Within Groups & 33.37 & 146 & .23 & & \\
\hline Total & 36.53 & 148 & & & \\
\hline \multicolumn{6}{|l|}{ Assistantship } \\
\hline Between Groups & 396.18 & 2 & 198.09 & \multirow[t]{3}{*}{5.88} & \multirow[t]{3}{*}{.004} \\
\hline Within Groups & 4922.66 & 146 & 33.72 & & \\
\hline Total & 5318.83 & 148 & & & \\
\hline \multicolumn{6}{|l|}{ Tuition Waiver } \\
\hline Between Groups & 2.65 & 2 & 1.32 & \multirow[t]{3}{*}{6.92} & \multirow[t]{3}{*}{.001} \\
\hline Within Groups & 27.94 & 146 & .19 & & \\
\hline Total & 30.59 & 148 & & & \\
\hline \multicolumn{6}{|c|}{ MBI Emotional Exhaustion (EE) } \\
\hline Between Groups & 636.17 & 2 & 318.09 & \multirow[t]{3}{*}{3.10} & \multirow[t]{3}{*}{.048} \\
\hline Within Groups & 14377.90 & 140 & 102.70 & & \\
\hline Total & 15014.07 & 142 & & & \\
\hline \multicolumn{6}{|c|}{ MPSSQ Average Intensity of Stress (MPSSQ.IE) } \\
\hline Between Groups & 4.97 & 2 & 2.49 & \multirow[t]{3}{*}{3.83} & \multirow[t]{3}{*}{.024} \\
\hline Within Groups & 95.39 & 147 & .65 & & \\
\hline Total & 100.36 & 149 & & & \\
\hline \multicolumn{6}{|l|}{ Friend Social Support } \\
\hline Between Groups & 1122.62 & 2 & 561.31 & \multirow[t]{3}{*}{4.56} & \multirow{3}{*}{.012} \\
\hline Within Groups & 18078.72 & 147 & 122.98 & & \\
\hline Total & 19201.33 & 149 & & & \\
\hline
\end{tabular}


Table 21

Frequency Data for Degree and Tuition Waiver Among Clinical, Counseling, and School Psychology Students

\begin{tabular}{llll}
\hline Variable & Clinical Psych. & Counseling Psych. & School Psych. \\
& Students & Students & Students
\end{tabular}

Degree Anticipated Upon Completion of Program

$\begin{array}{llll}\text { Ed.D. } & 1 & 0 & 1\end{array}$

$\begin{array}{lll}\text { Ph.D. } & 70 & 15\end{array}$

$\begin{array}{llll}\text { Psy.D. } & 48 & 1 & 1\end{array}$

Receive Tuition Waivers

\begin{tabular}{llll} 
Yes & 26 & 9 & 8 \\
No & 92 & 7 & 7 \\
& & \\
\hline
\end{tabular}


Table 22

Evaluation of Assistantship Hours, MBI Emotional Exhaustion, MPSSQ Average Intensity of Stress, and MSOSQ Friend Social Support Among Clinical, Counseling, and School Psychology Doctoral Students Using A Median-Split Procedure

\begin{tabular}{|c|c|c|c|}
\hline Variable & Median & $\begin{array}{l}\text { Number of } \\
\text { Scores }\end{array}$ & $\begin{array}{l}\text { Number of } \\
\text { Scores }\end{array}$ \\
\hline Variable & Ivieuran & r ivedian & $>$ iviearan \\
\hline
\end{tabular}

Hours Per Week Spent

Completing Assistantship

Obligations

9.00

Clinical Psychology

108

10

Counseling Psychology

10

6

School Psychology

12

3

MBI Emotional Exhaustion

22.00

Clinical Psychology

$55 \quad 57$

Counseling Psychology

7

School Psychology

12

9

3

MPSSQ Ave. Intensity of Stress

3.53

Clinical Psychology

57

8

62

Counseling Psychology

School Psychology

11

8

4

MSOSQ Friend Social Support

36.00

Clinical Psychology

49

70

Counseling Psychology

School Psychology

4

8

12

7 


\section{Chapter V}

\section{Discussion}

\section{Overview}

Burnout can develop when individuals encounter chronic exposure to stress in conjunction with perceptions that resources to alleviate the stress are inadequate (Maslach et al., 1996). Burnout among human service professionals has received significant attention in the literature (Leiter \& Harvie, 1996; Lubin et al., 1992). These individuals are particularly susceptible to burnout due to their tendency to perform long term "others oriented" work under conditions of consistent stress. One area of the burnout literature has focused on the influence of stress on the development of burnout symptoms. Generally a positive relationship has been observed between stress and burnout (Koeske \& Koeske, 1993; Maslach et al., 1996; Perlman \& Hartman, 1982; Richardsen \& Burke, 1995). The impact of social support on the stress-burnout relationship has also been highlighted in the literature, but with mixed results (Cohen \& Wills, 1985; Constable \& Russell, 1986; Etzion, 1984; Russell et al., 1987).

Graduate students in psychology face many of the challenges encountered by established professionals in the field of psychology (i.e., challenging caseload, large percentage of direct client contact hours, lack of support from institutional administrators). Graduate students are additionally challenged to meet a number of demands unique to the graduate school experience (i.e., completing class assignments and examinations, passing comprehensive examinations, completing a dissertation, attaining and completing a pre doctoral internship, and meeting assistantship demands). While research on graduate students has acknowledged the difficulties associated with attempts to manage multiple roles (Polson \& Nida, 1998; Mallinckrodt \& Leong, 1992), the experience of burnout has been studied infrequently within this population, despite the 
obvious academic, financial, social, and emotional demands inherent in graduate education in psychology. More specifically, the research on burnout among graduate students in psychology has not addressed the specific relationships between burnout, stress, and social support. As a result, the current study utilized the Moderator Model proposed by Baron \& Kenny (1986) to evaluate the relationships between burnout, stress, and social support among doctoral students in psychology.

The current study provides a description of burnout, stress, and social support experienced by graduate student members of the American Psychological Association enrolled in Clinical, Counseling, and School Psychology doctoral programs. Results provide strong evidence in support of the direct influence of stress on burnout. Minimal evidence was observed to support the direct influence of social support on burnout. Limited support for the moderating influence of social support on the stress - burnout relationship was observed. More comprehensive discussion of each of these findings, as well as information obtained through supplementary analyses, will be discussed and related to past research. Practice implications related to burnout will be presented. Limitations encountered throughout this study will also be discussed. Finally, suggestions for future research related to the evaluation of burnout, stress, and social support among doctoral students in psychology will be discussed.

\section{Discussion of Student Differences Related to Burnout}

No significant differences were observed among Clinical, Counseling, and School Psychology students with regard to burnout when overall burnout level, and overall Depersonalization, and Personal Accomplishment levels were considered. Results did suggest a significant difference among students enrolled in Clinical, Counseling, and School psychology 
programs in terms of Emotional Exhaustion. However, post hoc analyses did not suggest meaningful differences between these groups.

Although no direct comparisons can be made between burnout levels obtained in this study and other studies involving doctoral students in psychology, the burnout subscale scores of each type of program in psychology can be evaluated in terms of how each of these scores compare to those obtained from a sample of mental health professionals described by Maslach et al. (1996). According to the researchers, experienced burnout among mental health professionals can be classified in terms of a range of burnout, which includes "Low", "Moderate", and "High" burnout categories (see Appendix H). Utilizing the categorization method described by Maslach et al. (1996) to classify burnout levels, it appears that the overall sample utilized in this study falls in the "High" range on the Emotional Exhaustion subscale, the "Moderate" range on the Depersonalization subscale, and the "Low" range on the Personal Accomplishment subscale. These findings suggest that burnout is most significantly described or defined by feelings of emotional fatigue for this group.

Looking at the current sample and evaluating graduate programs separately, the Clinical and Counseling Psychology student samples utilized in this study fall within the "High" range of experienced burnout, as measured by the Emotional Exhaustion subscale of the Maslach Burnout Inventory (MBI). School Psychology students, as a group, fell within the "Moderate" range of experienced burnout. Results associated with the Emotional Exhaustion subscale, which includes items such as "I feel emotionally drained from my work," suggest that the majority of the student sample was experiencing a significant amount of emotional fatigue at the time of the study. In terms of the Depersonalization subscale, which includes items such as "I feel I treat some recipients as if they were impersonal objects," results suggest that all groups fell within the 
"Low" to "Moderate" range of experienced burnout. These results suggest that each group was experiencing some feelings of detachment from their work at the time of the study, but that these feelings were manageable. Finally, evaluation of the Personal Accomplishment subscale, which includes items such as "I feel I'm positively influencing other people's lives through my work", suggested that Clinical, Counseling, and School Psychology student groups all fell within the "Low" range of experienced burnout. These results suggest that despite the demands inherent in doctoral programs in psychology, students generally report feelings of success related to their overall graduate school experience.

Results from the current study can be indirectly compared to those obtained by the one study of burnout conducted using doctoral students in psychology as subjects (Kahill, 1986). "New" and "experienced" psychology practitioners were additionally used as subjects. Burnout was measured using the Tedium Burnout Measure. Results suggested that the overall burnout level of the sample fell in the low-moderate range. No differences were observed among doctoral students, "new" practitioners, and "experienced" practitioners with regard to burnout. Because the Maslach Burnout Inventory was not utilized to measure burnout, no direct comparisons between burnout levels obtained in the current study can be made to those reported by Kahill (1986). However, it is important to highlight that results reported by Kahill (1986) suggest that student practitioners are similar in their report of burnout to more experienced practitioners in the field of psychology.

Results from the current study can be directly compared to those obtained by Ackerley et al. (1988) in their sample of doctoral level psychologists, however. Data from this study was analyzed using the classification system of burnout originally developed by Maslach and Jackson (1986). According to Ackerley et al. (1988), 72\% of their sample of licensed psychologists were 
classified as "Moderate" or "High" on the Emotional Exhaustion subscale, $41 \%$ of the respondents were classified in the "Low" burnout category with regard to the Depersonalization subscale, and $96 \%$ of the respondents were classified in the "Low" burnout category of the Personal Accomplishment subscale. It appears, therefore, that doctoral level students in Clinical, Counseling, and School Psychology programs are similar in their experience of burnout to doctoral level psychologists, as described by Ackerley et al. (1988).

\section{Discussion of Student Differences Related to Stress}

No significant differences among psychology doctoral students in Clinical, Counseling, and School Psychology programs were observed in terms of overall stress levels, total number of stressful events, or total intensity of stressful events. Significant differences between doctoral students in psychology were observed with regard to Average Intensity of Stress scores, however. Post hoc analyses suggested that Clinical Psychology students reported higher average intensity of stress than did School Psychology or Counseling Psychology students. No other statistically significant differences between graduate programs were observed with regard to stress level. Comparisons of stress levels across graduate programs were also made by Hodgson and Simoni (1995) in their evaluation of 566 doctoral students enrolled in humanities, social sciences, life sciences, and physical science programs. In contrast to the current findings, Hodgson and Simoni (1995) reported no differences between the fields of study with regard to scores obtained on two measures of psychological distress, the Graduate Life Events Scale and the Graduate Student Stress Survey. Based on the results of these two studies, it appears that graduate students, in general, share some similar stress related experiences, regardless of graduate program of study. However, it also appears that differences related to perceptions of stress exist specifically among graduate programs in psychology. 
While it is not the purpose of this study to identify specifically why differences related to reported stress were observed between groups of psychology doctoral students, two hypotheses are offered. First, it is hypothesized that stress differences between programs observed in the current study may be related to variations in program training model foci. Stereotypically, Clinical Psychology programs follow a medical training model, while Counseling and School Psychology programs follow an educational training model. Perhaps more stress is perceived in programs which follow a pathology and outcome based model, rather than a model which promotes health and emphasizes process. Second, reports of stress may be influenced by the type of environments in which individuals seek practical opportunities during their graduate education. Again, viewing graduate programs in stereotypical terms, Clinical Psychology students often choose hospitals to do clinical work, and work with chronically mentally ill individuals more frequently than do Counseling and School Psychology students who stereotypically work with higher functioning individuals, frequently in counseling centers and schools.

$\underline{\text { Discussion of Student Differences Related to Social Support }}$

No significant differences were observed among doctoral students enrolled in Clinical, Counseling, and School Psychology doctoral programs in terms of their reports of classmate support, clinical supervisor support, faculty advisor support, spouse/significant other support, and relative not yet specified support. Significant differences among doctoral students in psychology were observed only in terms of friend social support. Post hoc analyses revealed that Counseling Psychology students reported significantly more friend social support than did Clinical Psychology students. No other statistically significant differences between graduate programs were observed with regard to social support. No hypotheses related to why Counseling 
Psychology students would report statistically greater social support obtained from friends than Clinical Psychology students are readily apparent. As a result, no hypotheses are offered.

No direct comparisons can be made regarding the results of the current study and other research which has assessed sources of support reported across related groups. The most closely related research involves comparisons of reported social support across graduate programs made by Hodgson and Simoni (1995) in their study of 566 doctoral students enrolled in humanities, social sciences, life sciences, and physical science programs. However, sources of support were not evaluated by Hodgson and Simoni (1995) as they were in the current study. Rather, the researchers assessed levels of reported social support across graduate programs. Life Sciences students reported the highest levels of social support, followed by Humanities and Physical Science students. Because only limited information is available related to how various graduate programs are similar to and different from each other in terms of their report of social support, it appears that program differences related to social support, specifically among doctoral students in psychology, is an area which should be addressed in future research.

Discussion of the Direct Influence of Stress on Burnout

According to the Moderator Model (Baron \& Kenny, 1986), stress has a direct influence on burnout when stress and burnout are significantly related to each other. Results of this study suggest that stress had a direct influence on all subscales of burnout, such that as stress levels increase, reports of emotional fatigue and detachment from individuals with whom one works increase, and perceptions that one is doing work that is worthwhile decrease. This finding is important because at the individual level, as stress is sustained over time, doctoral students in psychology may experience negative physical and emotional consequences such as sleep disturbances, weight changes, depression, and difficulties establishing a professional identity. At 
the organizational level, responses to chronic stress may be evidenced in doctoral students in psychology in terms of increased absenteeism from class or work, poor task commitment, and/or a desire to quit one's doctoral program in psychology prior to completion. Perhaps most importantly, at the service level, the current findings suggest that chronic stress could negatively influence the quality of care doctoral students in psychology provide to care recipients.

No previous studies have assessed the direct influence of stress on burnout among doctoral students in psychology. However, support for the direct influence of stress on burnout was reported for doctoral level counseling center staff members (Ross et al., 1989), undergraduate research assistants (Nowack et al., 1985), clinical psychology and nursing staff members (Corrigan et al., 1995), charge nurses and nursing assistants (Ray \& Miller, 1994), nursing home staff members (Northrup, 1996), and human service workers (Etzion, 1984; Shinn, 1984).

\section{Discussion of the Direct Influence of Social Support on Burnout}

According to the Moderator Model (Baron \& Kenny, 1986), social support has a direct influence on burnout when social support and burnout are significantly related to each other. The literature generally suggests a negative relationship between perceived social support and burnout (Corrigan et al., 1995; Etzion, 1984; Huebner, 1994; Kahill, 1986; Northrup, 1996; Nowack et al., 1985; Ross et al., 1989). In other words, as perceptions of social support increase, burnout symptoms tend to decrease. In the case of the current study, however, limited evidence was observed to support the direct influence of social support on burnout. Only Classmate Social Support had a direct influence on the Personal Accomplishment subscale of burnout, such that support from peers/classmates assists students in recognizing value in their work. No other social support subscale had a direct influence on any subscale of burnout. 
The aforementioned results differ from those reported by a number of researchers (Huebner, 1994; Kahill, 1986; Northrup, 1996; Ross et al., 1989). Huebner (1994) suggested that emotional fatigue was significantly and positively influenced by the support of friends, while detachment from work related activities decreased and a sense that one's work is worthwhile increased with support obtained from a supervisor. Kahill (1986) reported that burnout among doctoral students in psychology decreased as social support obtained from friends and family increased. Northrup (1996) found supervisor, coworker, spouse/significant other, and family/friend support all to be significantly correlated with each subscale of the Maslach Burnout Inventory, such that each of the aforementioned sources of social support assisted participants in feeling less emotionally exhausted, less detached from their work, and more like their work was worthwhile. Ross et al. (1989) reported direct effects of supervisor support on the Depersonalization and Personal Accomplishment subscales of the Maslach Burnout Inventory.

It is unclear why the impact of social support on burnout was so limited among the current sample. Perhaps it is because doctoral study in psychology requires students to focus significant time and attention on personal tasks, and on accomplishing personal goals, which may contribute to students having and making less frequent opportunity for quality contact with potential sources of support. Or, perhaps the multiple roles of doctoral students make it difficult for sources of support to offer social support across student roles, which is consistent, and of sufficient magnitude, to be reflected in the current results.

Whatever the reason social support had little direct effect on burnout, the current findings are important because they highlight that support obtained from clinical supervisors, faculty advisors, friends, relatives, and significant others does not appear to effectively alleviate the development of burnout symptoms among the current sample of doctoral students in psychology. 
These results emphasize the need to find appropriate ways to support graduate students in psychology as they progress through their graduate programs.

\section{$\underline{\text { Discussion of Social Support as Moderator of Stress and Burnout }}$}

According to Baron and Kenny (1986), social support moderates the stress - burnout relationship if social support, when regressed in combination with stress on burnout, produces a significant effect. Evidence of the moderating effect of social support on the stress - burnout relationship was observed in five of 18 relationships evaluated in this study. The moderating effect of social support was most evident with regard to its impact on the stress - Emotional Exhaustion subscale relationship. Classmate, faculty advisor, friend, and relative social support all moderated the stress - Emotional Exhaustion relationship. These results suggest that doctoral student experiences of emotional fatigue can be positively influenced when they perceive support from classmates, faculty advisors, friends, or relatives. Clinical supervisor support modified the stress - Personal Accomplishment subscale relationship, suggesting that doctoral student perceptions of personal success related to their graduate studies are positively influenced by support offered by clinical supervisors. These results support the moderating effect of social support on the stress - burnout relationship. No other combination of stress and social support moderated any stress - burnout relationship in the current study. Northrup (1996) also found supervisor support modified the stress - Personal Accomplishment subscale relationship. In contrast to the current findings, however, she observed no other moderating effects of social support on any other stress-burnout relationship, and Ross et al. (1989) reported no moderating effect of any source of social support (i.e., supervisor, coworker, spouse, friends/relatives) on any Maslach Burnout Inventory subscale. 
The aforementioned results of the current study, in combination with evidence that Classmate Support had a direct effect on the Personal Accomplishment subscale of the Maslach Burnout Inventory, support previous research which suggests that social support can have both direct and moderating effects on negative outcomes resulting from stress (Constable \& Russell, 1986; Etzion, 1984; Northrup, 1996; Russell et al., 1987). However, it appears that the current results suggest stronger support for the moderating or buffering effect of social support. These results appear to be in direct contrast to those reported by Northrup (1996) and Ross et al. (1989) who reported the direct effect of social support was more influential than the moderating effect of social support on the stress-burnout relationship. Applying information provided by Cohen and Wills (1985), the current results specifically suggest that social support is most effective for doctoral students in psychology who report high levels of stress. Social support appears to be less effective for students who are less stressed and seek social support primarily as a means to enhance their general well-being. In general, however, it appears that the influence of social support, whether direct and/or buffering in nature, is unique to the population being assessed.

\section{$\underline{\text { Additional Findings }}$}

Clinical, Counseling, and School Psychology students were observed to differ significantly with regard to Maslach Burnout Inventory Emotional Exhaustion, Modified Psychology Student Average of Intensity Stress, and Modified Sources of Support Questionnaire Friend Social Support. These differences have been discussed previously in this chapter. Students from Clinical, Counseling, and School Psychology programs also differed with regard to the following three variables: degree earned upon the completion of the doctoral program, number of hours spent completing assistantship duties, and whether or not students receive tuition waivers. 
Post hoc analyses suggested that Clinical Psychology students reported earning a Ph.D. significantly more frequently than did Counseling Psychology or School Psychology students. Results also suggested that Clinical Psychology students reported significantly fewer hours per week spent completing assistantship duties than did Counseling Psychology students, and that Clinical Psychology students reported receiving tuition waivers significantly less frequently than both Counseling Psychology and School Psychology students. These results should be interpreted with caution, however, due to large differences related to sample size within the Clinical $(n=118)$, Counseling $(n=16)$, and School Psychology $(n=14)$ student groups.

With regard to the relationship between demographic variables and burnout, stress, and social support, a number of significant relationships were observed in the current study. These results should also be interpreted with caution, however, as past research which addressed relationships between demographic variables and variables such as burnout (Corrigan et al., 1995; Jupp \& Shaul, 1991; Kahill, 1986; Maslach, 1982) have frequently produced contradictory results.

With regard to age, the most significant correlations observed in the current study suggested that as age increased, clinical service experience also increased. Similar to results reported by Huebner (1994) and Corrigan et al. (1995), results of the current study suggested that age was negatively related to Maslach Burnout Inventory Emotional Exhaustion and Depersonalization scores, suggesting that as individuals get older they experience less emotional fatigue associated with their work, and additionally report feeling less detached from the individuals to whom they provide service. With regard to the relationship between age and social support observed in the current study, older students reported less reliance upon external sources of support (i.e., clinical supervisor, classmate, and relatives) than did younger students. 
Based on the results of the current study, it appears that as individuals get older and gain more experience in the field, they may learn more adaptive ways to deal with the stresses and strains associated with graduate study in psychology. Methods of coping are likely to be more internally focused, and less dependent upon others than coping strategies utilized by younger, less experienced individuals.

Gender differences were also evaluated in the current study. No gender differences related to burnout were observed in the current study, results similar to a number of additional studies (Ackerley et al., 1988; Jupp \& Shaul, 1991; Kahill, 1986). In contrast, however, Maslach (1982) suggested women experience greater Emotional Exhaustion than men, and men are more likely to experience Depersonalization. Corrigan et al. (1995) reported women scored significantly higher on Personal Accomplishment than did men. Gender differences were observed in the current study with regard to sources of support. Women were more likely to report higher levels of friend support, while men were more likely to report higher levels of faculty advisor support. These results are somewhat consistent with results reported by Mallinckrodt and Leong (1992) who suggested that women perceive more support from familial rather than academic sources, and men perceive support from familial and academic sources. The effectiveness of sources of social support in moderating the stress-burnout relationship have also been discussed in the literature specifically with regard to gender. According to Etzion (1984), family and friend support was most influential in moderating the stress-burnout relationship for women, and supervisor and coworker support were more influential for men. With regard to gender differences related to stress, no gender differences were observed during the current study with regard to reported levels of stress. These results are similar to those reported by Hudson and O'Regan (1994) in their study of students from the Minnesota School of 
Professional Psychology, which suggest that men and women doctoral students in psychology report similar experiences of stress. In contrast, however, several studies have suggested that female graduate students scored significantly higher on measures of stress than did males (Cahir \& Morris, 1991; Hodgson \& Simoni, 1995; Mallinckrodt \& Leong, 1992).

Several additional findings are reported specifically with regard to stress. Results suggest a negative relationship between both emotional fatigue and reports of financial support, and stress levels and reports of financial support. These results suggest that individuals who lack financial support during their graduate studies are more likely to experience emotional exhaustion and perceive themselves to be stressed, than individuals who perceive themselves to have adequate financial support. These results highlight the impact of the financial strain experienced by a number of graduate students in psychology. As stated earlier, analysis of data on cumulative debt related to graduate education in psychology suggested that $67 \%$ of all 1996 doctoral recipients in the field of psychology reported debt as a result of their graduate education. Of those who reported debt, more that half reported debt of at least \$21,000 (APA, 1996). Additionally with regard to stress, it appears that, in general, the more hours individuals spend completing school related activities (i.e., hours spent in class, hours spent in meetings), the higher their reported stress levels.

Several additional findings are reported with regard to social support. Results of the current study suggest that perceptions of low faculty advisor, classmate, and relative support are significantly related to greater length of time needed to complete the graduate program. Interesting, no type of social support was significantly related to completing a graduate program in psychology in a more timely fashion. Additionally, perceptions of faculty advisor support decreased as students progressed through their programs. Perhaps more experienced students did 
not seek out faculty advisors for assistance as readily as they may have earlier in their program of study. Likewise, faculty advisors may focus their contact and support more frequently toward new students. Likely it is the combination of more experienced students wishing to have increased freedom and autonomy, and faculty advisors efforts to encourage them to become more autonomous. Not surprisingly, perceptions of clinical supervisor support increased with increased hours spent in supervision. Classmate support was positively related to an increased sense that one's work is worthwhile, but negatively related to hours spent working at another job. These results suggest that doctoral student perceptions of support are related to the amount of time spent with specific sources of support. Likely perceptions of support are highest when contact with sources of support is both consistent and frequent.

\section{Summary of Findings}

Clinical, Counseling, and School Psychology doctoral students are similar in their reports of burnout. These individuals, as a group, reported relatively high levels of emotional fatigue, some detachment from those to whom they provide service, and an adequate sense that the work that they perform is worthwhile and helpful to others. While the student sample was generally similar in their report of stress, Clinical Psychology students reported the average intensity of stressful events as higher than Counseling or School Psychology students. Students were similar in their report of sources of social support, they differed significantly only with regard to Friend Social Support. Counseling Psychology students reported significantly more Friend Social Support than did Clinical or School Psychology students. The direct influence of stress on burnout was supported. Minimal support was observed for the direct influence of social support on burnout. Only support from classmates was significantly related to any component of burnout, such that as Classmate Social Support increases, one's sense that one's work is 
worthwhile increases. Finally, limited support was observed for the moderating or buffering effect of social support on the stress-burnout relationship. Doctoral student reports of emotional fatigue decreased with support from classmates, faculty advisors, friends, and relatives. Doctoral student perceptions of accomplishment associated with their doctoral program were positively influenced by the support of clinical supervisors.

\section{$\underline{\text { Implications for Practice }}$}

According to Wood et al. (1985), only half of the psychologist respondents who acknowledged that symptoms of depression or burnout had influenced their work had ever sought psychological assistance for themselves. Denial is a critical characteristic of burnout (Freudenberger, 1985). Often people who experience burnout think their feelings of exhaustion will go away on their own, or think burnout will not happen to them. As denial persists, individuals may come to feel as though they are truly stronger than others. They may additionally become less objective regarding themselves and their own feelings. Frequent denial of conflict and physical, mental, and emotional exhaustion contribute to the development of burnout (Freudenberger, 1985). Persons in the health care professions, including doctoral students in psychology, are particularly susceptible to such denial since their "focus is directed outward, toward other people and their problems", leaving less time to focus on themselves (Maslach, 1982, p. 132). As a result, it appears to be particularly important for doctoral students in psychology, who may have an exaggerated sense of what their bodies can withstand, to listen to others when they detect the early signs of burnout, and to accept their concern as a sign of support (Maslach, 1982). This appears to be particularly important given the results of the current study which suggest that psychology graduate students experiences of burnout are quantitatively and qualitatively similar to psychologists' experience of burnout, as described by 
Ackerley et al. (1988) and Kahill (1986). These results additionally highlight the fact that burnout among doctoral students is both significant and concerning.

The American Psychological Association has attempted to protect care recipients, coworkers, third party payment sources, student trainees, practitioners, and the profession of psychology from the potential harm resulting from distressed, impaired and burned out helping professionals through the development and enforcement of its Code of Ethics (American Psychological Association, 1992). Even though psychological burnout is not specifically addressed in the Code of Ethics, therapists who practice incompetently while experiencing psychological burnout may have sanctions brought against them by the American Psychological Association. According to the 1992 edition of the Ethical Principles of Psychologists, "Because psychologists' scientific and professional judgments and actions may affect the lives of others, they are alert to and guard against personal, social, organizational, or political factors which might lead to the misuse of their influence" (American Psychological Association, 1992, Section $1.15)$.

Psychologists and psychologist trainees, therefore, are held accountable for their actions with care recipients at all times. Personal difficulties or impairment, including psychological burnout, do not excuse helping professionals from maintaining the highest standard of care possible for their care recipients (Skorupa \& Agresti, 1993; Stadler et al., 1988). As emphasized by Frame and Stevens-Smith (1995), and specifically according to the ethics code, psychologists and psychologist trainees must "recognize that their personal problems and conflicts may interfere with their effectiveness. Accordingly, they refrain from undertaking an activity when they know or should know that their personal problems are likely to lead to harm to a patient, client, colleague, student, research participant, or other person to whom they may owe a 
professional or scientific obligation...In addition, psychologists have an obligation to be alert to signs of, and to obtain assistance for, their personal problems at an early stage, in order to prevent significantly impaired performance... When psychologists become aware of personal problems that may interfere with their performing work-related duties adequately, they take measures, such as obtaining professional consultation or assistance, and determine whether they should limit, suspend, or terminate their work-related duties" (American Psychological Association, 1992, Section 1.13). It appears, therefore, that continued therapeutic practice, despite psychological burnout, may be in violation of this standard of the ethics code when there is a high potential for incompetent service.

Financial strain experienced during doctoral education in psychology also has implications for practice within the field of psychology. Results of the current study suggest that tuition waivers and stipends were received by approximately one-third of the sample. Financial aid, most frequently student loans, was reported by over half of the current sample. Jobs, not including school related assistantships, were held by over half of the sample, and students reported working an average of approximately 20 hours per week on these jobs. Despite these efforts to alleviate financial strain, the majority of doctoral students in psychology report significant financial debt as a result of their graduate study in psychology (APA, 1996). Results of the current study additionally suggest a negative relationship between reported stress levels and financial support, such that students who perceive themselves to have greater financial strain report higher stress levels. These results support the findings of Hodgson and Simoni (1995) which suggested that doctoral student stress increased as financial problems increased. As a result, it appears that efforts to make graduate study in psychology more affordable will help graduate programs in psychology continue to attract quality students to their programs. 
Finally, while social support has frequently been observed to have a positive impact on the development of burnout symptoms (Corrigan et al., 1995; Etzion, 1984; Huebner, 1994; Kahill, 1986; Northrup, 1996; Nowack et al., 1985), results of this study suggested that only social support received from friends was directly beneficial in limiting the development of burnout symptoms among doctoral students in psychology. Results further suggest limited but stronger support for the moderating or buffering effect of social support on the stress-burnout relationship. These findings suggest that social support is most effective for doctoral students in psychology who report high levels of stress. Social support is less effective for students who are less stressed and seek social support primarily as a means to enhance their general well-being. As a result, while friend support may be difficult to incorporate into training programs in psychology, it appears that individuals involved in training programs in psychology (i.e., training directors, professors) could assist students by attempting to: 1) identify students experiencing particularly high levels of stress; 2) provide increased social support contact to students experiencing high levels of stress, across a variety of sources (i.e., clinical supervisor, faculty advisor, classmate); 3) educate all students regarding the signs and symptoms of burnout; 4) make treatment of burnout related symptoms a viable and acceptable option for students (i.e., affordable, accessible); 5) encourage students to seek assistance from a variety of sources of support should they begin to develop burnout related symptoms; and 6) encourage students to develop and maintain healthy living behaviors during the course of their graduate study.

\section{Limitations of the Study}

Several limitations should be considered when assessing the utility of the data obtained from the present study. These limitations are related to measurement, sampling, and methodology. 


\section{Measures}

Each of the measures utilized in this study was modified in an effort to most accurately measure burnout, stress, and social support among doctoral students in psychology. Despite these modifications, all subscale and total scores associated with each measure utilized in this study exhibited satisfactory internal consistency, with two exceptions. The Cronbach alpha coefficient did not suggest satisfactory internal consistency for the Depersonalization subscale or the Personal Accomplishment subscale of the Maslach Burnout Inventory. These Cronbach alpha coefficients were .59 and .75 , respectively. However, these results are consistent with Cronbach alpha coefficients of .86 for Emotional Exhaustion, .62 for Depersonalization, and .72 for Personal Accomplishment reported for a sample of undergraduate and graduate students (Powers \& Gose, 1986). Notably, in the current study the Emotional Exhaustion subscale of the Maslach Burnout Inventory consistently demonstrated the most significant findings. It is unclear, however, whether the findings associated with the Emotional Exhaustion subscale are suggestive of stronger relationships between the Emotional Exhaustion subscale and variables evaluated in the current study, or if more significant results for the Depersonalizaton and Personal Accomplishment subscales may have been masked due to their low alpha levels.

The utility of the social support measure utilized in this study is limited because several respondents did not complete the second page of the Modified Sources of Support Questionnaire (MSOSQ). Although it was written "Continue on other side" at the bottom of the first page of the MSOSQ, several respondents completed only the first side. As a result, these individuals did not provide a complete picture of their social support network. The utility of the MSOSQ is additionally limited by difficulty associated with defining the construct of social support, a difficulty which has been documented throughout the literature (Sarason et al., 1987; Tardy, 
1985), and which when combined with use of only one measure of social support, makes it difficult to know if social support was the construct actually measured by the MSOSQ. These difficulties are viewed as limitations of the current study.

The Demographic Questionnaire for Doctoral Students in Psychology appeared to lack distinctiveness within categories eliciting information regarding how many hours per week students spend completing specific activities related to graduate study in psychology. Because several categories were not sufficiently distinct, several respondents appeared to report hours spent completing similar activities in more than one category (i.e., number of hours per week spent doing practicum/clinical related activities, number of hours per week spent in direct contact with clients). Since data obtained from respondents may have overlapped categories, quantitative information obtained from these questions is difficult to interpret. As a result, the ambiguous construction of the aforementioned portion of the Demographic Questionnaire for Doctoral Students in Psychology is viewed as a limitation of the study.

$\underline{\text { Sample }}$

One hundred fifty-nine individuals, $44 \%$ of the sample, returned data which could be utilized in this study. Fifty-six percent of the original sample did not return usable data. As a result, it is impossible to determine how those who did not return usable data may have differed from the sample who did return data which could be utilized.

In addition, despite requesting the use of random sampling procedures from APA staff members in an effort to acquire data of relatively equal numbers from students enrolled Clinical, Counseling, and School Psychology doctoral programs, 77\% of the respondents were enrolled in Clinical Psychology programs. As a result, the data obtained from the current sample was skewed and at times difficult to analyze. For example, due to the differences within the sample 
with regard to graduate program enrollment, a number of statistical analyses, especially post hoc analyses, did not provide meaningful results. Conclusions are also difficult to make based on information obtained from this sample, as demographic information obtained suggests that the majority of respondents were female (76.6\%), Caucasian (75.3\%), and had no children (79.0\%). While sampling difficulties limited the utility of the data obtained in the current study, it should be noted that similar sampling difficulties have been reported in other areas of the burnout literature (Etzion, 1984).

Methodology

Packets of questionnaires were sent to students in late November 1999. Reminder letters were sent to students in mid December 1999. It is possible that the time in which the packets were mailed to participants may have negatively influenced the response rate (i.e., students may have been busy completing final papers and exams at the end of the Fall semester, and therefore, may have chosen not to complete and return the questionnaires).

\section{Recommendations for Future Research}

Drawing conclusions regarding information obtained from studies of the stress-social support-burnout relationship are made difficult for a variety of reasons. First, burnout, stress, and social support have been measured inconsistently across studies. For example, most studies have used the Maslach Burnout Inventory to measure burnout among human service professionals (Leiter \& Harvie, 1996). However, the only prior published empirical study of burnout to use doctoral students in psychology as subjects utilized the Tedium Measure of Burnout (Kahill, 1986). Measurement of social support and stress have also varied across studies. With regard to social support, the choice of measure was significantly dependent upon whether the quantity and satisfaction with the social support network was being assessed 
(Corrigan et al., 1995; Nowack, 1985), or if information associated with sources of support were being assessed (Huebner, 1994; Kahill, 1986). Second, burnout has been conceptualized differently by researchers. Some researchers have conceptualized burnout according to the three Maslach Burnout Inventory subscales (Huebner, 1994; Nowack et al., 1985), while other researchers modified the three subscale conceptualization of burnout in their research (Corrigan et al., 1995; Kahill, 1986). Finally, research on the stress-social support-burnout relationship has spanned a variety of populations, making generalizations of findings difficult. As a result, it appears that additional research associated with the stress-social support-burnout relationship needs to replicate studies which have utilized measures previously established in the stress-social support-burnout literature, using construct conceptualizations which have also been consistently utilized in the literature. Then, after a strong base has been established in the stress-social support-burnout literature, findings may be more appropriately generalized to additional populations.

Future research of burnout, stress, and social support specifically among doctoral students in psychology should attempt to obtain data from a larger sample, which includes greater diversity among participants, and more equal representation across doctoral programs (i.e., Clincal, Counseling, and School Psychology). Such data could be compared to data obtained in the current study, and ultimately be used in the establishment of Maslach Burnout Inventory norms for doctoral students in psychology. Modifications of the research design utilized in the current study could provide additional information related to the relationships between burnout, stress, and social support among doctoral students in psychology. Research design changes could enable data to be collected at different times during the completion of the doctoral degree in psychology (i.e., collect data during each year of study, collect data at 
different times during a specific academic year). In addition, because relationships among demographic variables and burnout, stress, and social support have produced mixed results in the literature (Cahir \& Morris, 1991; Hudson \& O’Regan, 1994), more extensive evaluation of these relationships among doctoral students in psychology appears to be necessary in order to most accurately draw reliable and valid conclusions about these relationships.

Future research could additionally focus on more specific identification of stressors frequently endorsed by graduate students in psychology. The current study, and research conducted by Shinn et al. (1984), emphasized the evaluation of specific work related stressors when evaluating the relationships between burnout, stress, and social support. The Modified Psychology Student Stress Questionnaire was observed to be a reliable measure of student stress for graduate students in psychology. As a result, future research could utilize this measure to supplement more extensive evaluation of stress among graduate students in psychology. Research could also focus on identifying the type and source of social support most beneficial to alleviating the negative impact of identified stressors. The Modified Sources of Support Questionnaire utilized in this study was determined to be a reliable measure. However, little support was observed with regard to the influence of sources of social support on graduate student burnout. As a result, the Modified Sources of Support Questionnaire could be utilized to complement future, more extensive research of the evaluation of psychology student social support. This research could serve both to determine the extent to which the Modified Sources of Support Questionnaire actually measures graduate student perceptions of social support (i.e., correlate its subscales with other measures of social support), and more generally expand knowledge of how social support most effectively influences graduate student burnout. Evaluation of the manner in which social support influences the stress-burnout relationship, 
whether directly or through a buffering effect, should also be emphasized in future research. Such evaluation was emphasized by Etzion (1984) and in the current study, but should be evaluated further in future research due to the inconsistent results of research assessing the role of social support observed throughout the literature.

Future research could additionally focus on the prevention and treatment of burnout among doctoral students in psychology. Such research could include asking doctoral students in psychology how specific sources of support (i.e., clinical supervisor, faculty advisor, classmates, spouse/significant other) could most effectively assist them in addressing the stress inherent in doctoral programs in psychology.

Doctoral student awareness of the ethical implications of continued therapeutic practice despite suffering from burnout could also be addressed in future research. According to Skorupa and Agresti (1993), a negative relationship was observed between the Maslach Burnout Inventory Emotional Exhaustion subscale and strong ethical beliefs related to therapeutic practice while experiencing burnout, among a sample of psychologists. However, evaluation of the relationship between doctoral student ethical beliefs and burnout has not been yet been explored.

Results of the current study suggest that each subscale of the Maslach Burnout Inventory (MBI), Emotional Exhaustion, Depersonalization, and Personal Accomplishment was significantly related to stress. Results further suggest that the Personal Accomplishment subscale was significantly related to Classmate Social Support. These results suggest support for the multidimensional conceptualization of the burnout construct among doctoral students in psychology. While such multidimensional conceptualization has been questioned in the burnout literature (Koeske \& Koeske, 1989; Um \& Harrison, 1998), the majority of the literature on 
burnout appears to conceptualize burnout using all three of the aforementioned dimensions of the construct. The current research on doctoral students in psychology appears to support the use of the multidimensional model of burnout utilized in this study (Maslach et al., 1996). As a result, future research on burnout among doctoral students in psychology should utilize the Structural Model of Burnout proposed by Maslach et al. (1996), and address portions of the model not assessed in the current study (see Figure 1). These components include exploraton of the "costs" which can result when an individual burns out, including diminished organizational commitment, turnover, absenteeism, and physical illness. Resource deficits could additionally be evaluated more extensively. Specifically, control coping, autonomy, and decision involvement were areas described in the aforementioned Structural Model of Burnout, and not evaluated in the current study.

Finally, in the current study students in Clinical, Counseling, and School Psychology doctoral programs were asked to rate their overall satisfaction with their current doctoral program. Forty percent of the student sample reported they were unsatisfied with their current doctoral program. Clearly research is needed to identify the specific aspects of doctoral programs in psychology which most significantly and negatively influence student satisfaction with their graduate experience. Additionally, specific ways to increase student satisfaction with their doctoral program in psychology should be addressed in future research associated with this population. Such an emphasis is necessary in order to identify methods to continue to attract quality students to graduate programs in psychology, and to help ensure that students will successfully complete their programs once they are enrolled. 


\section{References}

Ackerley, G. D., Burnell, J., Holder, D. C., \& Kurdek, L. A. (1988). Burnout among licensed psychologists. Professional Psychology: Research and Practice, 19 (6), 624-631.

American Psychological Association. (1992). Ethical principles of psychologists and code of conduct. American Psychologist, 47, 1597-1611.

American Psychological Association. (1996). Level of cumulative debt related to graduate education: 1996 doctorate recipients in psychology. 1996 Doctorate Employment Survey. APA Research Office.

Bair, J. P., \& Greenspan, B. K. (1986). TEAMS: Teamwork training for interns, residents, and nurses. Hospital and Community Psychiatry, 37(6), 633-635.

Baron, R. M., \& Kenny, D. A. (1986). The moderator-mediator variable distinction in social psychological research: Conceptual, strategic, and statistical considerations. Journal of Personality and Social Psychology, 51(6), 1173-1182.

Bedini, L. A., Williams, L., \& Thompson, D. (1995). The relationship between burnout and role stress in Therapeutic Recreation Specialists. Therapeutic Recreation Journal, 29(3), 163-174.

Beehr, T. A., \& Newman, J. E. (1978). Job stress, employees' health, and organizational effectiveness: A facet analysis, model, and literature review. Personnel Psychology, 31, 665699.

Berkley Planning Associates. (1977). Project management and worker burnout; Final report. Evaluation of Child Abuse and Neglect Demonstration Project 1974-1977, Volume IX.

Bowman, R. L., Bowman, V. E., \& DeLucia, J. L. (1990). Mentoring in a graduate counseling program: Students helping students. Counselor Education and Supervision, 30(1), $58-65$.

Brantley, P. J., Deitz, L. S., McKnight, G. T., Jones, G. N., \& Tulley, R. (1988). 
Convergence between Daily Stress Inventory and endocrine measures of stress. Journal of Consulting and Clinical Psychology, 4, 549-551.

Brantley, P.J., \& Jones, G.N. (1989). Daily Stress Inventory: Professional Manual. Odessa, FL: Psychological Assessment Resources, Inc.

Brantley, P. J., Waggoner, C. D., Jones, G. N., \& Rappaport, N. B. (1987). A daily stress inventory: Development, reliability, and validity. Journal of Behavioral Medicine, 10, 6174.

Cahir, N., \& Morris, R. D. (1991). The Psychology Student Stress Questionnaire. Journal of Clinical Psychology, 47 (3), 414-417.

Cherniss, C. (1980). Staff burnout: Job stress in the human services. Beverly Hills: Sage Publications.

Cheuk, W., Wong, K., \& Rosen, S. (1994). The effects of spurning and social support on teacher burnout. Journal of Social Behavior and Personality, 9(4), 657-664.

Cohen, S., \& Hoberman, H. (1983). Positive events and social support as buffers of life change stress. Journal of Applied Social Psychology, 13, 99-125.

Cohen, S., \& Wills, T. (1985). Stress, social support, and the buffering hypothesis. Psychological Bulletin, 98, 310-357.

Cohn, P. J. (1990). An exploratory study on sources of stress and athlete burnout in youth golf. Sport Psychologist, 4(2), 95-106.

Constable, J. G., \& Russell, D. W. (1986). The effect of social support and the work environment upon burnout among nurses. Journal of Human Stress, 38, 20-26.

Corrigan, P. W., Holmes, E. P., \& Luchins, D. (1995). Burnout and collegial support in state psychiatric hospital staff. Journal of Clinical Psychology, 51(5), 703-710.

Csikszentmihalyi, M. (1975). Beyond boredom and anxiety. San Francisco, CA: Jossey-Bass Publishers. 
Cutrona, C. (1986). Behavioral manifestations of social support: A microanalytic investigation. Journal of Personality and Social Psychology, 51, 201-208.

Cutrona, C. E., \& Russell, D. (1987). The provisions of social relationships and adaption to stress. In W.H. Jones \& D. Perlman (Eds.), Advances in social relationships (Vol. 1, pp. 3767). Greenwich, CT: JAI Press.

D’Aurora, D. L., \& Fimian, M. J. (1988). Dimensions of life and school stress experienced by young people. Psychology in the Schools, 25(1), 44-53.

De-Palpe, J., \& Croce, R. (1986). The existence of burnout among corrective therapists: A descriptive analytical investigation. American Corrective Therapy Journal, March/April, 3238.

Derogatis, L. R. (1987). The Derogatis Stress Profile: A quantification of psychological status. Advances in Psychosomatic Medicine: Research Paradigm in Psychosomatics, 17, 30-54.

Dietzel, L. C., \& Coursey, R. D. (1998). Predictors of emotional exhaustion among nonresidential staff persons. Psychiatric Rehabilitation Journal, 21(4), 340-348.

Etzion, D. (1984). Moderating effect of social support on the stress-burnout relationship. Journal of Applied Psychology, 69(4), 615-622.

Farber, B. A. (1983). Introduction: A critical perspective on burnout. In B. A. Farber (Ed.), Stress and burnout in the human service professions (pp. 1-20). New York, NY: Pergamon Press.

Farber, B. A., \& Heifetz, L. J. (1982). The process and dimensions of burnout in psychotherapists. Professional Psychology, 13(2), 293-301.

Fimian, M. J., \& Blanton, L. P. (1987). Stress, burnout, and role problems among teacher trainers and first-year teachers. Journal of Occupational Behavior, 8(2), 157-165.

Fly, B. J., Van Bark, W. P., Weinman, L., Kitchener, K. S., \& Lang, P. R. (1997). Ethical transgressions of psychology graduate students: Critical incidents with implications for 
training. Professional Psychology: Research and Practice, 28(5), 492-495.

Frame, M. W., \& Stevens-Smith, P. (1995). Out of harm's way: Enhancing monitoring and dismissal processes in counselor education programs. Counselor Education and Supervision, $\underline{35}(2), 119-129$.

Freudenberger, H. J. (1980). Burnout. New York: Doubleday.

Freudenberger, H. J. (1985). Women's burnout: How to spot it, how to reverse it, and how to prevent it. Garden City, NY: Doubleday.

Freudenberger, H. J., \& Richelson, G. (1980). Burnout: The high cost of high achievement. New York: Anchor Press.

Freudenberger, H. J., \& Richelson, G. (1981). Burnout: How to beat the high cost of success. New York: Bantam Books.

Gibson, F., McGrath, A., \& Reid, N. (1989). Occupational stress in social work. British Journal of Social Work, 19, 1-16.

Gold, Y. (1985). Does teacher burnout begin with student teaching. Education, 105(3), 254-257.

Gold, Y., Bachelor, P. A., \& Michael, W. B. (1989). The dimensionality of a modified form of the Maslach Burnout Inventory for university students in a teacher training program. Educational and Psychological Measurement, 49(3), 549-561.

Golembrewski, R. T., \& Munzenrider, R. F. (1988). Phases of burnout: Developments in concepts and applications. New York: Praeger Publishers.

Goplerud, E. N. (1980). Social support and stress during the first year of graduate school. Professional Psychology, 11(2), 283-290.

Gould, D., Tuffey, S., Udry, E., \& Loehr, J. (1996). Burnout in competitive junior tennis players: II. Qualitative analysis. Sport Psychologist, 10(4), 341-366.

Halleck, S. L. (1976). Emotional problems of the graduate student. In J. Katz \& R. T. 
Hartnett (Eds.), Scholars in the making. Cambridge, MA: Ballinger.

Himle, D. P., Jayaratne, S., \& Thyness, P. A. (1989a). The buffering effects of four types of supervisory support on work stress. Administration in Social Work, 13(1), 19-34.

Himle, D. P., Jayaratne, S., \& Thyness, P. (1989b). The effects of emotional support on burnout, work stress and mental health among Norwegian and American social workers. $\underline{\text { Journal }}$ of Social Service Research, 13(1), 27-45.

Himle, D. P., Jayaratne, S., \& Thyness, P. (1991). Buffering effects of four social support types on burnout among social workers. Social Work Research \& Abstracts, 27(1), 2227.

Hockey, R. (1983). Stress and fatigue in human performance. New York: John Wiley \& Sons.

Hodgson, C. S., \& Simoni, J. M. (1995). Graduate student academic and psychological functioning. Journal of College Student Development, 36 (3), 244-253.

Holmes, T. H., \& Masuda, M. (1974). Life changes and illness susceptibility. In B. S. Dohrenwend \& B. P. Dohrenwend (Eds.), Stressful life events: Their nature and effects. New York: Wiley.

Holmes, T. H., \& Rahe, R. H. (1967). The Social Readjustment Rating Subtest. Journal of Psychosomatic Research, 11, 213-218.

House, J. S. (1981). Work stress and social support. Reading, MA: Addison-Wesley Publishing Company.

Hudson, S. A., \& O’Regan, J. (1994). Stress and the graduate psychology student. Journal of Clinical Psychology, 50 (6), 973-977.

Huebner, E. S. (1994). Relationships among demographics, social support, job satisfaction and burnout among school psychologists. School Psychology International, 15(2), 181-186. 
Jemmott, J., \& Magliore, K. (1988). Academic stress, social support, and secretory immunoglobulin A. Journal of Personality and Social Psychology, 55, 803-810.

Jupp, J. J., \& Shaul, V. (1991). Burnout in student counsellors. Counseling Psychology Quarterly, 4(2/3), 157-167.

Kahill, S. (1986). Relationship of burnout among professional psychologists to professional expectations and social support. Psychological Reports, 59, 1043-1051.

Kanner, A. D., Coyne, J. C., Schaefer, C., \& Lazarus, R. S. (1981). Comparison of two modes of stress management: Daily hassles and uplifts versus major life events. $\underline{\text { Journal of }}$ Behavioral Medicine, 4, 1-39.

Koeske, G. F., \& Koeske, R. D. (1991). Student "burnout" as a mediator of the stressoutcome relationship. Research in Higher Education, 32(4), 415-431.

Koeske, G. F., \& Koeske, R. D. (1993). A preliminary test of a Stress-Strain-Outcome model for reconceptualizing the burnout phenomenon. Journal of Social Service Research, $\underline{17}(3 / 4), 107-135$.

Koeske, R. D., \& Koeske, G. F. (1989). Working and non-working students: Roles, support, and well-being. Journal of Social Work Education, 3, 244-256.

Kruger, L. J., Botman, H. I., \& Goodenow, C. (1991). An investigation of social support and burnout among residential counselors. Child \& Youth Care Forum, 20(5), 335-352.

Lee, R. T., \& Ashforth, B. E. (1993). A longitudinal study of burnout among supervisors and managers: Comparisons between the Leiter and Maslach (1988) and Golembiewski et al. (1986) models. Organizational Behavior and Human Decision Processes, 54, 369-398.

Leiter, M. P., \& Harvie, P. L. (1996). Burnout among mental health workers: A review and a research agenda. International Journal of Social Psychiatry, 42(2), 90-101.

LeUnes, A. D., \& Nation, J. R. (1989). Sport psychology: An introduction. Chicago: Nelson-Hall. 
Lin, N., Ensel, W., Simeone, R., \& Kuo, W. (1979). Social support, stressful life events, and illness: A model and empirical test. Journal of Health and Social Behavior, 20, 108-119.

Lubin, B., Robinson, A. J., \& Sailors, J. R. (1992). Burnout in organizations: A bibliography of the literature, 1980 through 1991. Organization Development Journal, 10(2), 6690.

Mallinckrodt, B., \& Leong, F. T. (1992). Social support in academic programs and family environments: Sex differences and role conflicts for graduate students. $\underline{\text { Journal of }}$ Counseling and Development, 70(6), 716-723.

Maslach, C. (1982). Burnout, the cost of caring. Englewood Cliffs: Prentice Hall.

Maslach, C., \& Jackson, S. E. (1981). The measurement of experienced burnout. Journal of Occupational Behavior, 2, 99-113.

Maslach, C., \& Jackson, S. E. (1986). Maslach Burnout Inventory Manual (2nd ed.). Palo Alto, CA: Consulting Psychologists Press.

Maslach, C., Jackson, S. E., \& Leiter, M. P. (1996). Maslach Burnout Inventory Manual (3rd ed.). Palo Alto, CA: Consulting Psychologists Press, Inc.

Maslach, C., \& Pines, A. (1977). The burnout syndrome in the day care setting. Child Care Quarterly, 6(2), 100-113.

Matheny, K. B., Aycock, D. W., Curlette, W. L., \& Junker, G. N. (1993). The Coping Resources Inventory for Stress: A measure of perceived resourcefulness. Journal of Clinical Psychology, 49(6), 815-830.

McCarthy, M. E., Pretty, G. M., \& Catano, V. (1990). Psychological sense of community and student burnout. Journal of College Student Development, 31(3), 211-216.

Meier, S. T., \& Schmeck, R. R. (1985). The burned-out college student: A descriptive profile. Journal of College Student Personnel, 26(1), 63-69.

Melendez, W. A., \& DeGuzman, R. M. (1983). Burnout: The new academic disease. 
Washington, D.C.: Association for the Study of Higher Education.

Mitchell, M. M., \& Kampke, C. M. (1993). Student coping strategies and perceptions of fieldwork. American Journal of Occupational Therapy, 47(6), 535-540.

Morrissette, P. J. (1996). Recurring critical issues of student counselors. Canadian Journal of Counseling, 30(1), 31-41.

Northrup, L. M. (1996). Stress, social support, and burnout in nursing home staff. Unpublished doctoral dissertation, West Virginia University.

Nowack, K. M., Gibbons, J. M., \& Hanson, A. L. (1985). Factors affecting burnout and job performance of resident assistants. Journal of College Student Personnel, 26(2), 137-142.

Parham, W. D. (1992). Personal and professional issues for counseling center psychologists: 7-10 years postdoctorate. The Counseling Psychologist, 20(1), 32-38.

Perlman, B., Hartman, E. A. (1982). Burnout: Summary and future research. Human Relations, 35(4), 283-305.

Pines, A., Aronson, E., \& Kafry, D. (1981). Burnout: From tedium to personal growth. New York: The Free Press.

Polson, M., \& Nida, R. (1998). Program and trainee lifestyle stress: A survey of AAMFT student members. Journal of Marital and Family Therapy, 24(1), 95-112.

Powers, S., \& Gose, K. (1986). Reliability and construct validity of the Maslach Burnout Inventory in a sample of university students. Educational and Psychological Measurement, 46, 251-255.

Pradhan, M., \& Misra, N. (1995). Life stress and burnout among couples in medical profession. Indian Journal of Clinical Psychology, 22(2), 17-22.

Procidano, M. E., \& Heller, K. (1983). Measures of perceived social support from friends and from family: Three validation studies. American Journal of Community Psychology, 11(1), 1-24. 
Raquepaw, J. M., \& Miller, R. S. (1989). Psychotherapist burnout: A component analysis. Professional Psychology: Research and Practice, 20(1), 32-36.

Ray, E. B., \& Miller, K. I. (1994). Social support, home/work stress, and burnout: Who can help? Journal of Applied Behavioral Science, 30,(3), 357-373.

Reifman, A., \& Dunkel-Schetter, C. (1990). Stress, structural social support, and wellbeing in university students. Journal of Applied College Health, 38, 271-277.

Richardsen, A. M., \& Burke, R. J. (1995). Models of burnout: Implications for interventions. International Journal of Stress Management, 2(1), 31-43.

Ross, R. R., Altmaier, E. M., \& Russell, D. W. (1989). Job stress, social support, and burnout among counseling center staff. Journal of Counseling Psychology, 36(4), 464-470.

Russell, D. W., Altmaier, E., \& Van Velzen, D. (1987). job-related stress, social support, and burnout among classroom teachers. Journal of Applied Psychology, 72, 269-274.

Sarason, I., Johnson, J., \& Siegel, J. (1978). Assessing the impact of life changes: Development of the Life Experiences Survey. Journal of Consulting and Clinical Psychology, $\underline{46}, 932-946$.

Sarason, I., Levine, H., Basham, R., \& Sarason, B. (1983). Assessing social support: The Social Support Questionnaire. Journal of Personality and Social Psychology, 44, 127-139.

Sarason, B., Shearin, E., Pierce, G., \& Sarason, I. (1987). Interrelations of social support measures: Theoretical and practical implications. Journal of Personality and Social Psychology, 52(4), 813-832.

Schaefer, C., Coyne, J., \& Lazarus, R. (1981). The health related functions of social support. Journal of Behavioral Medicine, 4, 381-406.

Schaufeli, W. B., Van Dierendonck, D., \& Van Gorp, K. (1996). Burnout and reciprocity: Towards a dual-level social exchange model. Work \& Stress, 10(3), 225-237.

Shinn, M., Rosario, M., Morch, H., \& Chestnut, D. E. (1984). Coping with job stress 
and burnout in the human services. Journal of Personality and Social Psychology, 46(4), 864876.

Skorupa, J., \& Agresti, A. A. (1993). Ethical beliefs about burnout and continued professional practice. Professional Psychology: Research and Practice, 24(3), 281-285.

Smith, C. E., Fernengel, K., Holcroft, C., Gerald, K., \& Marien, L. (1994). Metaanalysis of the associations between social support and health outcomes. Annals of Behavioral Medicine, 16(4), 352-362.

Snibbe, J. R., Radcliffe, T., Weisberger, C., Richards, M., \& Kelly, J. (1989). Burnout among primary care physicians and mental health professionals in a managed health care setting. Psychological Reports, 65, 775-780.

Speilberger, C. D., Gorsuch, R. L., \& Lushene, R. E. (1970). Manual for the State-Trait Anxiety Inventory: STAI ("Self-Evaluation Questionnaire”). Palo Alto, CA: Consulting Psychologist Press.

Stadler, H. A., Willing, K. L., Eberhage, M. G., \& Ward, W. H. (1988). Impairment: Implications for the counseling profession. Journal of Counseling and Development, 66, 258260.

Stevenson, J., Norcross, J., King, J., \& Tobin, K. (1984). Evaluating clinical training programs: A formative effort. Professional Psychology: Research and Practice, 15, 218-229.

Suran, B. G., \& Sheridan, E. P. (1985). Management of burnout: Training psychologists in professional life span perspectives. Professional Psychology: Research and Practice, 16(6), $741-752$.

Tardy, C. H. (1985). Social support measurement. American Journal of Community Psychology, 13(2), 187-202.

Thoreson, R. W., Miller, M., \& Krauskopf, C. J. (1989). The distressed psychologist: Prevalence and treatment considerations. Professional Psychology: Research and Practice, 
20(3), 153-158.

Tobin, P. J., \& Carson, J. (1994). Stress and the student social worker. Social Work and Social Sciences Review, 5(3), 246-255.

Toews, J. A., Lockyer, J. M., Dobson, D. H., \& Brownell, A. K. (1993). Stress among residents, medical students, and graduate science $(\mathrm{MSc} / \mathrm{PhD})$ students. Academic Medicine, 68 (10), S46-S48.

Um, M., \& Brown-Standridge, M. D. (1993). Discovering organizational "rules" that contribute to student stress in social work field placements. The Journal of Applied Social Sciences, 17(2), 157-177.

Um, M., \& Harrison, D. F. (1998). Role stressors, burnout, mediators, and job satisfaction: A stress-strain-outcome model and an empirical test. Social Work Research, 22(2), $100-115$.

Van Wijk, C. (1997). Factors influencing burnout and job stress among military nurses. Military Medicine, 162(10), 707-710.

Vaux, A., Phillips, J., Holly, L., Thomson, B., Williams, D., \& Stewart, D. (1986). The Social Support Appraisals (SS-A) Scale: Studies of reliability and validity. American Journal of Community Psychology, 14(2), 195-219.

Watkins, C. E. (1983). Combating student burnout: A structured group approach. Journal of Specialists in Group Work, 8(4), 218-225.

Weathers, P. L., Furlong, M. J., \& Solorzano, D. (1993). Mail survey research in counseling psychology: Current practice and suggested guidelines. Journal of Counseling Psychology, 40(2), 238-244.

Weinberger, M., Tierney, W., Booker, P., \& Hiner, S. (1990). Social support, stress and functional status in patients with osteoarthritis. Social Sciences and Medicine, 30, 503-508.

Weiss, R. S. (1974). The provisions of social relationships. In Z. Rubin (Ed.), Doing 
unto others (pp. 17-26). Englewood Cliffs, NJ: Prentice-Hall.

Wethington, E., \& Kessler, R. C. (1986). Perceived support, received support, and adjustment to stressful life events. Journal of Health and Social Behavior, 27, 78-89.

Wolf, T. M. (1994). Stress, coping and health: Enhancing well-being in medical school. Medical Education, 28, 8-17.

Wolf, T. M., Balson, P. M., Faucett, J. M., Randall, H. M. (1989). A retrospective study of attitude change during medical school. Medical Education, 23(1), 19-23.

Wood, B. J., Klein, S., Cross, H. J., Lammers, C. J., \& Elliot, J. K. (1985). Impaired practitioners: Psychologists' opinions about prevalence, and proposals for intervention. Professional Psychology: Research and Practice, 16(6), 843-850.

Zuckerman, M., \& Lubin, B. (1965). Manual for the Multiple Affect Adjective Checklist. San Diego, CA: Educational and Industrial Testing Service. 


\section{Dear Doctoral Student in Psychology:}

\section{Appendix A}

November 8, 1999

Likely you have received this packet of questionnaires and cover letter at a time when you could be reading for your classes, working on your dissertation, finishing applications for internship, or spending time with family and/or friends. In any event, the list of "other things" you could be doing is probably a lengthy one. As a fellow doctoral student in psychology I can relate to the need to prioritize obligations. I am asking you, however, to take some time to make evaluation of your current lifestyle as a doctoral student in psychology a priority.

You have received the questionnaires sent to you because you are currently enrolled in a doctoral program in psychology. Doctoral students are being utilized as subjects in this study because I wish to learn more about the specific stressors, utilization of social support resources, and burnout symptoms experienced by doctoral students in psychology during their educational training. As a result, I am asking you to complete the questionnaires sent to you and to return them to me using the enclosed self-addressed, stamped envelope. Returning these questionnaires to me will serve as confirmation of your voluntary participation in this study. Confidentiality regarding your responses to questionnaire items will be maintained at all times, and you may choose not to respond to every item or every question. In addition, at no time will your identity be linked to the responses you provide. Instead, your responses will be coded by the numerical identification number found at the bottom of each questionnaire and envelope provided to you. The numerical identification number will also be utilized in a raffle procedure. Two identification numbers will be randomly selected from a list of all returned numbers which include a complete set of usable questionnaires. The two individuals matched to those numerical identification numbers will be sent a check in the amount of $\$ 35.00$.

Thank you for taking the time to read this letter. I hope that you will help me to gain information about your experience in your doctoral program. I hope to use this information to provide others with insight regarding the experiences of doctoral students in psychology, hoping that programs will utilize this information in order to make the experience of attaining a doctoral degree in psychology a positive one for all future professionals in our field. Best wishes as you continue your studies.

Sincerely,

Kelli L. Weaver, M.A.

Counseling Psychology Student

West Virginia University 


\section{Appendix B}

Dear Doctoral Student in Psychology:

This letter is sent to you in an attempt to encourage you to complete the packet of questionnaires that I sent to you two weeks ago. At this time you are likely very busy and have many obligations which place tremendous time constraints on you. However, assessment of your challenging lifestyle, which may include classwork, assistantship obligations, outside employment, writing a dissertation, applying for internship positions, and maintaining social and familial relationships, is precisely my intent. Specifically, it is my intention to identify the stressors most frequently experienced by doctoral students in psychology, the sources of support most beneficial to psychology doctoral students, and the prevalence and magnitude of burnout symptoms experienced by such students. Ultimately I hope to utilize the data obtained from my research to identify ways to make the attainment of a doctoral degree in psychology a consistently positive experience for students.

If you have already completed the questionnaires sent to you and returned them to me please disregard this letter. The information you returned to me must me in the mail at this time. However, if you have not already completed the questionnaires that I sent to you, I hope that you will consider completing the questionnaires, and that you will return them to me in the selfaddressed, stamped envelope that I provided to you. You will likely be able to complete the entire packet of questionnaires in approximately 20 minutes.

I feel that evaluation of the relationship between burnout, stress, and social support among doctoral students in psychology is a very important topic to explore. As a result, I would appreciate your assistance with my dissertation research. Thank you for taking the time to read this letter. Best wishes as you continue your studies.

Sincerely,

Kelli L. Weaver, M.A.

Counseling Psychology Student

West Virginia University 
Appendix C

Demographic Questionnaire for Doctoral Students in Psychology (DQDSP)

Age:

Gender: $M$ $\mathrm{F}$

Race: African American American Indian

Asian

Caucasian

Pacific Islander
Latino

Other

Current marital status:

Single

Divorced
Separated

Widowed

Married

Number of children who currently reside in your household:

Type of graduate program you are currently enrolled in:

Counseling Psychology

Clinical Psychology

School Psychology

Other

Year in current graduate program:

$1^{\text {st }}-2^{\text {nd }}-\quad 3^{\text {rd }}-\quad 4^{\text {th }}-\quad 5^{\text {th }}-\quad$ Other

Number of years you anticipate that it will take you to complete all requirements for your program (including requirements for dissertation and internship):
3
4
5
7
$8+$

Degree anticipated following completion of your current program:

Ed.D

Ph.D.

PsyD.

Other

Years spent providing clinical services prior to enrollment in your current program:

Number of credit hours you are currently taking: 
Average number of hours/week you currently spend doing the following activities:

In class

Traveling to class

Research/writing related to your dissertation

Research other than your dissertation

Assistantship duties not including teaching

Teaching

Practicum/clinical related activities (including time spent traveling to sites)

In direct contact with clients

Reading/writing papers/doing homework outside of class

Meeting with faculty members regarding classwork/research/etc.

In formal (individual + group) supervision

Do you take oral comprehensive exams?

yes

no

Do you take written comprehensive exams?

yes

no

Do you have a tuition waiver?

yes

no

Do you receive a school related stipend?

yes

Do you receive other financial support for your doctoral education outside of the above?

yes

no

If yes, please identify the type of aid:

Do you hold a job (not including a school supported assistantship) in addition to your school related activities:

yes

no

If yes, how many hours/week do you work?

Overall level of satisfaction with your current graduate program:

$\begin{array}{lllllll}1 & 2 & 3 & 4 & 5 & 6 & 7 \\ \text { very } & & & & & & \text { very } \\ \text { satisfied } & & & & & & \\ \text { unsatisfied }\end{array}$




\section{Appendix D}

\section{MBI - Human Services Survey Scoring Procedures Emotional Exhaustion Subscale (EE)}

(Maslach et al., 1996)

1. Scores on the following items of the MBI are added to determine a total score for the EE subscale: \#1, \#2, \#3, \#6, \#8, \#13, \#14, \#16, \#20.

2. Total scores on the EE subscale can then be compared to normative scores established for the EE subscale. The following score ranges have been reported for a sample of mental health professionals $(n=730)$ : scores of 0 to 13 fall in the 'low' burnout range, scores of 14 to 20 fall in the 'average' burnout range, scores of 21 or higher fall in the 'high' burnout range. 
Appendix E

\section{MBI - Human Services Survey Scoring Procedures Depersonalization Subscale (DP)}

(Maslach et al., 1996)

1. Scores on the following items of the MBI are added to determine a total score for the DP subscale: \#5, \#10,\#11, \#15, \#22.

2. Total scores on the DP subscale can then be compared to normative scores established for the DP subscale. The following score ranges have been reported for a sample of mental health professionals $(n=730)$ : scores of 0 to 4 fall in the 'low' burnout range, scores of 5 to 7 fall in the 'average' burnout range, scores of 8 or higher fall in the 'high' burnout range. 
Appendix F

\section{MBI - Human Services Survey Scoring Procedures Personal Accomplishment (PA)}

(Maslach et al., 1996)

1. Scores on the following items of the MBI are added to determine a total score for the PA subscale: \#4, \#7, \#9, \#12, \#17, \#18, \#19, \#21.

2. Total scores on the PA subscale can then be compared to normative scores established for the PA subscale. The following score ranges have been reported for a sample of mental health professionals $(n=730)$ : scores of 34 or higher fall in the 'low' burnout range, scores of 29 to 33 fall in the 'average' burnout range, scores of 0 to 28 fall in the 'high' burnout range. 


\section{Appendix G}

\section{Categorization of MBI Frequency Scores for Mental Health Professionals}

(Maslach et al., 1996)

MBI Subscales

\section{Range of Experienced Burnout}

Low Moderate High

Emotional Exhaustion

$0-13$

$14-20$

21 or higher

Depersonalization

$0-4$

$5-7$

8 or higher

Personal Accomplishment 34 or higher $\quad 29-33 \quad 0-28$ 
Appendix $\mathrm{H}$

FOR THE PURPOSES OF THIS STUDY, CONSIDER YOUR COMBINED STUDENT RESPONSIBILITIES (IE: GOING TO CLASSES, STUDYING FOR EXAMS, CLINICAL DUTIES, RESEARCH COMMITMENTS, ASSISTANTSHIP RESPONSIBILITIES, ETC.) AS YOUR 'WORK' OR 'JOB', AND ANSWER THE FOLLOWING QUESTIONS ACCORDINGLY. ADDITIONALLY, ANSWER SPECIFIC QUESTIONS WHICH REFER TO 'RECIPIENTS' OF CARE IN TERMS OF YOUR CLINICAL INTERACTIONS WITH CLIENTS. 


\section{Appendix I}

\section{The Modified Psychology Student Stress Questionnaire (MPSSQ)}

Listed below are events which you may have experienced as a psychology graduate student. Think about the events of the past academic year (the period from the Fall of 1998 to the current time) and then read each item carefully. If that event occurred, rate how stressful it was for you, using the scale below. If the event did not occur during the past academic year, do not make a rating.

\begin{tabular}{|c|c|c|c|c|c|}
\hline $\begin{array}{l}\mathbf{1} \\
\text { occurred } \\
\text { but was } \\
\text { not } \\
\text { stressful }\end{array}$ & $\begin{array}{l}\mathbf{2} \\
\text { caused } \\
\text { very little } \\
\text { stress }\end{array}$ & $\begin{array}{l}\mathbf{3} \\
\text { caused } \\
\text { a little } \\
\text { stress }\end{array}$ & $\begin{array}{l}\mathbf{4} \\
\text { caused } \\
\text { some } \\
\text { stress }\end{array}$ & $\begin{array}{l}\mathbf{5} \\
\text { caused } \\
\text { much } \\
\text { stress }\end{array}$ & $\begin{array}{ll}\mathbf{6} & \mathbf{7} \\
\text { caused } & \text { caused } \\
\text { very much } & \text { me to } \\
\text { stress } & \text { panic }\end{array}$ \\
\hline
\end{tabular}

\footnotetext{
1. Moved to accommodate academic demands.

2. Experienced problems with academic registration.

3. Wished my family was more supportive.

4. Applied for a student loan.

5. Was enrolled in a rigorous academic course.

6. Wished I had more leisure time.

7. Approached a faculty member for emotional support.

8. Attempted to acquire a psychology related job.

9. Wished I had more leisure time to spend with classmates.

10. Was supported financially by another person.

11. Wished I had more emotional support from classmates.

12. Did not receive adequate academic performance feedback from faculty.

13. Maintained a graduate assistantship or tried to acquire one.

14. Worked other than assistantship responsibilities.

15. Did not receive as much academic advisement from faculty as desired.

16. Approached faculty for help in securing a psychology related job.

17. Asked classmates for help in securing a psychology related position.

18. Did not spend as much time alone as desired.

19. Was challenged by the number of hours spent completing coursework.

20. Was challenged by the number of hours spent completing assignments other than coursework (i.e.: dissertation).

21. Was unable to spend desired time with spouse/significant other.

22. Received feedback from faculty regarding clinical or research skills.

23. Asked faculty to be on thesis, prelims, or dissertation committee.

24. Chose or changed an academic advisor.

25. Did not have as many close friendships as desired.

26. Asked administrative staff (other than faculty) for help answering institutional/academic questions.

27. Asked classmates for help related to institutional/academic questions.

28. Asked faculty for help in answering institutional/academic questions.

29. Did not have as much input as desired in making administrative decisions which would effect psychology graduate students.

30. Had direct therapy contact with clients, students, etc.
} 
Appendix $\mathbf{J}$

\section{The Modified Sources of Support Questionnaire (MSOSQ)}

DIRECTIONS: CONSIDER YOUR COMBINED STUDENT RESPONSIBILITIES (I.E.: GOING TO CLASSES, STUDYING FOR EXAMS, CLINICAL DUTIES, RESEARCH COMMITMENTS, ASSISTANTSHIP DUTIES, ETC.) AS YOUR 'SCHOOL RELATED ACTIVITIES', AND ANSWER THE FOLLOWING QUESTIONS USING THE SCALE BELOW.

\begin{tabular}{lllll}
\hline $\mathbf{1}$ & $\mathbf{2}$ & $\mathbf{3}$ & $\mathbf{4}$ & $\mathbf{5}$ \\
Not at all & A Little & Somewhat & Very Much & Completely \\
& & & \\
\hline
\end{tabular}

1. How much can the following individuals be relied on when things get tough at school or with school related activities?

Clinical Supervisor

Faculty Advisor

Classmates

Spouse/Significant Other

Friends (not yet specified)

Relatives (not yet specified)

2. How much are the following individuals willing to listen to your school-related problems?

Clinical Supervisor

Faculty Advisor

Classmates

Friends (not yet specified)

Spouse/Significant Other

Relatives (not yet specified)

3. How much are the following people helpful to you in getting your school related activities done?
Clinical Supervisor
Classmates
Friends (not yet specified)
Faculty Advisor
Spouse/Significant Other
Relatives (not yet specified)

4. How much are the following people concerned about your welfare?

Clinical Supervisor

Classmates

Faculty Advisor

Friends (not yet specified)

Spouse/Significant Other

Relatives (not yet specified)

5. How much could you count on the following people to understand and be supportive if you were feeling emotionally drained or overwhelmed from your school related responsibilities?

Clinical Supervisor

Classmates

Friends (not yet specified)
Faculty Advisor

Spouse/Significant Other

Relatives (not yet specified) 
6. If you had lost empathy for a client because you were stressed or burned out, how helpful would the following people be in helping you to get your empathy back?

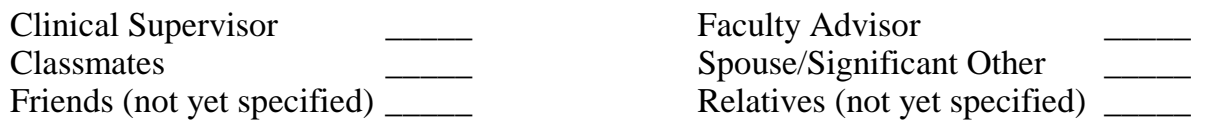

8. If you were feeling incompetent or ineffective regarding something school related, how much could you count on the following people to be understanding and help you to feel better about yourself and your school related activities?

Clinical Supervisor

Classmates

Faculty Advisor

Friends (not yet specified)

Spouse/Significant Other

Relatives (not yet specified)

9. If you were having problems outside of school that were affecting your ability to get your school related work done, how much could you count on the following people to help you in some way (e.g., offer comfort or helpful advice, give you a hand with your work, etc.)?

Clinical Supervisor

Faculty Advisor

Classmates Spouse/Significant Other

Friends (not yet specified)

Relatives (not yet specified)

10. If you were having a conflict with a client or someone at school, how much could you count on the following people to support you and help you resolve the conflict?

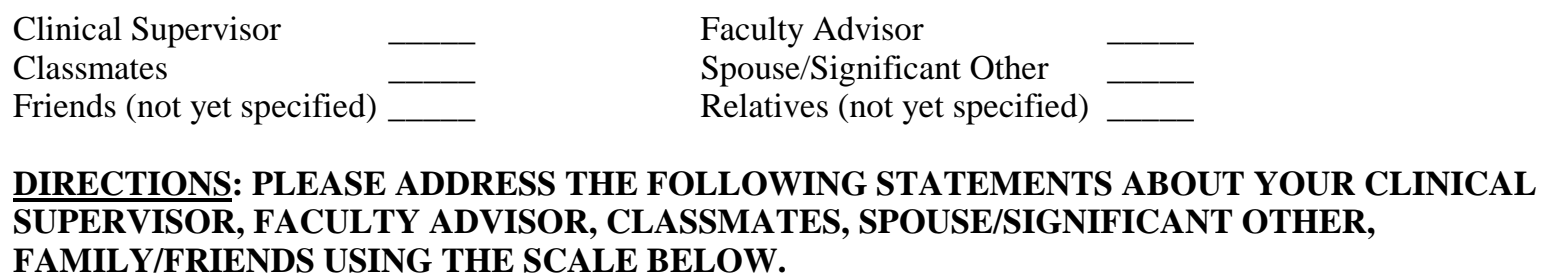

\begin{tabular}{lllll}
\hline $\mathbf{1}$ & $\mathbf{2}$ & $\mathbf{3}$ & $\mathbf{4}$ & $\mathbf{5}$ \\
$\begin{array}{l}\text { Not at all } \\
\text { True }\end{array}$ & $\begin{array}{l}\text { Not too } \\
\text { True }\end{array}$ & $\begin{array}{l}\text { Somewhat } \\
\text { True }\end{array}$ & Very True & $\begin{array}{l}\text { Always } \\
\text { True }\end{array}$ \\
\hline
\end{tabular}

11. Your is/are likely to praise you or to tell you that you have done a good job when you have done something school related well.

Clinical Supervisor

Faculty Advisor

Classmates

Spouse/Significant Other

Friends (not yet specified)

Relatives (not yet specified)

12. Your provide(s) you with helpful, constructive feedback when you are having trouble doing something school related.

Clinical Supervisor

Classmates

Friends (not yet specified)
Faculty Advisor

Spouse/Significant Other

Relatives (not yet specified) 


\section{Appendix K}

Summary Table of the Direct Influence of Stress on Burnout (Research Questions 4a to 4c) and the Direct Influence of Social Support on Burnout (Research Questions $\underline{5 \text { a to } 10 \mathrm{c})}$

\begin{tabular}{|c|c|c|c|c|c|}
\hline Research & Burnout & Stress & Social Support & & \\
\hline Question & Subscale & Subscale & Subscale & $\underline{\mathrm{r}}$ & Sig. \\
\hline $4 a$ & MBI EE & MPSSQ.IE & & .435 & $* *$ \\
\hline $4 b$ & MBI DP & MPSSQ.IE & & .186 & $* *$ \\
\hline $4 c$ & MBI PA & MPSSQ.IE & & -.310 & $* *$ \\
\hline $5 \mathrm{a}$ & MBI EE & & Classmate & -.098 & ns \\
\hline $5 b$ & MBI DP & & Classmate & -.096 & ns \\
\hline $5 c$ & MBI PA & & Classmate & .177 & $*$ \\
\hline $6 a$ & MBI EE & & Clin. Supervisor & .101 & ns \\
\hline $6 b$ & MBI DP & & Clin. Supervisor & .032 & ns \\
\hline $6 c$ & MBI PA & & Clin. Supervisor & .036 & ns \\
\hline $7 \mathrm{a}$ & MBI EE & & Faculty Advisor & -.039 & ns \\
\hline $7 b$ & MBI DP & & Faculty Advisor & -.112 & ns \\
\hline $7 \mathrm{c}$ & MBI PA & & Faculty Advisor & .111 & ns \\
\hline $8 a$ & MBI EE & & Friend & .023 & ns \\
\hline $8 b$ & MBI DP & & Friend & -.141 & ns \\
\hline $8 c$ & MBI PA & & Friend & .090 & ns \\
\hline $9 \mathrm{a}$ & MBI EE & & Relative & .007 & ns \\
\hline $9 b$ & MBI DP & & Relative & -.042 & ns \\
\hline $9 \mathrm{c}$ & MBI PA & & Relative & .070 & ns \\
\hline $10 \mathrm{a}$ & MBI EE & & Spouse/Sig. Oth. & -.124 & ns \\
\hline $10 b$ & MBI DP & & Spouse/Sig. Oth. & -.074 & ns \\
\hline $10 \mathrm{c}$ & MBI PA & & Spouse/Sig. Oth. & .155 & ns \\
\hline
\end{tabular}

\footnotetext{
$* * \mathrm{p}<.01$

$* \mathrm{p}<.05$

ns non significant
} 


\section{Appendix L}

Summary Table of the Moderating Influence of Social Support on the Stress - Burnout Relationship (Research Questions 11a to 16c)

\begin{tabular}{llllllllllll}
\hline $\begin{array}{l}\text { Res. } \\
\text { Quest. }\end{array}$ & $\begin{array}{l}\text { Burnout } \\
\text { Subscale }\end{array}$ & $\begin{array}{l}\text { Stress } \\
\text { Subscale }\end{array}$ & $\begin{array}{l}\text { Soc. Supp. } \\
\text { Subscale }\end{array}$ & $\mathrm{t}$ & Sig. & $\underline{\mathrm{r}}$ & $\mathrm{r}^{2}$ & $\mathrm{~F}$ & Sig. \\
\hline & & & & & & & & & \\
$11 \mathrm{a}$ & MBI EE & MPSSQ.IE & Classmate & 2.45 & $*$ & .197 & .039 & 5.99 & $*$ \\
$11 \mathrm{~b}$ & MBI DP & MPSSQ.IE & Classmate & .76 & $\mathrm{~ns}$ & .062 & .004 & .58 & $\mathrm{~ns}$ \\
$11 \mathrm{c}$ & MBI PA & MPSSQ.IE & Classmate & -.59 & $\mathrm{~ns}$ & .048 & .002 & .34 & $\mathrm{~ns}$ \\
\hline
\end{tabular}

$\begin{array}{llllllllll}\text { 12a } & \text { MBI EE } & \text { MPSSQ.IE } & \text { Clin. Sup. } & 1.67 & \mathrm{~ns} & .136 & .018 & 2.79 & \mathrm{~ns} \\ \text { 12b } & \text { MBI DP } & \text { MPSSQ.IE } & \text { Clin. Sup. } & 1.21 & \mathrm{~ns} & .098 & .010 & 1.47 & \mathrm{~ns} \\ 12 \mathrm{c} & \text { MBI PA } & \text { MPSSQ.IE } & \text { Clin. Sup. } & -2.03 & * & .165 & .027 & 4.12 & *\end{array}$

\begin{tabular}{|c|c|c|c|c|c|c|c|c|c|}
\hline $13 a$ & MBI EE & MPSSQ.IE & Fac. Adv. & 2.59 & $*$ & .207 & .043 & 6.70 & $*$ \\
\hline $13 b$ & MBI DP & MPSSQ.IE & Fac. Adv. & .27 & ns & .022 & .000 & .071 & $\mathrm{~ns}$ \\
\hline $13 \mathrm{c}$ & MBI PA & MPSSQ.IE & Fac. Adv. & -1.06 & ns & .087 & .008 & 1.13 & $\mathrm{~ns}$ \\
\hline $14 \mathrm{a}$ & MBI EE & MPSSQ.IE & Friend & 3.90 & $* *$ & .305 & .093 & 15.24 & $* *$ \\
\hline $14 \mathrm{~b}$ & MBI DP & MPSSQ.IE & Friend & .24 & ns & .020 & .000 & .058 & ns \\
\hline $14 \mathrm{c}$ & MBI PA & MPSSQ.IE & Friend & -1.72 & ns & .140 & .020 & 2.96 & $\mathrm{~ns}$ \\
\hline $15 \mathrm{a}$ & MBI EE & MPSSQ.IE & Relative & 3.01 & $* *$ & .239 & .057 & 9.04 & $* *$ \\
\hline $15 b$ & MBI DP & MPSSQ.IE & Relative & .84 & ns & .069 & .005 & .71 & ns \\
\hline $15 \mathrm{c}$ & MBI PA & MPSSQ.IE & Relative & -1.23 & ns & .101 & .010 & 1.51 & ns \\
\hline $16 \mathrm{a}$ & MBI EE & MPSSQ.IE & Spouse/SO & .53 & ns & .044 & .002 & .28 & $\mathrm{~ns}$ \\
\hline $16 b$ & MBI DP & MPSSQ.IE & Spouse/SO & .01 & ns & .001 & .000 & .000 & ns \\
\hline $16 \mathrm{c}$ & MBI PA & MPSSQ.IE & Spouse/SO & .31 & ns & .026 & .001 & .10 & $\mathrm{~ns}$ \\
\hline
\end{tabular}

\footnotetext{
$* * \mathrm{p}<.01$

$* \quad \mathrm{p}<.05$

ns non significant
} 


\section{Kelli L. Weaver}

425 Aaron Circle

Durham, NC 27713

(919) 806-3171

kellileeweaver@aol.com

\section{EDUCATION:}

APA Accredited Clinical-Forensic Psychology Internship

Federal Correctional Institution - Butner, NC

Ph.D., Counseling Psychology

West Virginia University - Morgantown, WV

Dissertation Title: "Stress, Social Support and Burnout Among Doctoral Students in Psychology"

Awards and Honors:

WVU Counseling Psychology Outstanding Graduate Student Award WVU Endowed Supplemental Fellowship
$9 / 99-8 / 25 / 00$

8/25/00 (anticipated)

1999

1996-1999

8/95-8/96

3/96-4/96

$1 / 96-4 / 96$

8/93-12/94

9/89-5/93

$12 / 92-5 / 93$

$12 / 89-5 / 93$

1989-1993

1989-1993

$1992-1993$

1991

$9 / 92-5 / 93$

$5 / 91-5 / 93$

9/91-5/93

Boston College Committee for Drug and Alcohol Awareness

Student Athlete Representative 


\section{WORK AND PRACTICUM EXPERIENCE IN CORRECTIONAL SETTINGS:}

Federal Correctional Institution - Butner, NC

9/99-present

Site Description: FCI-Butner is a medium security prison for adult male offenders.

Position Held: Pre-Doctoral Clinical-Forensic Psychology Intern

\section{Sex Offender Treatment Program Rotation}

Duties: 1) Write evaluations addressing client progress in sex offender treatment; 2) provide individual therapy addressing issues related to victim identification, victim empathy, identification of offense and arousal patterns, and relapse prevention; 3) colead three therapy groups per week; 4) present case material at weekly staff meetings; 5) write discharge summaries which include recommendations for conditions of supervised release and risk assessment; and 6) participate in a presentation of sex offender issues to probation officers. Supervisor: Karen Steinour, Ph.D.

\section{Forensic Psychology Rotation}

Duties: 1) Conduct court ordered forensic evaluations addressing competency, criminal responsibility, dangerousness, and sentencing issues; 2) provide reports and consultations to Federal Courts, United States Attorneys, and Federal Public Defenders; 3) administer, score, and interpret psychological tests such as the Bender Visual Motor Gestalt Test, MMPI-2, Rey 15-Item Visual Memory Test, Rey Word Recognition Test, TOMM, TONI-3, Trail Making Test, The Booklet Category Test -II, and the WAIS-III, as part of forensic evaluations and also as a consultation service to psychiatrists; 4) conduct admissions interviews and mental status assessments of individuals in the Admission/Seclusion Unit; 5) present forensic cases and interview patients at multidisciplinary Forensic Team meetings; 6) participate in weekly seminars addressing issues related to psychology and the law, such as malingering, professional ethics, prison and jail mental health services, and dangerousness; 7) present cases at the Landmark Case Seminar which addresses case law pertinent to forensic psychology; and 8) participate in a mock testimony exercise as an expert witness.

Supervisor: Angela Walden, Ph.D.

\section{General Population Rotation}

Duties: 1) Complete intake interviews; 2) provide individual therapy addressing issues related to suicidal ideation, depression, anxiety, institutional adjustment, dependency, addictions, anger management, impulse control, and pre-release issues; 3) lead an Anger Management group; 4) monitor clients identified as having significant mental health concerns; 5) provide crisis intervention; 6) conduct mental status assessments of individuals housed in special housing units; and 7) write half-way house evaluations.

Supervisor: Roy Hill, Psy.D.

\section{Adult Admissions Unit Rotation at John Umstead Hospital (Outplacement)}

Duties: 1) Lead Anger Management, Adjustment Skills, and Medication Education groups for chronically mentally ill adults; 2) provide individual therapy addressing issues related to medication compliance, anger management, suicidal ideation, and impulse control; and 3 ) provide verbal reports of patient group participation at morning report meetings. Supervisor: Jennifer Snyder, Ph.D. 


\section{Greene County State Correctional Institution - Waynesburg, PA}

Site Description: SCI-Greene is a maximum security prison for adult male offenders.

Position Held: Doctoral Practicum Student

9/98-12/98

Duties: 1) Completed comprehensive psychological evaluations using clinical interviews and the MMPI-2, TAT, WRAT-3, WAIS-R, Rotter Incomplete Sentences Blank, House-TreePerson, and Bender-Gestalt Visual Motor Test; and 2) conducted parole evaluations. Supervisors: Mark Markiewicz, Ed.D.; and David J. Srebalus, Ed.D.

Postion Held: Doctoral Practicum Student $8 / 97-8 / 98$

Duties: 1) Provided individual therapy addressing issues related to institutional adjustment, suicidal ideation, depression, anxiety, sexual orientation, dependency, addictions, anger management, impulse control, and pre-release concerns; 2) co led a Sex Offender Therapy group; 3) co led two psychoeducational Family Issues groups; 4) administered, scored, and interpreted WAIS-R and WRAT-3 test results for intellectual assessments; and 5) conducted parole evaluations.

Supervisors: L. Sherilyn Cormier, Ph.D.; Mark Markiewicz, Ed.D.; David Srebalus, Ed.D; Ursula Teuter, Ph.D; and Sandy Vujnovic, Ph.D.

\section{Federal Correctional Institution - Morgantown, WV}

Site Description: FCI-Morgantown is a low security prison for adult male offenders.

Position Held: Masters Practicum Student

$1 / 96-8 / 96$

Duties: 1) Conducted intake interviews; 2) provided individual counseling to inmates addressing addictions, sexual orientation, anger management, impulse control, depression, suicidal ideation, behavior modification, and pre-release issues; 3) led groups addressing prerelease and drug and alcohol related issues; 4) evaluated inmates for drug treatment programs; and 5) taught Drug Education classes.

Supervisors: James DeLo, Ed.D.; Paul Anderson, M.A.; and Paul Sundell, M.A.

\section{Pelletier Youth Detention Center - Marlboro, MA}

Site Description: Pelletier Center is a secure detention facility for adolescent females awaiting court decisions.

Position Held: Group Worker I

9/94-5/95

Duties: 1) Conducted intake interviews; 2) performed client orientation duties; and

3) monitored detained youth.

Position Held: Summer Training Coordinator

6/93-9/93, 6/94-9/94, 6/95-9/95

Duties: 1) Coordinated on-site summer employment opportunities available to detained youth;

2) conducted interviews to evaluate detained youth for summer employment; 3) supervised staff involvement in youth training; 4) assisted with maintenance of security during training hours; and 5) performed record-keeping duties. 


\section{WORK AND PRACTICUM EXPERIENCE IN COLLEGE OR UNIVERSITY SETTINGS:}

\section{West Virginia University Carruth Center for Counseling and Psychological Services - Morgantown, WV}

Site Description: The Carruth Center is West Virginia University's counseling center. WVU students and staff members, as well as individuals from the Morgantown, WV community utilize the Center's services.

Position Held: Doctoral Practicum Student

8/98-5/99

Duties: 1) Conducted intake interviews; 2) provided clinical assessment and treatment to Walk-in-Clinic clients; 3) provided individual therapy addressing issues related to depression, anxiety, suicidal ideation, eating disorders, and relationship and adjustment difficulties; 4) administered and interpreted career and psychological inventories such as the SDS, SII, MBTI, and MMPI-2; 5) provided consultation services to a WVU residence hall; 6) served as a Diversity Week Committee member; and 7) assisted with the WVU "Safe Zone" project which enlists university support for gay, lesbian, and bisexual students. Supervisors: Phillip Comer, Ph.D.; Sue Hodgeson, Ph.D.; and David Srebalus, Ed.D.

Position Held: Chief Psychometrist $8 / 95-8 / 96$ Duties: 1) Administered and scored the following psychological inventories for Carruth Center counselors: MMPI-2, Self-Directed Search, Myers-Briggs Type Indicator, Strong Interest Inventory, Edwards Personal Preference Schedule, Bem Sex Role Inventory, and the California Personality Inventory; 2) wrote a grant proposal requesting funds to upgrade testing room equipment which resulted in an award of $\$ 3000.00 ; 3$ ) provided vocational resource assistance to clients making career choices; 4) served as stress management and video technician; 5) conducted weekly inventory of psychological tests; 6) trained and supervised undergraduate psychometrists; 7) assisted counselors with research projects; and 8) participated in the Center's clinical training activities. Supervisor: Claude Southerly, M.A.

\section{Boston College Office of Learning Resources for Student Athletes (LRSA) - Chestnut Hill, MA}

Site Description: LRSA at Boston College assists student athletes with academic and adjustment difficulties associated with the transition from high school to college. LRSA services are available to all Boston College varsity athletes.

Position Held: Graduate Intern/Academic Counselor

9/94-5/95

Duties: 1) Provided academic counseling and career guidance to student athletes from five Boston College varsity teams; 2) wrote academic progress reports; 3) served as a liaison between coaches, professors, and student athletes; 4) tutored academically challenged and learning disabled student athletes.

Supervisors: Edward Etzel, Ed.D.; Ferna Phillips, M.Ed. 


\section{ADDITIONAL NON-CLINICAL EXPERIENCE WITHIN UNIVERSITY SETTINGS:}

West Virginia University Department of Counseling, Rehabilitation Counseling, and Counseling Psychology - Morgantown, WV

Position Held: Graduate Intern/Academic Counselor $8 / 96-5 / 98$

Duties: 1) Instructed Masters-level Counseling Techniques and Theory and Practice of Human Appraisal courses; 2) served as Assistant Editor of the APA Division 17 Newsletter; and 3) coordinated the APA-accredited Counseling Psychology admissions process.

\section{West Virginia University Department of Physical Education - Morgantown, WV}

Position Held: Graduate Research Assistant

9/93-5/94

Duties: 1) Assisted with the organization, distribution, collection, and evaluation of a survey assessing the backgrounds and qualifications of academic advisors for college student athletes; 2) performed computerized statistical analysis (SAS) of research data; 3) proctored undergraduate examinations; and 4) assisted professors with individual research projects.

Position Held: Graduate Intern/Assistant $1 / 94-5 / 94$ Duties: 1) Supervised student athlete study hours; and 2) monitored student athlete class attendance.

\section{GRADUATE LEVEL TEACHING EXPERIENCE:}

West Virginia University Department of Counseling, Rehabilitation Counseling, and Counseling Psychology - Morgantown, WV

Course Taught: Counseling Techniques Fall 1996, Spring 1997, Summer 1997 Duties: 1) Developed course syllabi, lesson plans, and examinations addressing basic counseling techniques; and 2) supplemented lectures with role-play activities, audiotapes, videotapes, and discussions of ethical issues related to counseling.

Course Taught: Theory and Practice of Human Appraisal Fall 1997, Spring 1997 Duties: 1) Developed course syllabi, lesson plans, and examinations associated with basic statistics, test evaluation, assessment techniques, and ethical issues related to testing and assessment.

\section{EDITING EXPERIENCE:}

American Psychological Association Division 17 Newsletter

Position Held: Assistant Editor

8/96-5/99

Duties: 1) Obtain article submissions from division members; 2) edit article submissions; and 3) organize submissions using Page Maker computer program. 


\section{PUBLICATIONS:}

Etzel, E.F., Weaver, K.L., \& Ostrow, A.C. (Spring, 1995). Job responsibilities and backgrounds of NCAA Division I athletic advisors and counselors: A replication. The Academic Athletic Journal, $1-10$.

\section{PRESENTATIONS:}

Boyce, J., Braun, L., Cormier, S., DeLo, J., Glenn, L., Krolczyk, B., Meit, H., Melcher, J., \& Weaver, K.L. (1998, September). Supervisors Training Workshop. Information presented to West Virginia University Masters level counseling practicum supervisors, Morgantown, WV.

Kenny, P.A., \& Weaver, K.L. (1998, April). Teaching Introductory Statistical Methods for Understanding: Techniques, Assessment, and Affect. Information presented by P.A. Kenney at the AERA Annual Meeting, Pittsburgh, PA.

Weaver, K.L. (1997, August). Basic Counseling Skills. Presentation to Housing and Residence Life Learning Center and Student Support Center Staff, West Virginia University, Morgantown, WV.

\section{TESTING AND ASSESSMENT EXPERIENCE AT WEST VIRGINIA UNIVERSITY:}

Educational Testing Service

Test Administered: SAT

Position Held: Exam Supervisor

Position Held: Associate Supervisor

Position Held: Proctor

Praxis Educational Testing Service

Position Held: Room Supervisor

$11 / 96-5 / 99$

ACT Assessment

Test Administered: ACT

Position Held: Room Supervisor

Position Held: Proctor

$11 / 95-5 / 99$

$11 / 95-5 / 99$

West Virginia University Carruth Center for Counseling and

Psychological Services

Position Held: Chief Psychometrist Duties: Described on page 4.

8/95-8/96

PROFESSIONAL MEMBERSHIPS:

American Psychological Association Student Affiliate Group

1996-present

American Psychological Association Division 17 Student Affiliate Group

1996-present 


\section{REFERENCES:}

Cynthia R. Kalodner, Ph.D.

Director of Clinical Training, Dissertation Chair

Department of Counseling, Rehabilitation Counseling, and Counseling Psychology

502 Allen Hall

PO Box 6122

West Virginia University

Morgantown, WV 26506-6122

(304) 293-3807

Edward “Rhett" Landis, Ph.D., ABPP

Director of Clinical Training

Federal Correctional Complex

PO Box 1000

Butner, NC 27509-1000

(919) 575-4541, x3658

Karen Steinour, Ph.D.

Staff Psychologist, Former Supervisor of

FCI Butner Sex Offender Treatment Program Rotation

Federal Medical Center

PO Box 1500

Old North Carolina Highway

Butner, NC 27509-1500

(919) 575-3900

David J. Srebalus, Ed.D.

Professor, Academic Practicum Supervisor

Department of Counseling, Rehabilitation Counseling, and Counseling Psychology

502 Allen Hall

PO Box 6122

West Virginia University

Morgantown, WV 26506-6122

(304) 293-3807

Ursula Teuter, Ph.D.

Psychologist, Supervisor at Greene County SCI

144 North Dithridge, Suite 109

Pittsburgh, PA 15213

(412) 683-1182 